\title{
Steel Processing Properties and Their Effect on Impact Deformation of Lightweight Structures
}

September 6, 2002

Prepared by

Srdan Simunovic and Gustavo Aramayo

Computational Materials Science Group

Computer Science and Mathematics Division 


\section{DOCUMENT AVAILABILITY}

Reports produced after January 1, 1996, are generally available free via the U.S. Department of Energy (DOE) Information Bridge.

Web site http://www.osti.gov/bridge

Reports produced before January 1, 1996, may be purchased by members of the public from the following source.

National Technical Information Service

5285 Port Royal Road

Springfield, VA 22161

Telephone 703-605-6000 (1-800-553-6847)

TDD 703-487-4639

Fax 703-605-6900

E-mailinfo@ntis.fedworld.gov

Web site http://www.ntis.gov/support/ordernowabout.htm

Reports are available to DOE employees, DOE contractors, Energy Technology Data Exchange (ETDE) representatives, and International Nuclear Information System (INIS) representatives from the following source.

Office of Scientific and Technical Information

P.O. Box 62

Oak Ridge, TN 37831

Telephone 865-576-8401

Fax 865-576-5728

E-mail reports@adonis.osti.gov

Web site http://www.osti.gov/contact.html

This report was prepared as an account of work sponsored by an agency of the United States Government. Neither the United States government nor any agency thereof, nor any of their employees, makes any warranty, express or implied, or assumes any legal liability or responsibility for the accuracy, completeness, or usefulness of any information, apparatus, product, or process disclosed, or represents that its use would not infringe privately owned rights. Reference herein to any specific commercial product, process, or service by trade name, trademark,

manufacturer, or otherwise, does not necessarily constitute or imply its endorsement, recommendation, or favoring by the United States Government or any agency thereof. The views and opinions of authors expressed herein do not necessarily state or reflect those of the United States Government or any agency thereof. 
ORNL/TM-2002/148

\title{
STEEL PROCESSING PROPERTIES AND THEIR EFFECT ON IMPACT DEFORMATION OF LIGHTWEIGHT STRUCTURES
}

\author{
Srdan Simunovic \\ Gustavo Aramayo
}

Date Published: September 6, 2002

Prepared by

OAK RIDGE NATIONAL LABORATORY

P.O. Box 2008

Oak Ridge, Tennessee 37831-6285

managed by

UT-Battelle, LLC

for the

U.S. DEPARTMENT OF ENERGY

under contract DE-AC05-00OR22725 


\section{CONTENTS}

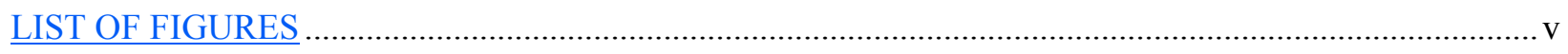

LIST OF TABLES

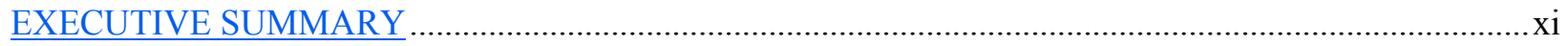

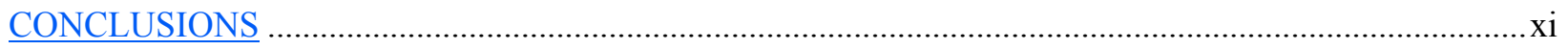

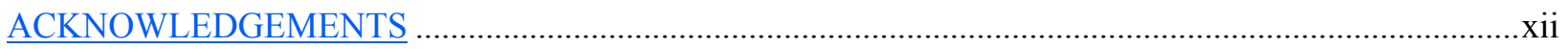

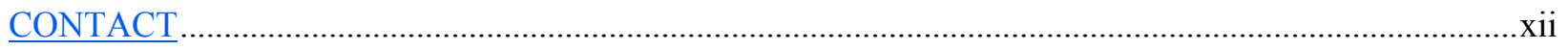

1. MATERIAL MODELING EFFECTS ON DEFROMATION OF ULSAB ......................................... 1

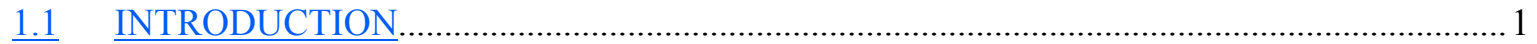

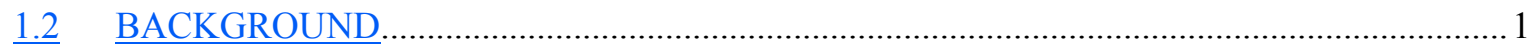

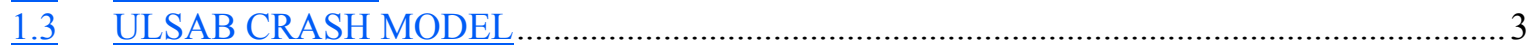

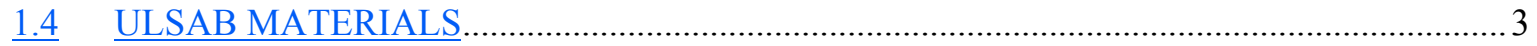

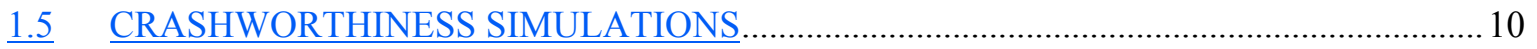

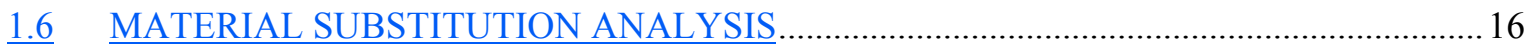

$\underline{1.7}$ CRASHWORTHINESS SIMULATIONS FOR MATERIAL SUBSTITUTION ...................16

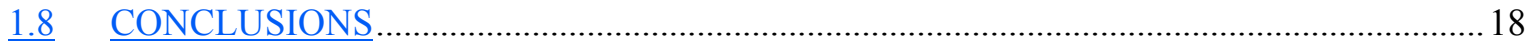

2. STEEL PROCESSING EFFECTS ON IMPACT DEFORMATION OF ULSAB …….....................19

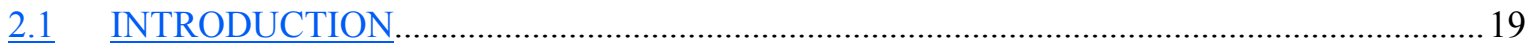

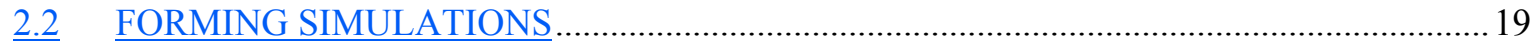

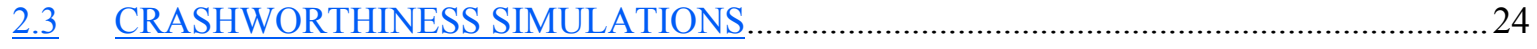

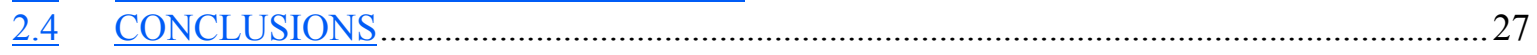

3. $\quad$ CRASH COMPATIBILITY OF THE ULSAB WITH CARS OF THE SAME SIZE.......................29

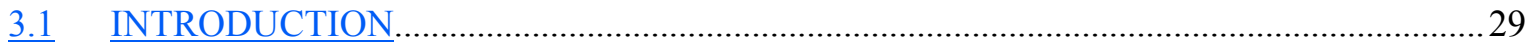

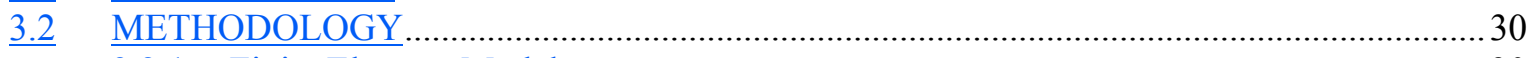

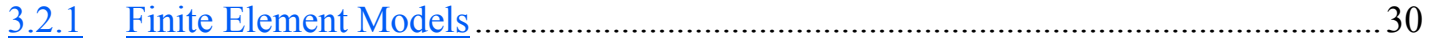

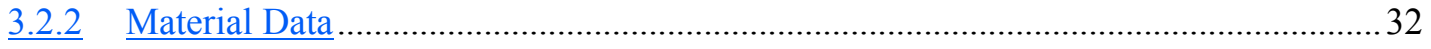

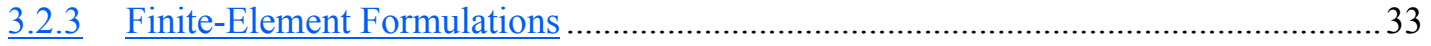

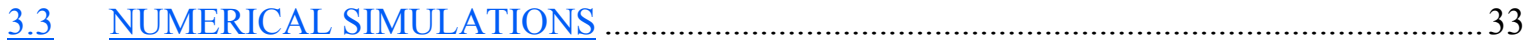

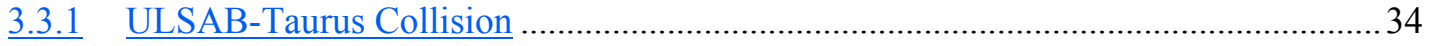

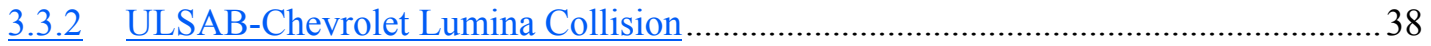

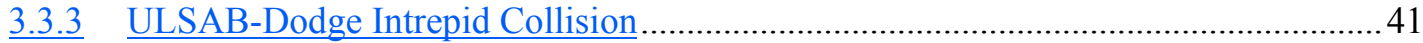

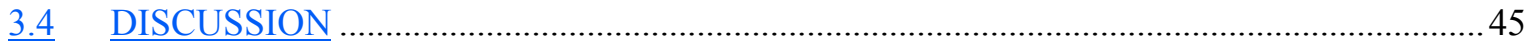

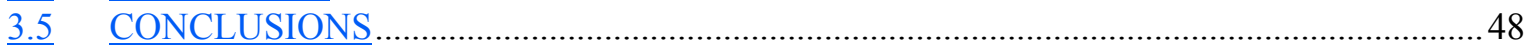

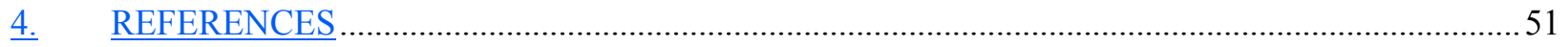





\section{LIST OF FIGURES}

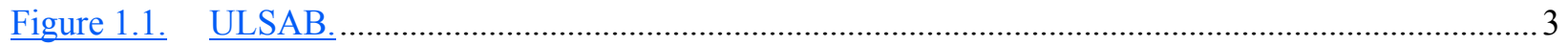

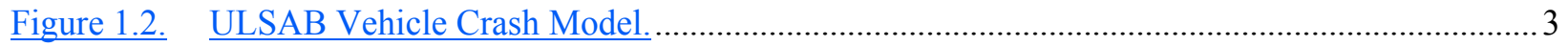

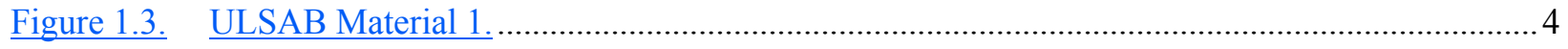

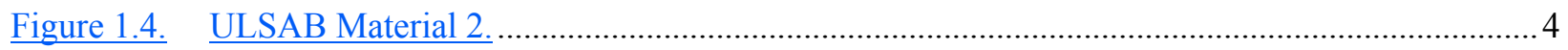

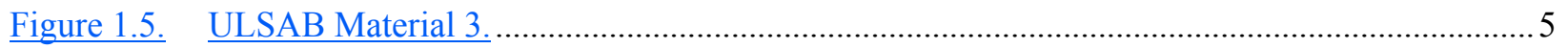

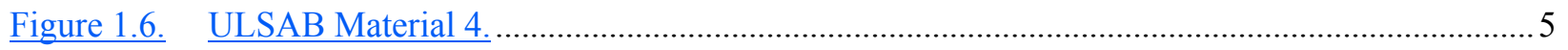

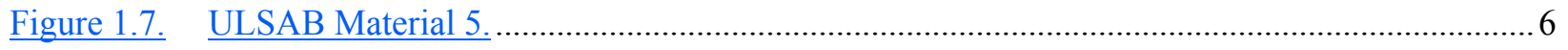

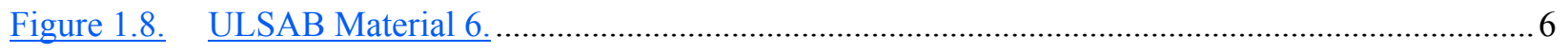

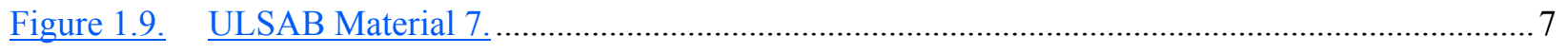

Figure 1.10. $\quad$ Original ULSAB Material Properties................................................................................ 7

Figure 1.11. Quasi-static Material Properties from A/SP.................................................................... 8

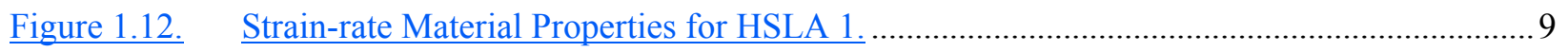

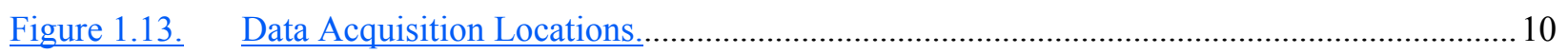

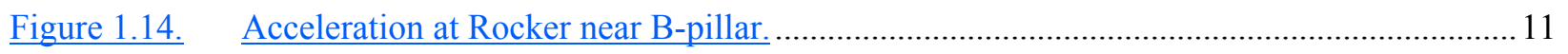

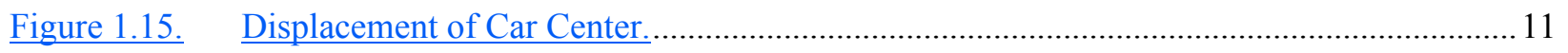

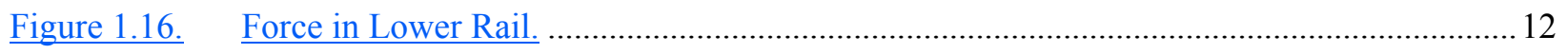

Figure 1.17. Lower Rail - Quasi-static Model. ….................................................................................... 12

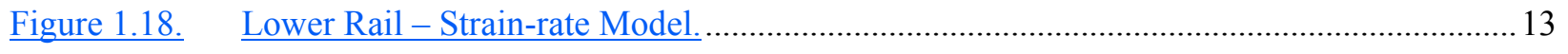

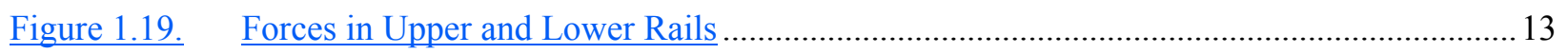

Figure 1.20. Deformation of Rails for Quasi-Static Model..................................................................... 14

Figure 1.21. Deformation of Rails for Strain-rate Model....................................................................... 14

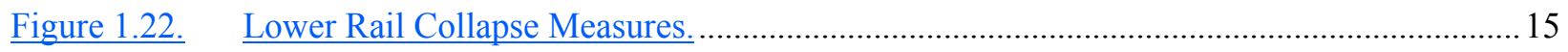

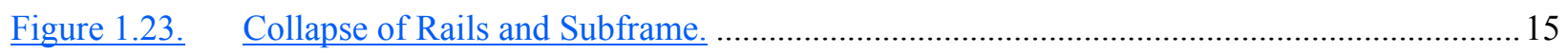

Figure 1.24. Comparison of Substituted Material Properties. ............................................................. 16

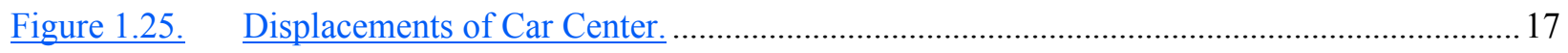




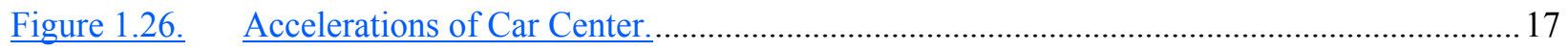

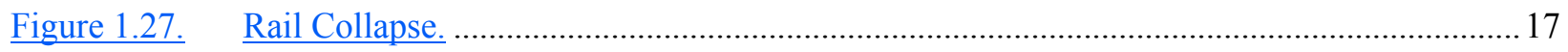

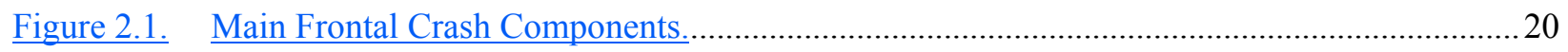

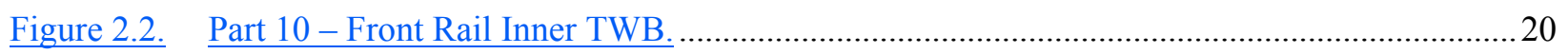

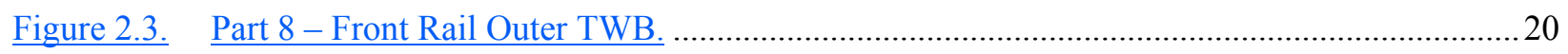

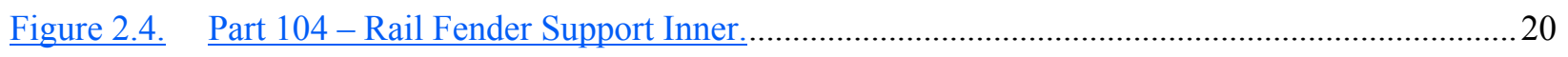

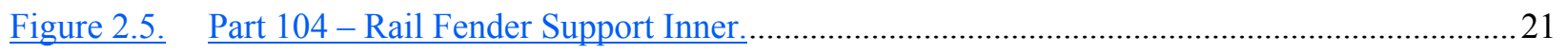

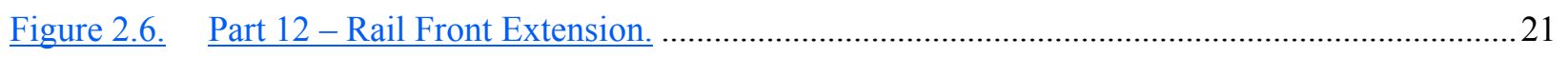

Figure 2.7. Part 2 Reinforcement Rail Front Extension. ….................................................................. 21

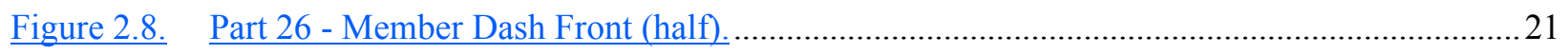

Figure 2.9. Part 108 - Reinforcement Front Rail. ............................................................................ 21

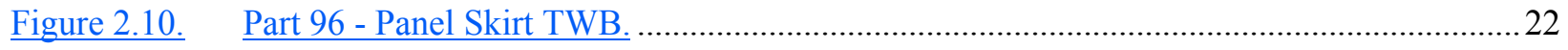

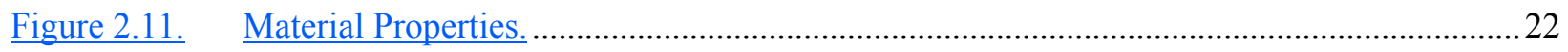

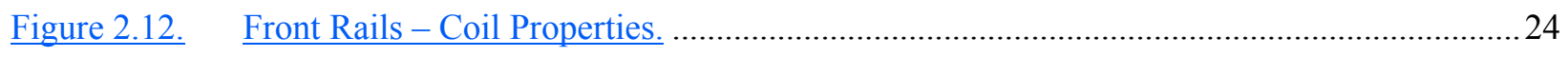

Figure 2.13. $\quad$ Front Rails - As-Formed Properties.................................................................................2

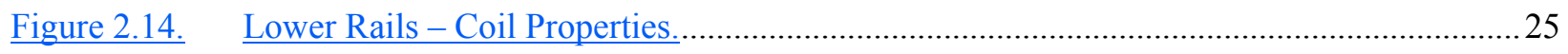

Figure 2.15. Lower Rails - As-Formed Properties..............................................................................25

Figure 2.16. $\quad$ Acceleration at Rocker near B-pillar............................................................................25

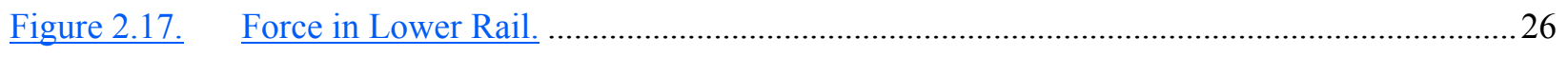

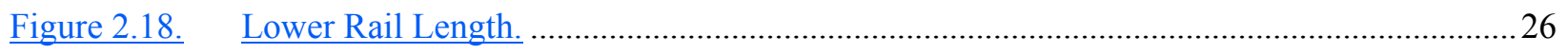

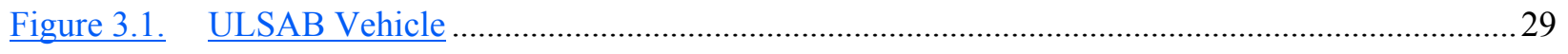

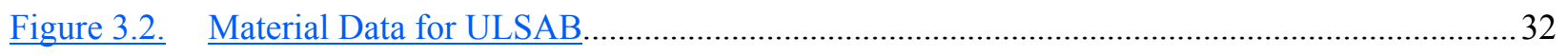

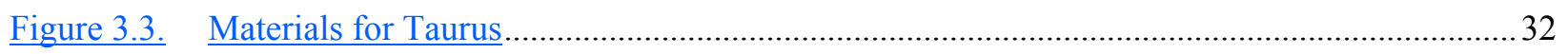

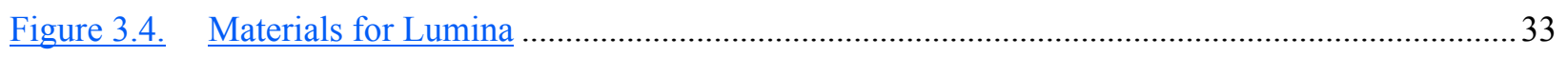

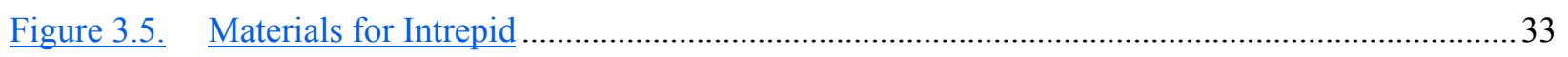




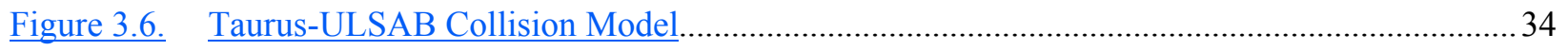

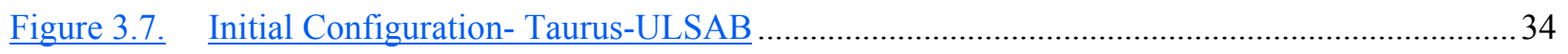

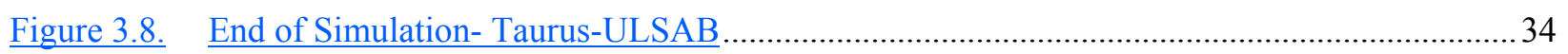

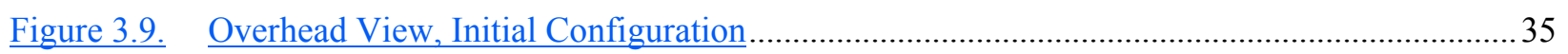

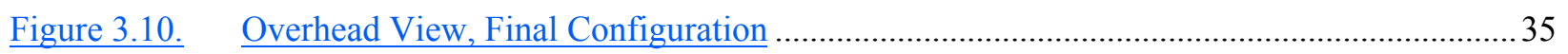

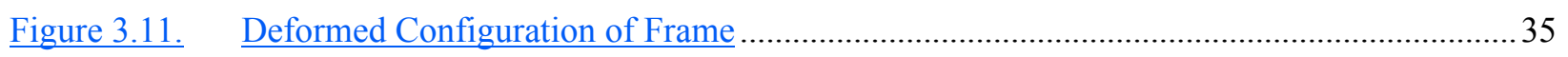

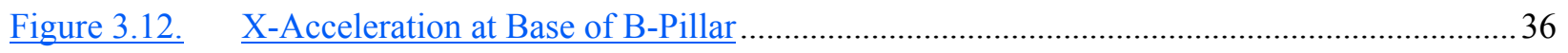

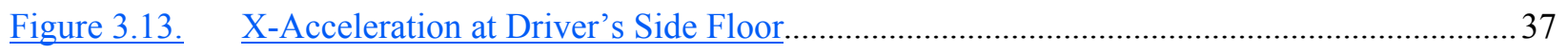

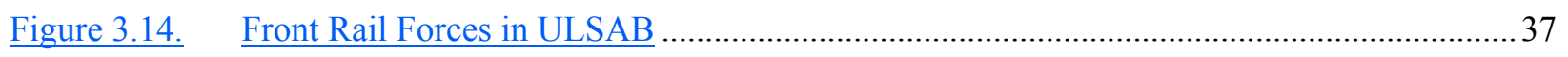

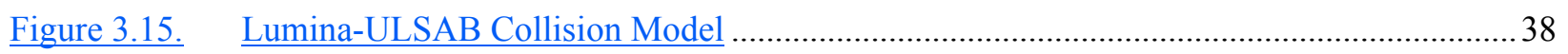

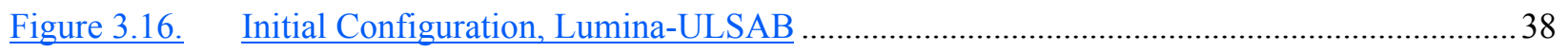

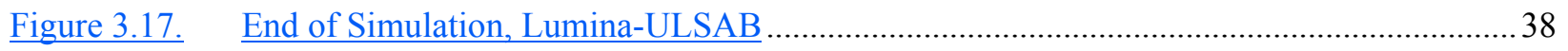

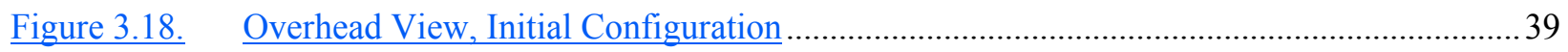

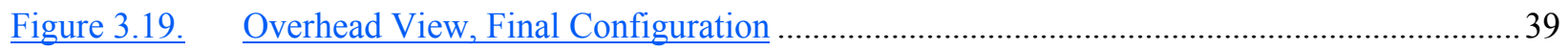

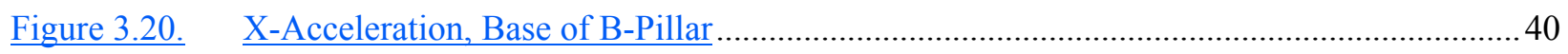

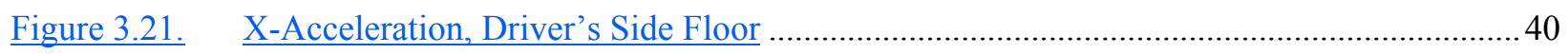

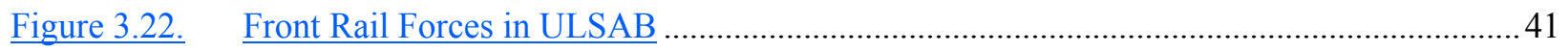

Figure 3.23. Dodge Intrepid-ULSAB Collision Model …..................................................................... 41

Figure 3.24. Initial Configuration, Dodge Intrepid-ULSAB …........................................................... 42

Figure 3.25. End of Simulation, Intrepid-ULSAB ….......................................................................... 42

Figure 3.26. Overhead View, Initial Configuration................................................................................. 42

Figure 3.27. Overhead View, Final Configuration …........................................................................... 43

Figure 3.28. Sub-Frame Initial Configuration..................................................................................... 43

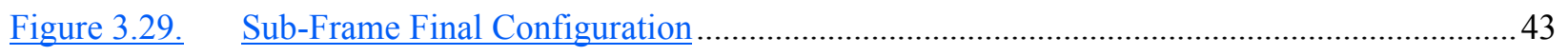

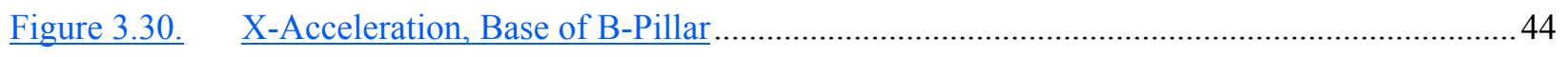

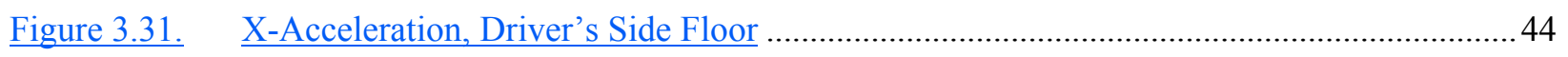

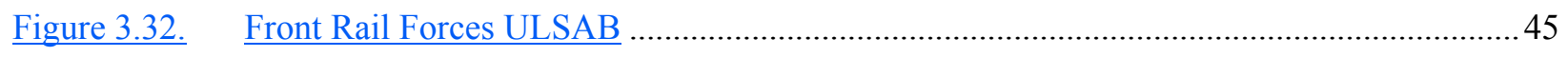


Figure 3.33. Comparison of Crush Zone Lengths............................................................................... 46

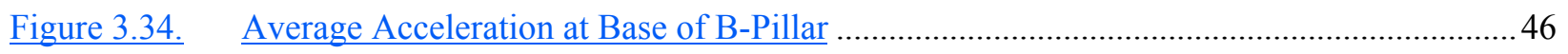

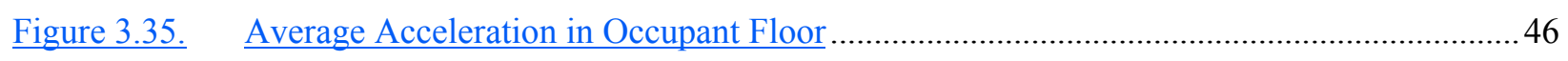

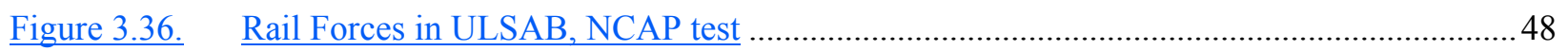




\section{LIST OF TABLES}

Table 1.1. $\quad$ Pairing of ULSAB and A/SP Tested Materials.................................................................

Table 2.1. $\quad$ Averages of Forming Effects on Selected Parts...................................................................23

Table 3.1. $\quad$ Crash Simulations Used in ULSAB Design.............................................................................29

Table 3.2. $\quad$ FE Model Statistics of Vehicles used in Analysis ............................................................... 31

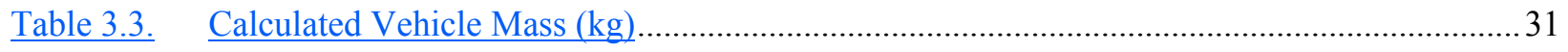

Table 3.4. Reduction of Length in Crush Zone …............................................................................... 36

Table 3.5. Accelerations (G's) at Selected Locations ......................................................................... 36

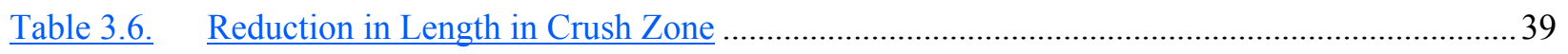

Table 3.7. Average Accelerations (G's) at Selected Locations ............................................................... 40

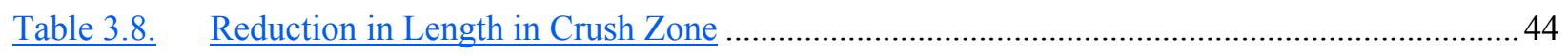

Table 3.9. Accelerations (G's) at Selected Locations ............................................................................. 45

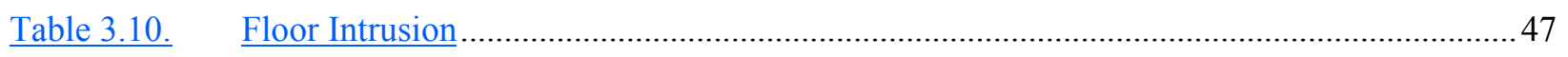

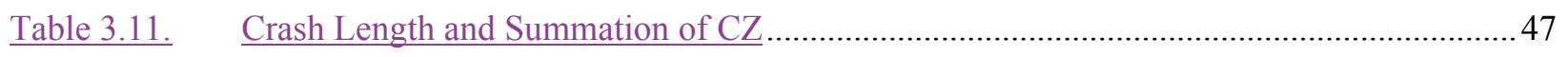





\section{EXECUTIVE SUMMARY}

The objective of the research was to perform a comprehensive computational analysis of the effects of material and process modeling approaches on performance of UltraLight Steel Auto Body (ULSAB) vehicle models. The research addressed numerous material related effects, impact conditions as well as analyzed the performance of the ULSAB vehicles in crashes against designs representing the current US vehicle fleet.

This report is organized into three main sections. The first section describes the results of the computational analysis of ULSAB crash simulations that were performed using advanced material modeling techniques. The effects of strain-rate sensitivity on a high strength steel (HSS) intensive vehicle were analyzed. Frontal and frontal offset crash scenarios were used in a finite element parametric study of the ULSAB body structure. Comparisons are made between the crash results using the piece-wise-linear isotropic plasticity strain-rate dependent material model, and the isotropic plasticity material model based on quasi-static properties. The simulation results show the importance of advanced material modeling techniques for vehicle crash simulations due to strain-rate sensitivity and rapid hardening characteristics of advanced high strength steels. Material substitution was investigated for the main frontal crush structure using the material of similar yield stress a significantly different strain-rate and hardening characteristics.

The objective of the research presented in Section 2 was to assess the influence of stamping process on crash response of ULSAB vehicle. Considered forming effects included thickness variations and plastic strain hardening imparted in the part forming process. The as-formed thickness and plastic strain for front crash parts were used as input data for vehicle crash analysis. Differences in structural performance between crash models with and without forming data were analyzed in order to determine the effects and feasibility of integration of forming processes and crash models.

Computational analysis of vehicle-to-vehicle crashes between ULSAB and conventional car designs is reported in Section 3. The study involved vehicles of comparable weights and dimensions to assess the compatibility of the ULSAB with existing designs. Deformation and acceleration data for crashed vehicles were analyzed. Vehicle-modeling approaches have strong influence on computational results and the requirements for compatibility of models were identified for future research on vehicle-to-vehicle crash modeling.

\section{CONCLUSIONS}

Crash modeling simulations show a clear effect of strain-rate sensitivity on high strength steel (HSS) intensive vehicle. The influence of a strain-rate model can be an incremental sensitivity due to the increased flow stress when similar structure collapse modes are predicted. However, significant differences in crash energy management capacity can be predicted if the change in loading on members alters the predicted collapse mode of the structure. From the material substitution study it can be concluded that HSS material substitution cannot be performed on the basis of the material yield point only and that, especially for advanced HSS vehicle designs, the entire region of material plastic response has to be considered. However, the problem of modeling of the overall dynamic crush process still remains open and requires further experimental and theoretical investigation.

Crash modeling simulations show a moderate effect of forming on overall crash performance. The design is the determining factor on the vehicle performance and, therefore, the results of this research cannot provide measures that can be used in a general case. However, it has been shown that for materials that 
have modest strain hardening, the forming effect is observable and that when more complex forming operations are used, especially in combination with rapid strain hardening materials, forming effects should be taken in the consideration in the computational crash models.

Crash compatibility study between ULSAB and cars of similar geometric characteristics have shown that the ULSAB design is compatible with the conventional designs of existing cars with similar inertia and geometric characteristics. This was a computational study that had the objective of quantifying the crash compatibility of ULSAB relative to cars with similar geometric and inertia characteristics. Experimental verification has not been conducted and, as such, the study is confined to the realm of computational modeling. The structural-performance characteristics of the vehicles involved in a car-to-car collision when one of the cars is the ULSAB are governed by the stiffness and geometry of the CZ in the vehicles. The effects of mass, being traditionally one of the most important parameters used to assess compatibility, could not be evaluated because of the similar mass of the vehicle models used in the analysis. Within the constraints of the current analysis it appears that, for the ULSAB, the effects of stiffness dominate the compatibility aspects for collisions with similar vehicles. The study identified several areas that should be carefully considered to computationally simulate crash-compatibility.

\section{ACKNOWLEDGEMENTS}

The research discussed in this report was sponsored by the American Iron and Steel Institute (AISI) under Project Number ERD-97-XM001 with the U.S. Department of Energy. Work was performed at the Oak Ridge National Laboratory (ORNL), which is managed by UT-Battelle, LLC for the U.S. Department of Energy under contract DE-AC05-00OR22725.

The authors wish to thank the Safety Panel of AISI for their support in writing this report. In addition to that the authors would like to thank Jon Harrington from AISI for reviewing the report. They also would like to thank the Automotive Applications Committee of AISI. Lastly, the ULSAB consortium needs to be recognized for granting permission to use the ULSAB study - the project was conducted by Porsche Engineering Services, Inc. and finished in 1998 - as basis for the work done by ORNL.

\section{CONTACT}

For additional information on details on the research project please contact Srdan Simunovic, simunovics@ornl.gov. Dr. Simunovic is a materials research engineer in the Computational Materials Science Group (http://www-cms.ornl.gov) at the Oak Ridge National Laboratory. For additional information on the scope and other AISI related areas please contact Marcel van Schaik, vanschaikm@autosteel.org. Marcel van Schaik is Manager, Advanced Materials Technology at the American Iron and Steel Institute. 


\section{MATERIAL MODELING EFFECTS ON DEFROMATION OF ULSAB}

\subsection{INTRODUCTION}

The remarkable evolution of steel technology in recent years has resulted in the development of new high strength steel materials and processes that are increasingly used in today's automobiles. The combination of formability, strength, ductility, strain-rate sensitivity and strain hardening characteristics of HSS materials indicates their potential to absorb significantly higher amounts of energy during crashes than conventional low-carbon steels, while reducing the overall weight of a vehicle.

The ULSAB [1] is an aggressive attempt of reduction in automobile weight using the existing technologies and materials. ULSAB uses high strength steel and ultra high strength steel for more than 90 percent of the body structure in order to improve structural performance and reduce mass. ULSAB also utilizes new technologies such as hydroforming, tailor-welded steel blanks, steel sandwich materials and laser welding and applies them at performance-critical regions. In order to reduce weight, the ultra-light steel vehicles use fewer and more slender parts placed at the critical positions in the structure. Connections between those parts are also optimized for weight and often involve innovative joining techniques in order to transmit higher level of forces through smaller sections. The reduced number of parts and joints also means that there is less redundancy in the structure. Components that dissipate crash energy have to perform exactly to the specifications of the design team. Therefore, the modeling of these parts has to involve high accuracy and employ realistic material models that will allow vehicle designers to fully explore the potential of increased yield, strain hardening, strain-rate sensitivity, formability, postform processing and strength of HSS.

The section outline is as follows: in the next subsection, brief background information on material modeling for crashworthiness of high strength steels is presented. The following subsection describes the ULSAB crash model and material models used in the original design. In the next subsection, material information that was developed by the Auto/Steel Partnership experimental program is described in the context of its applicability to the ULSAB materials. The new material models that incorporate strain-rate sensitivity were incorporated into the ULSAB crash model and the results are discussed in the Crashworthiness Results subsection. Next, substitution of High Strength Low Alloy (HSLA) 340 steel, which comprises the main frontal crash structure, with Dual Phase (DP) 430 steel is considered, and results from the corresponding crashworthiness simulations are compared to A/SP materials-based design. Strain-rate sensitivity of DP design is assessed by comparing simulations based on quasi-static and strainrate sensitive material models, respectively. The conclusions of the presented research are stated in the final subsection.

\subsection{BACKGROUND}

Automotive design, impact mechanics, material and structural science and modeling, and various modeling approaches all come together in the process of development of detailed Finite Element Method (FEM) models of automotive crashes. These fields have advanced so dramatically, driven in large part by the automotive industry, that a general overview of the subject can be achieved by referencing standard textbooks. In-depth discussion of the automotive crashworthiness design and modeling approaches can be found in a review of the state-of-the-art of automobile structural crashworthiness [2]. Analytical treatment and overview of the low velocity impact mechanics can be found in Reference 3 . Reference 4 can be used 
for steel material information, while References 5 and 6 provide comprehensive treatments of material and impact modeling using FEM.

During an axial-type collapse (a.k.a. crush), well-behaved frontal energy dissipation structures collapse approximately to one-fourth of their original length. Dissipation of energy can be related to the magnitude, duration and the time history of the forces sustained in the structure. In current vehicle designs, the brunt of the impact is dissipated by a limited number of components, such as lower and upper car rails. Control of the spatial distribution of impact forces is also important, since it is desirable to align the crush forces with the vehicle center of gravity so that the overturning moment does not compound on the vehicle and the passenger kinematics. Any reduction of the structural redundancy in the energy absorbing structure results in a commensurate requirement for better control of the collapse process in the remaining components. Down gauging using HSS can be viewed as a reduction in structural redundancy as well. It is not difficult to see that understanding of the material response is a primary building block for understanding impact response of a HSS structure.

Strain hardening of the HSS is generally different than that of conventional mild steel materials. In particular, DP and Transformation Induced Plasticity (TRIP) steels exhibit very steep and sustained hardening rates. Rapid strain hardening has the benefits of increased forming limits, increased buckling resistance and increased capacity for impact energy dissipation. However, the increase in the apparent material yield and flow stresses has to be carefully managed because of the resulting increase in peak magnitudes and oscillations of reacting forces in HSS components during an axial collapse. Rapid strain hardening has the effect of wider re-distribution of plastic zones, effectively engaging larger material volumes in the energy dissipation. The size of the plastic regions and formation of the folding patterns may be different than the case of mild steel because of different characteristic lengths of plastic zones that are influenced by material properties. Effect of strain-rate sensitivity (see for example Reference 7) is in some ways similar to strain hardening effect since, for dynamic loading, it raises the magnitude of yield and flow stresses and; consequently, changes redistribution of forces compared to quasi-static loading situation. Rapid strain hardening can result in more diffused plastic zones which influence the strain-rate effects and vice-versa.

There is considerable uncertainty and lack of reliable data for deformation of the HSS under uniaxial dynamic loads. Furthermore, constitutive models for HSS under complex loading conditions have not been established and the data for dynamic multiaxial loading are even scarcer than for the uniaxial case. Therefore, isotropic plasticity constitutive models that have been proven to work well for conventional automotive mild steels and corresponding materials characterization programs have been used in practice. Current vehicle crash models have been developed for conventional mild steel designs and include various dynamic sensitivity parameters that reflect the understanding of the characteristics of mild steel performance and the limitations of the numerical modeling techniques [8-11]. Such modeling experience with HSS is not yet available, although reports have been made on application of engineering approaches for advanced HSS, such as Reference 12. Efforts to characterize the new advanced HSS materials are underway and some of the results are already available from automotive and material producer associations [13]. The materials data developed from these projects were used in development of advanced material models for ULSAB to assess the influence of the modeling approaches on crash response. It must be noted that even with the incredible advances in computer power and modeling theory, every crash simulation model requires experimental validation to fine tune its performance. Nevertheless, the objective of this research was to determine the effect that advanced material models can have on the simulation response and to provide measures that can be used for determining whether the increased experimental and modeling complexity is significant enough to warrant their use in practical design. 


\subsection{ULSAB CRASH MODEL}

ULSAB design and computational models were developed by the Porsche Engineering Services, Inc. (PES) for the ULSAB Consortium [1]. ULSAB, shown in Figure 1.1, is a lightweight vehicle design that uses HSS and ultra HSS for more than 90 percent of the body. ULSAB also utilizes new technologies such as hydroforming, tailor-welded blanks (TWB), steel sandwich materials and laser welding.

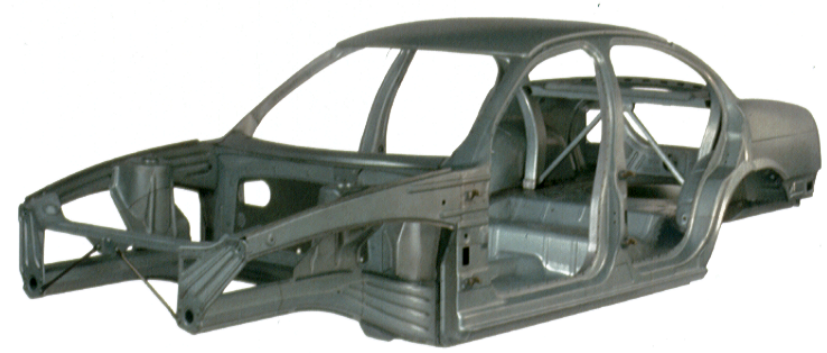

Figure 1.1. ULSAB.

The ULSAB vehicle LS-DYNA3D [14] crash model is shown in Figure 1.2.

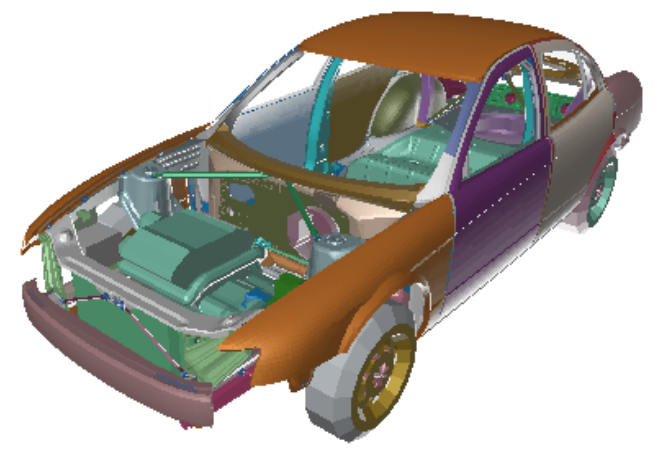

Figure 1.2. ULSAB Vehicle Crash Model.

The crash model includes closure panels, drivetrain and additional masses necessary to simulate vehicle in-service conditions. Details of the crash model can be found in Reference 1.

\subsection{ULSAB MATERIALS}

ULSAB vehicle crash model provided a starting point for the material modeling evaluations. The original ULSAB materials were selected primarily on the basis of their yield values and commercial availability of the formable grades at the time of the design. Most of the crash energy management structures were made of HSLA steels. In fact, 45 percent of the total ULSAB weight is made of a HSLA steel with yield strength of $350 \mathrm{MPa}$, which is used in all major crash related areas. Specific issues and discussion on selection of steel materials based on required performance characteristics of the ULSAB sub-structures can be found in intermediate reports on the ULSAB project. However, exact designations of steels used were not available, and materials were identified by their yield value only. The original design uses seven different steel materials for sheet metal parts. Material sub-systems for each of the different ULSAB 
materials are shown in Figures 1.3 to 1.9. The materials are denoted with numbers 1-7 and will be referred to in that manner in the remainder of the report.

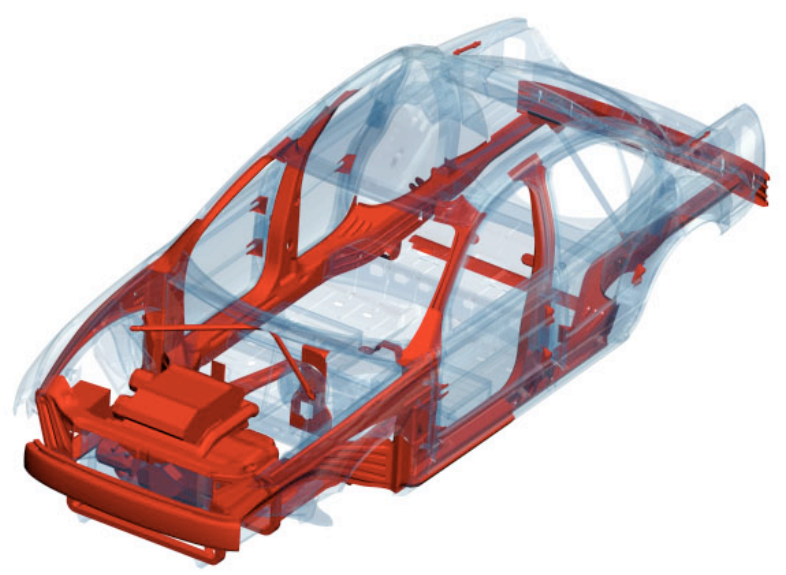

Figure 1.3. $\quad$ ULSAB Material 1.

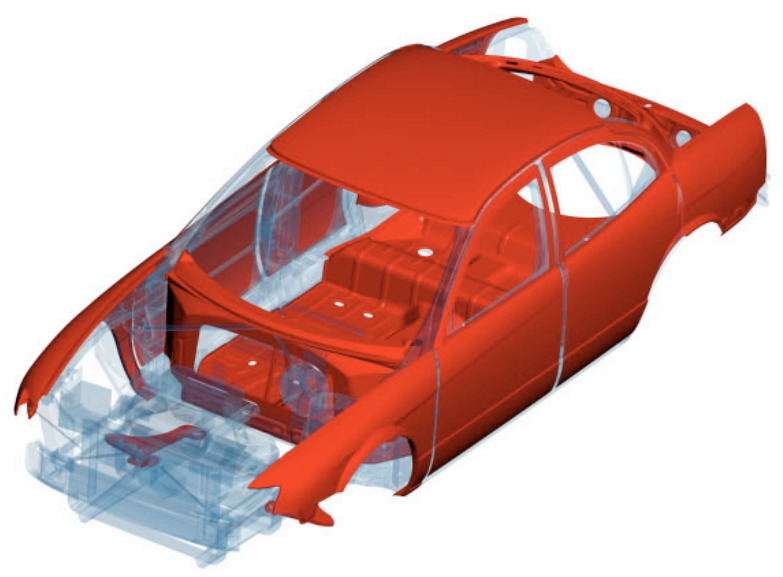

Figure 1.4. $\quad$ ULSAB Material 2. 


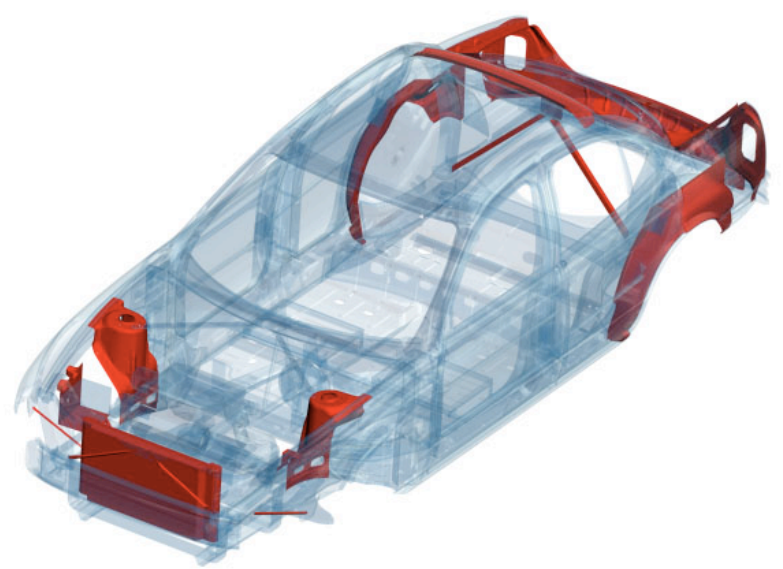

Figure 1.5. ULSAB Material 3.

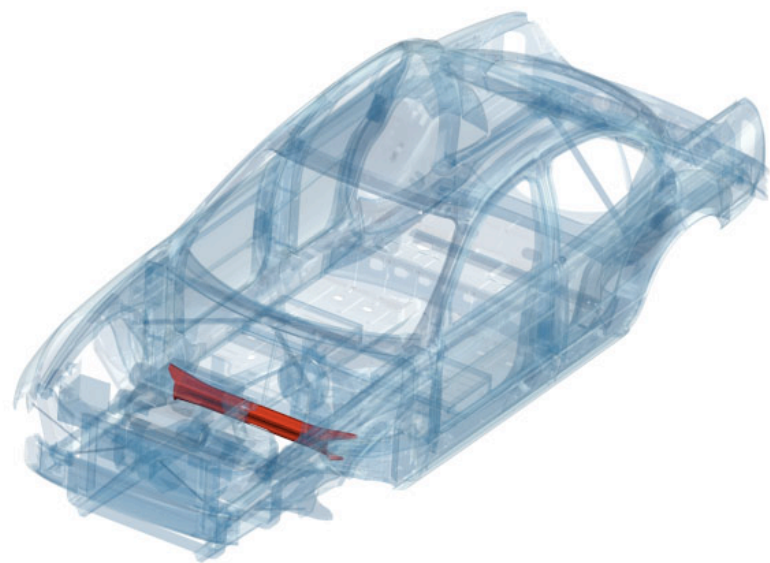

Figure 1.6. $\quad$ ULSAB Material 4. 


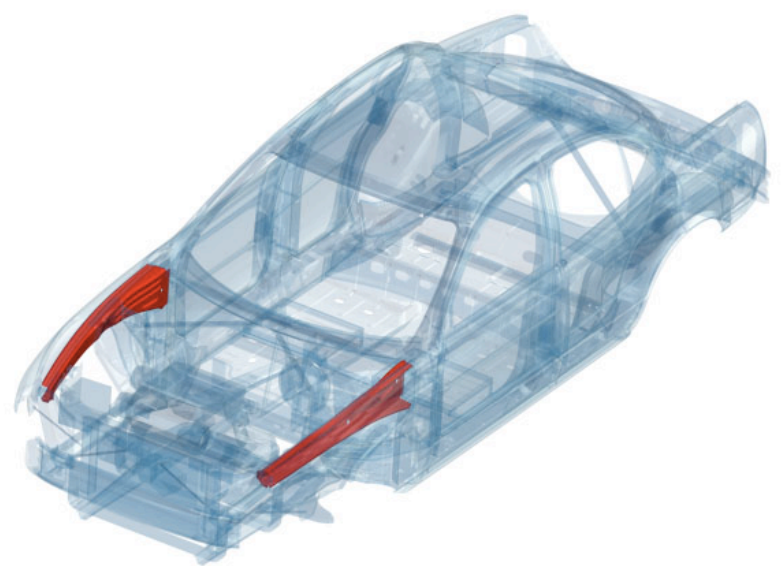

Figure 1.7. ULSAB Material 5.

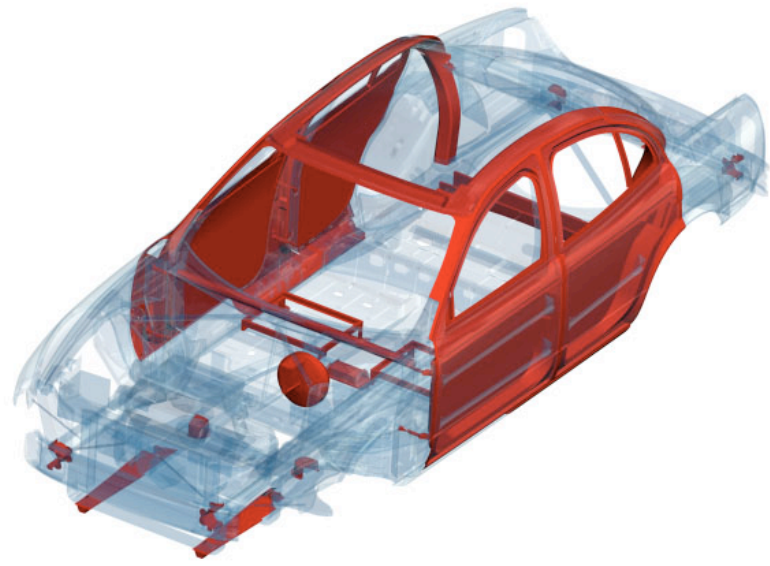

Figure 1.8. ULSAB Material 6. 


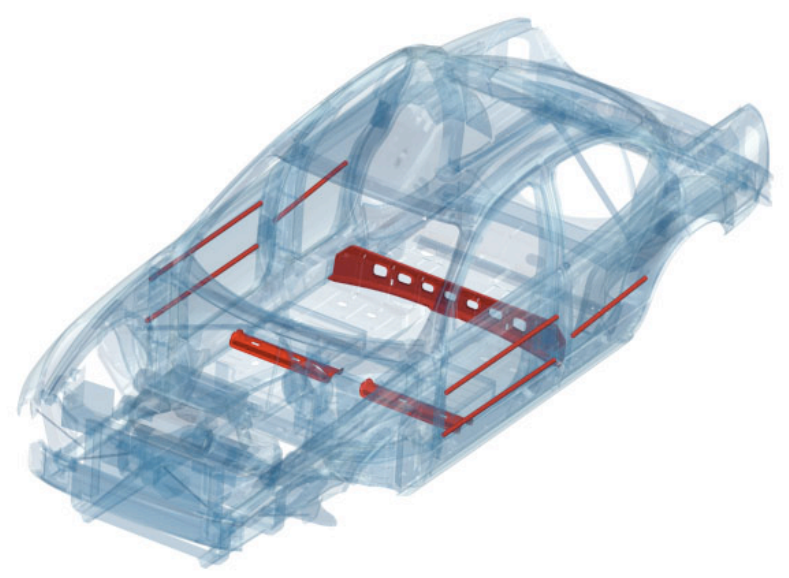

Figure 1.9.

ULSAB Material 7.

The material properties from the original PES model are shown in Figure 1.10. The material data are based on quasi-static experiments and the corresponding true plastic strain-true plastic stress curves were used as parameters for the piece-wise-linear isotropic plasticity material model (LS-DYNA3D material 24).

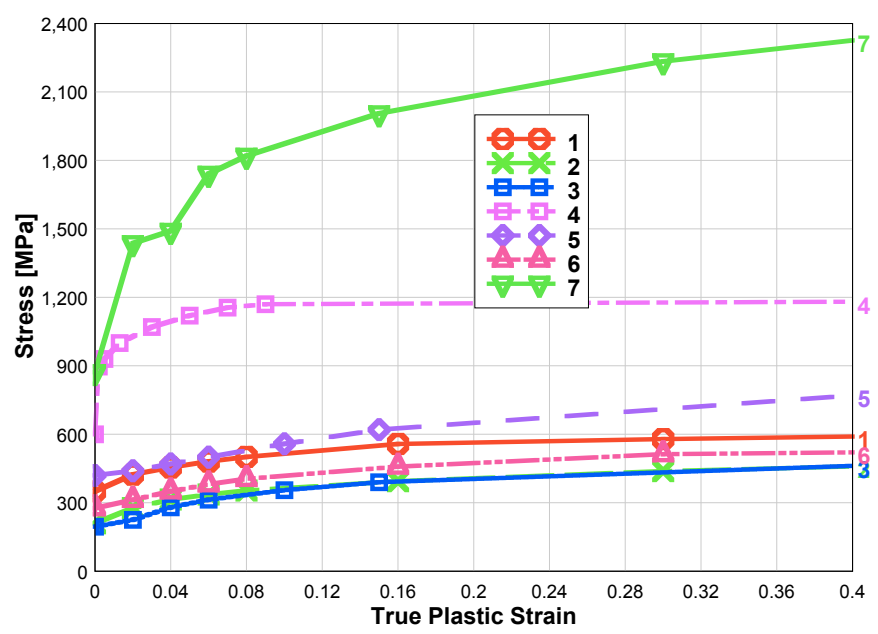

Figure 1.10. Original ULSAB Material Properties.

ULSAB has been designed to satisfy various safety requirements based on both U.S. and European standards. The scope of the presented research was the analysis of frontal impact situations and, therefore, the focus will be on the frontal energy management structures. Materials 1 and 5 comprise the main frontal safety structure that is designed to absorb frontal impact energy in a controlled manner. The authors used frontal impact into flat rigid barrier with vehicle speed of $35 \mathrm{mph}$ as specified in the U.S. Department of Transportation, New Vehicle Assessment Program (NCAP) test, and frontal impact into flat $50 \%$ offset rigid barrier in order to more aggressively engage specific safety structures.

Over the last decade, automotive and steel companies have been developing material properties for the automotive high strength steels under dynamic loading conditions. Spot- and laser-welded steel columns were investigated in Reference 15. Yoshitake et al. [16] used double-hat specimens made out of steels 
having 440 to $780 \mathrm{MPa}$ tensile strengths and used effective width theory to estimate average forces in the specimens. Sato et al. [17] performed axial compression experiments and corresponding FEM numerical simulations with steel grades of 300 to $590 \mathrm{MPa}$. The authors used two approaches for material modeling, Cowper-Symonds [7] and piece-wise-linear isotropic plasticity model. Results show better correlation of simulations with experimental for the piece-wise-linear isotropic plasticity model. Miura et al. [18] have shown a good agreement between experiments and FEM simulations for crushing of hat shaped DP specimens. However, particulars of the material models were not stated. Hourman [19] analyzed performance of DP steels for side intrusion rail, which deforms primarily in bending.

The U. S. Auto/Steel Partnership has been developing automotive steels for a wide range of dynamic conditions. Strain-rates from quasi-static values $(0.001 / \mathrm{s})$ to high velocity dynamic impact using split Hopkinson bar experiments $(1000+/ \mathrm{s})$ were considered [13]. Mahadevan et al. [13] used the developed dynamic material data and employed it for FEM simulation of crush experiments of various tubular steel geometries using Johnson-Cook [20] and Zerilli-Armstrong [21] material models. They concluded that higher fidelity correlation was achieved with the Johnson-Cook model and that the modeling, especially, finite element discretization, had a significant effect on the results. In the follow-up paper [22], Mahadevan et al. investigated effects of strain-rate in full vehicle frontal crash analysis and have analyzed the effects of various material model fitting strategies and element discretizations. The material information from A/SP research was made available to this project and was used for the development of advanced HSS material models for ULSAB. The first task involved pairing of the ULSAB materials and available materials from the A/SP project. Figure 1.11 shows the quasi-static properties of the materials used in the A/SP study.

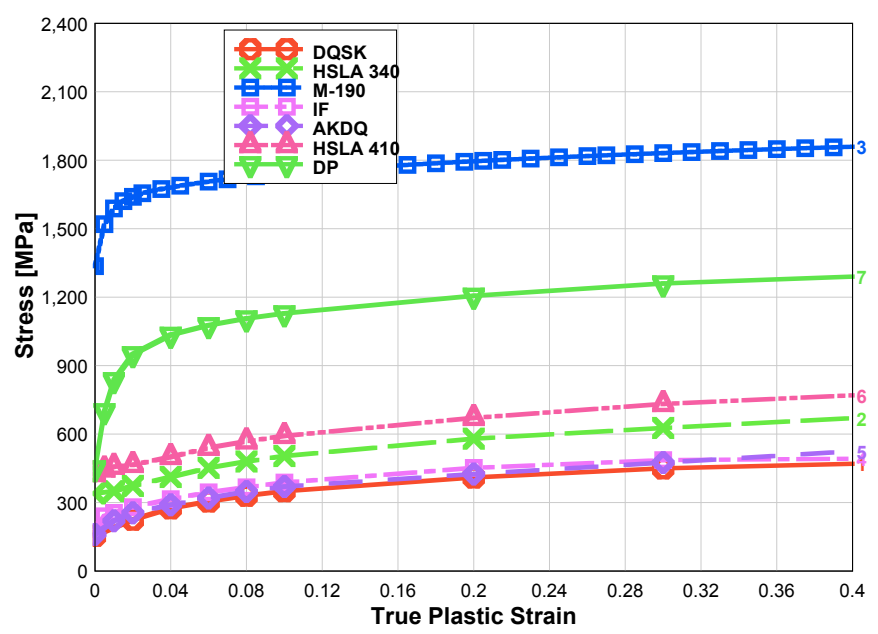

Figure 1.11. Quasi-static Material Properties from A/SP.

The quasi-static material properties from A/SP were related to ULSAB material properties used in the crash model (Figure 1.8). Table 1.1 shows how the materials were substituted. Modification of material properties to match exactly the yield points [2] was considered, however they were not used because the overall fit between the respective strain-stress curves was adequate. 


\begin{tabular}{|c|c|c|c|}
\hline $\begin{array}{c}\text { ULSAB } \\
\text { Mat. ID }\end{array}$ & $\begin{array}{c}\text { Yield Stress } \\
{[\text { MPa] }}\end{array}$ & $\begin{array}{c}\text { A/SP Mat. } \\
\text { Substitute }\end{array}$ & $\begin{array}{c}\text { A/SP Yield } \\
\text { Stress [MPa] }\end{array}$ \\
\hline 1 & 350 & HSLA & 340 \\
\hline 2 & 210 & DQSK & 155 \\
\hline 3 & 195 & DQSK & 160 \\
\hline 4 & 600 & DP & 450 \\
\hline 5 & 420 & HSLA & 425 \\
\hline 6 & 276 & IF & 180 \\
\hline 7 & 872 & M-190 & 1336 \\
\hline
\end{tabular}

Table 1.1. Pairing of ULSAB and A/SP Tested Materials.

As can be seen from the table, some of the materials have yield values significantly higher than is customarily expected for those steel designations. The yield values may have been increased in the original quasi-static model in order to include experience that the designers had with the modeling of the dynamic behavior of these materials and automotive structures. Properties of the substituted materials under different strain-rates were used as input data for the piece-wise-linear plasticity model in LSDYNA3D (material 24 with strain-rate table option). In this model, true strain-true stress curves for different strain-rates are tabulated, and computed equivalent plastic strains and strain-rates are then interpolated between the values in the table to determine the equivalent plastic stress. Material data for material designated as HSLA 1 is shown in Figure 1.12.

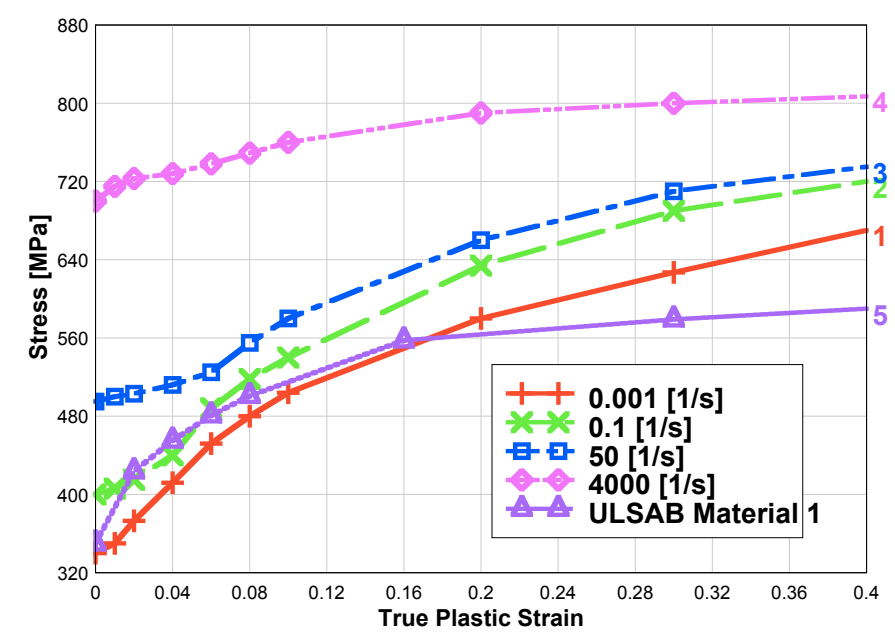

Figure 1.12. Strain-rate Material Properties for HSLA 1.

It is evident from the character of the curves in Figure 1.10 that they do not have the same hardening rates across the strain-rates and as such would be difficult to fit to the constitutive models that are based on that assumption. Obvious questions on the effects of differences in the experimental hardening rates and accuracy of the measured responses in the context of crashworthiness models still need to be answered. These and other modeling and experimentation issues, are presently addressed by the research within the A/SP and the U.S. Department of Energy. 


\subsection{CRASHWORTHINESS SIMULATIONS}

The ULSAB model with new material properties was used for various crash simulations to investigate effects of advanced material modeling on computational results. Only the results from the NCAP crash simulations are presented in this report because they suffice for illustration of the main trends that are observed across different impact scenarios. During the course of the project, a large number of impact scenarios and material modeling approaches has been considered. These simulations result in large amounts of data that tend to overwhelm the analyst. A new interactive, Web-based problem solving environment system has been developed to facilitate analysis between remote project participants [23]. A set of characteristic locations has been selected for monitoring displacements and accelerations. Crosssection forces and displacements on several positions have also been used to assess the magnitude and dynamic of forces in main crash structures. The locations of the data points, cross-sections and components are shown in Figure 1.13.

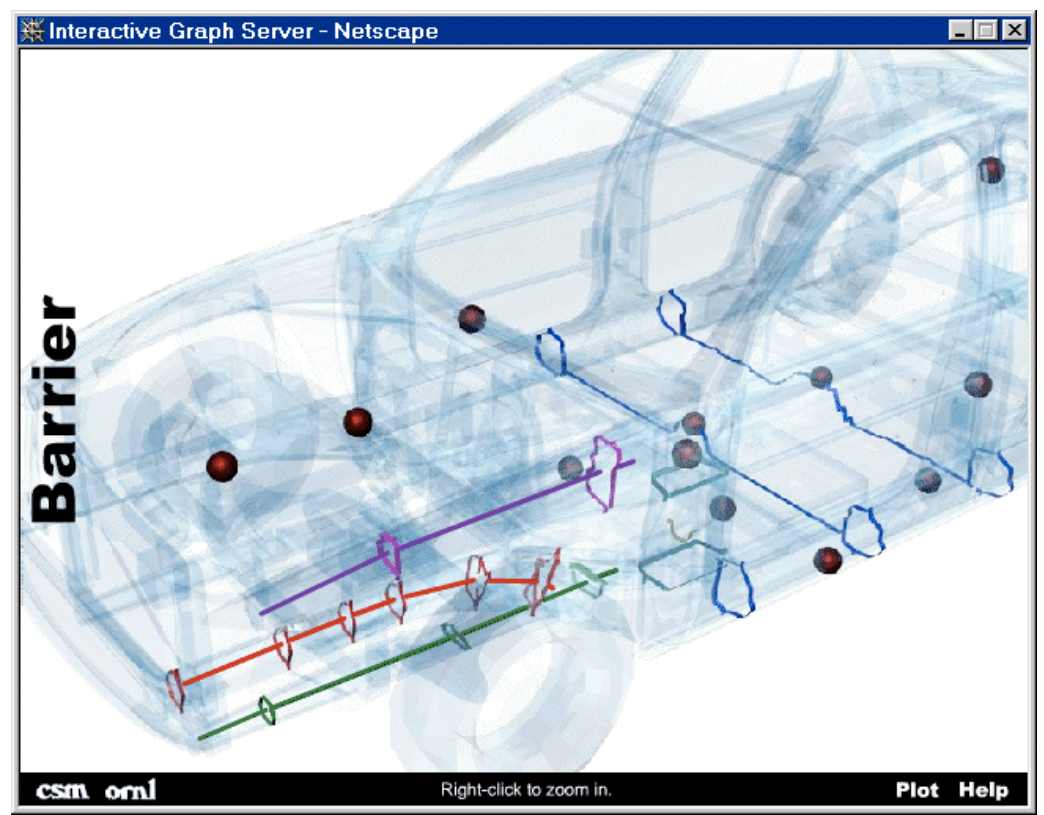

Figure 1.13. Data Acquisition Locations.

Red (dark) spheres are associated with displacement and acceleration data, cross sections are associated with forces in the direction perpendicular to the cross section and lines are associated with collapse measures of the structural components.

NCAP crash simulations for vehicle models with and without material strain-rate sensitivity were performed. Filtered (SAE J211) acceleration traces for the node at the rocker near the bottom of B-pillar are shown in Figure 1.14. 


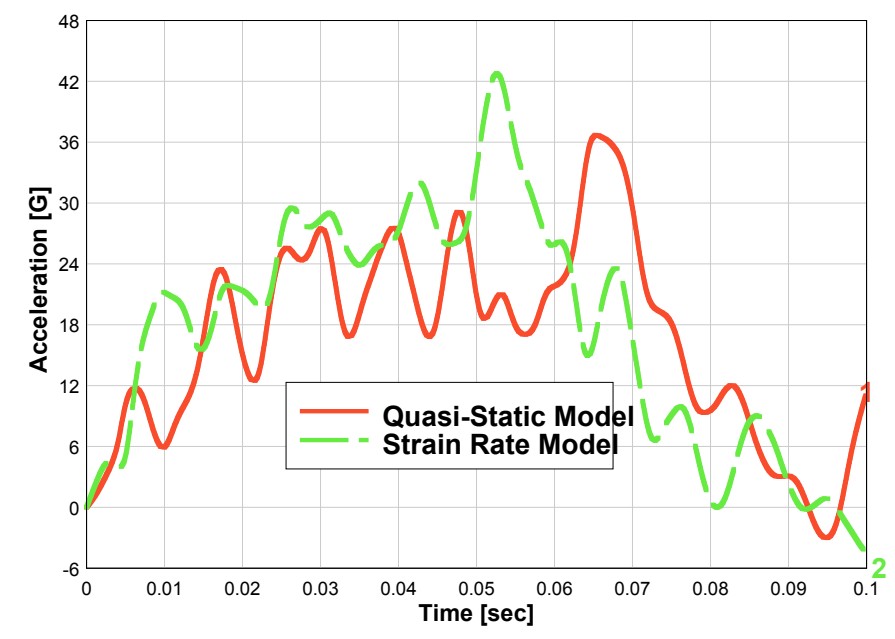

Figure 1.14. Acceleration at Rocker near B-pillar.

This point on the vehicle is usually used as a link between occupant environment and the vehicle dynamics models. Crash pulses on the rocker are transferred from one model to another to determine crashworthiness of a design. On average, the acceleration levels for material modeling with strain-rate sensitivity are compared to the simulations using quasi-static material models. The average acceleration for two cases between the impact start, $\boldsymbol{t}_{0}$ ("time zero"), and the end of the forward movement of the vehicle $\boldsymbol{t}_{\mathrm{v}=0}$ ("velocity zero"), are $19.9 \mathrm{G}$ and $23.5 \mathrm{G}$, respectively. The trend is consistent across the vehicle points. The longitudinal displacement of the point on the floor of the vehicle is shown in Figure 1.15 .

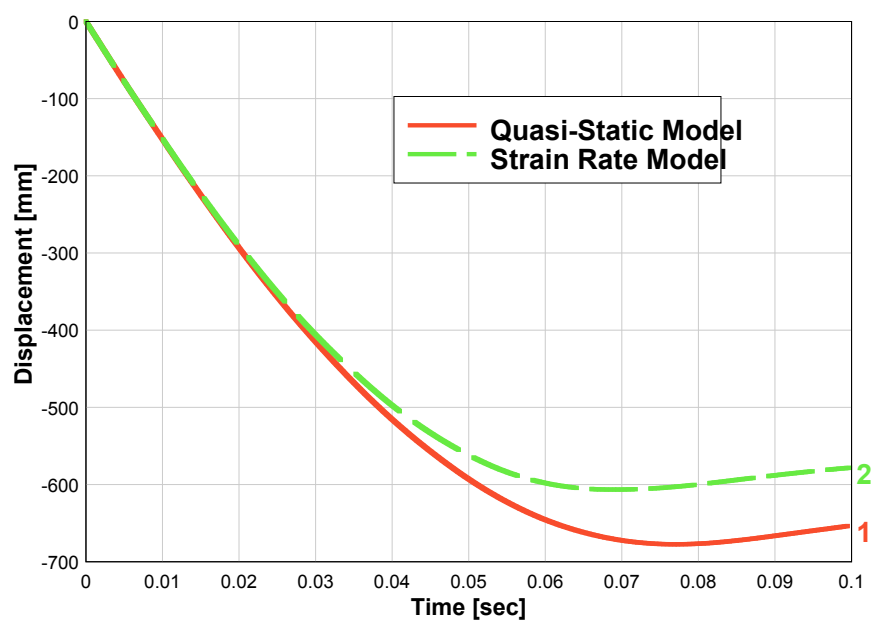

Figure 1.15. Displacement of Car Center.

The strain-rate sensitivity results in $11 \%$ reduced displacement and shorter vehicle stopping time. The results are consistent with values reported in the literature [22]. The higher accelerations and shorter stopping distance come from the increase in rail forces due to the strain-rate sensitivity of the material. The force in the rear of the lower rail is shown in Figure 1.16. 


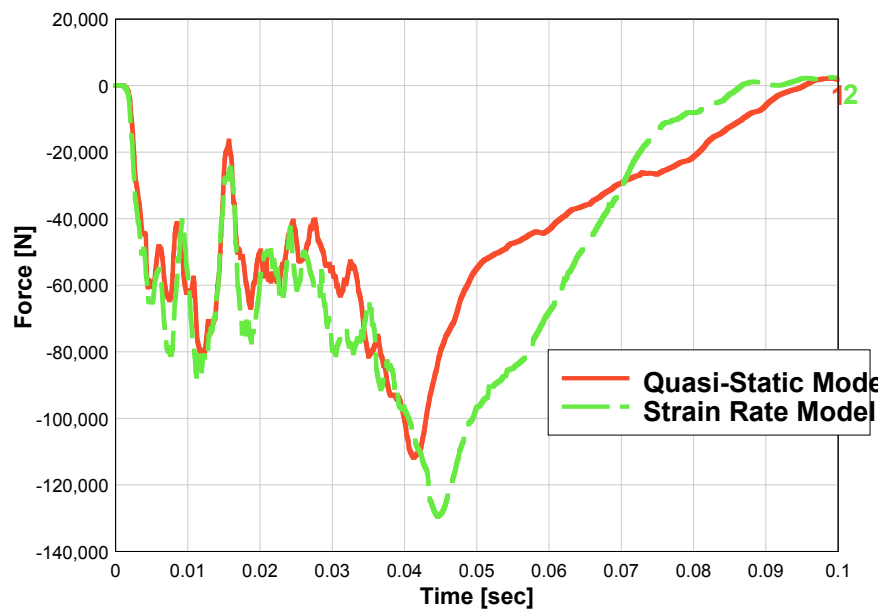

Figure 1.16. $\quad$ Force in Lower Rail.

Not only does the strain-rate sensitivity increase the force peak in the lower rail, it also extends its duration, which results in more energy dissipation of the component. The average force between the "time zero" and "velocity zero" in the rail for quasi-static case is $52.6 \mathrm{kN}$ and for the strain-rate model is 70.1 $\mathrm{kN}$ (33\% increase). Figures 1.17 and 1.18 show deformation of the lower rail at $80 \mathrm{~ms}$.

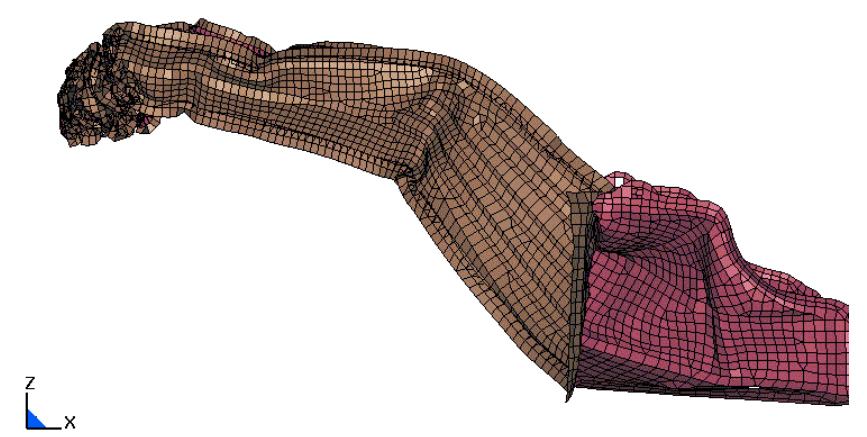

Figure 1.17. $\quad$ Lower Rail - Quasi-static Model. 


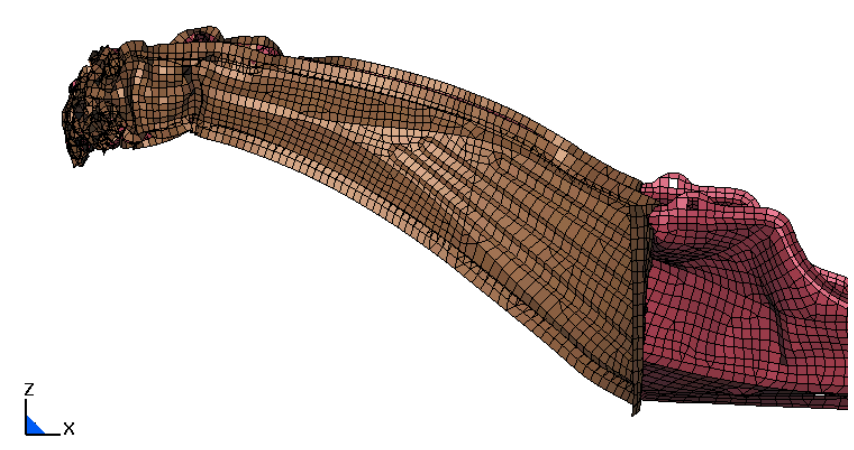

Figure 1.18. $\quad$ Lower Rail - Strain-rate Model.

The quasi-static model has a pronounced plastic hinge near the middle of the rail. This hinge is created just after .04 seconds, which corresponds to the significant loss of load carrying capacity of the lower rail in the quasi-static model as seen in Figure 1.16.

The use of the strain rate material model influences the energy management prediction relative to the static material model in two ways. An incremental advantage is predicted due to the increased flow stress of the strain rate model when the structure is predicted to collapse in a similar manner to that predicted by the quasi-static model. This is seen in Figure 1.16 prior to .04 seconds and corresponds to the similar folding of the leading edge of the rail for both material models. However, after .04 seconds the two material models predict a significantly difference collapse modes of the lower rail. A pronounced hinge is predicted to form near the middle of the rail for the quasi-static model. The creation of this hinge at .04 seconds predicts a significant reduction in the energy management capacity of the lower rail as shown in Figure 1.16

The structural response of the lower rail has to be viewed in the context of the entire design. Figure 1.19 shows the response of upper and lower rails for different material models.

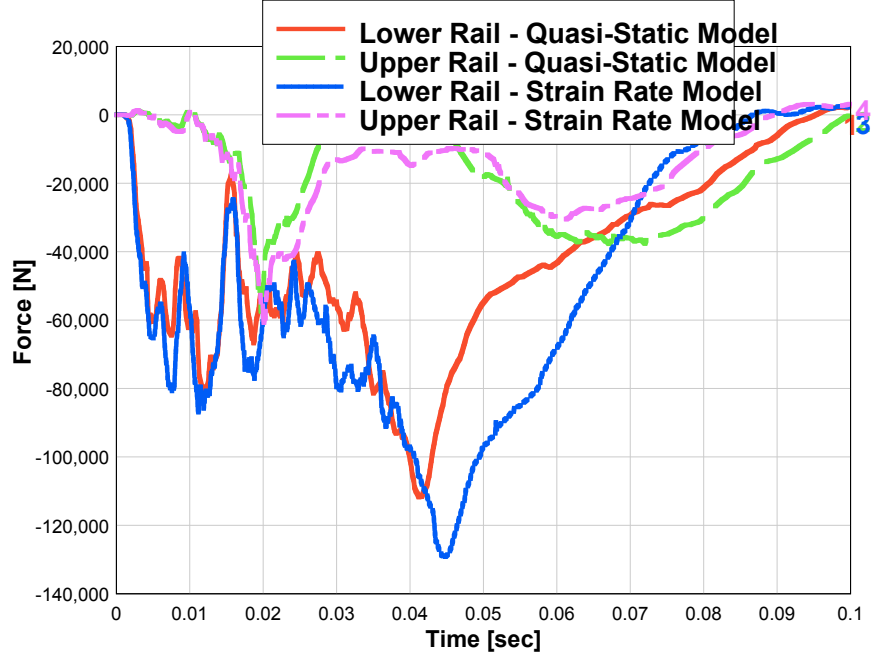

Figure 1.19. $\quad$ Forces in Upper and Lower Rails 
Average force in the upper rail remains almost the same (changes less than 1\%). Addition of more force traces in the graph would quickly make the graph too crowded for illustration of global trends. Corresponding deformation of the front crash system as shown in Figures 1.20 and 1.21, provides a good illustration of the overall trend.

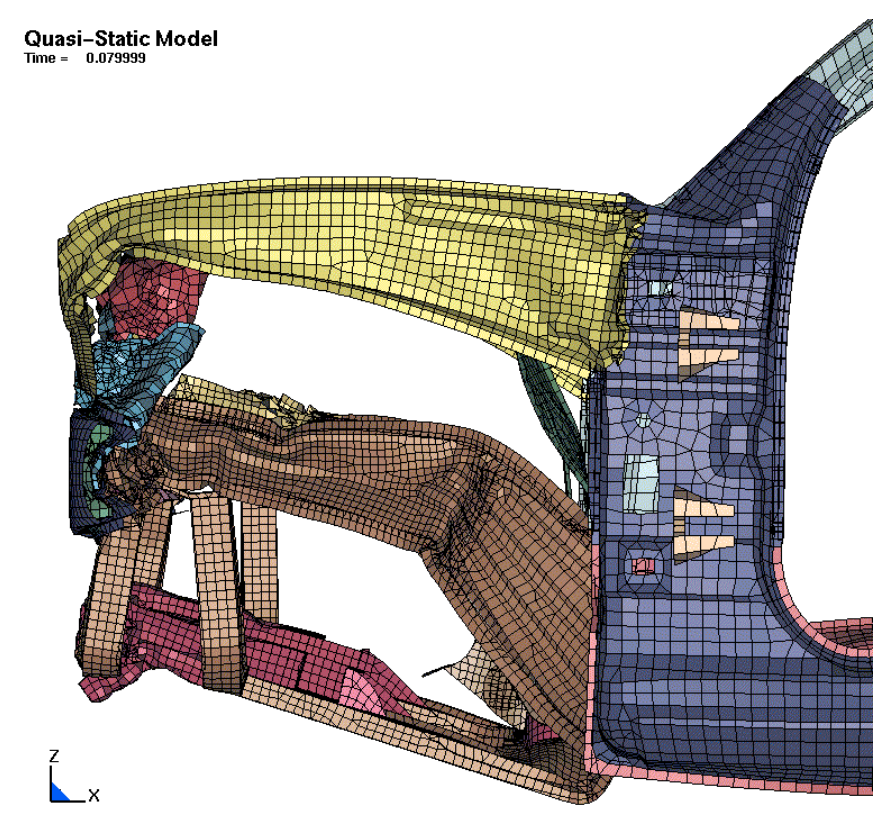

Figure 1.20. Deformation of Rails for Quasi-Static Model.

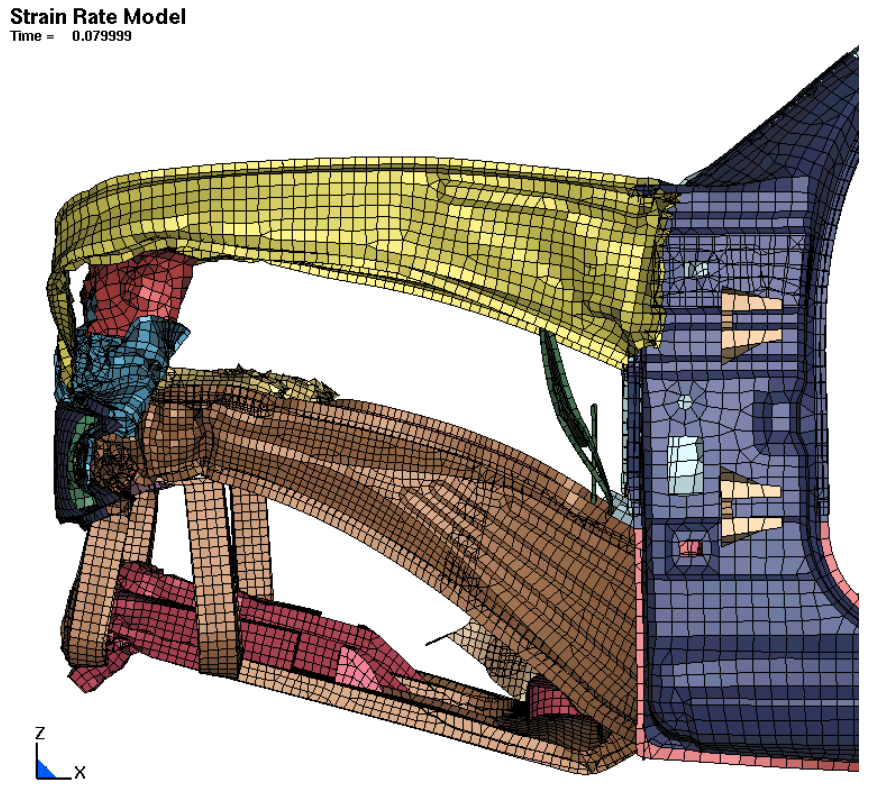

Figure 1.21. Deformation of Rails for Strain-rate Model.

Overall a shorter crush zone, and less localization into plastic hinges are the two most prominent effects of strain-rate in the above figures. Other views reveal that the amount of forward pitching of the occupant compartment, as indicated by the angle of the hinge-pillar, is larger for the quasi-static case. 
As the advance in computer hardware allows for ever more detailed and finer element discretizations, data interpretation on the component level quickly becomes a problem. To consolidate the simulation results into measurable representation, two collapse deformation measures for the components (upper and lower rails and sub-frame) were defined. The first measure is defined as the distance between the centroids of the end cross sections of the component. The second measure is defined as the sum of distances between the consecutive cross sections on the component. For a sufficient number of cross sections, the compactness of the collapse process will be indicated by the small difference between the two measures. These measures integrate information about large material volumes and can be shown in a single graph. In addition, they can provide a link between semi-empirical design tools and FEM approaches. More detailed collapse measures are currently being developed and will be included in the later publications on the subject. The two collapse measures of the lower rail are shown in Figure 1.22.

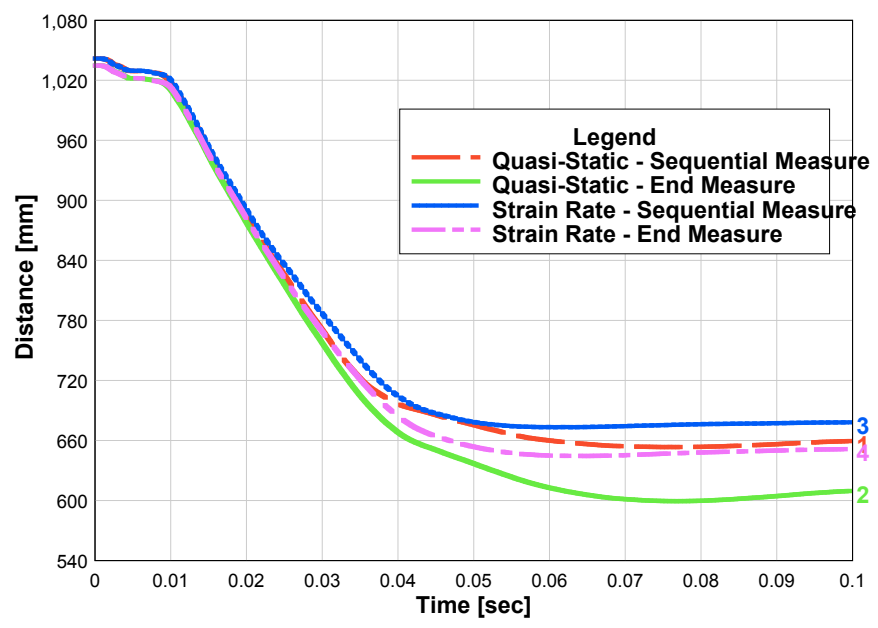

Figure 1.22. Lower Rail Collapse Measures.

Similar to the displacement data in Figure 1.15, the strain-rate sensitivity results in the overall shorter collapse. The difference between the end and sequential collapse measures is smaller for the strain-rate sensitive model which indicates a more compact collapse. Similarly to the force analysis, it is necessary to consider the entire rail system that is shown in Figure 1.23.

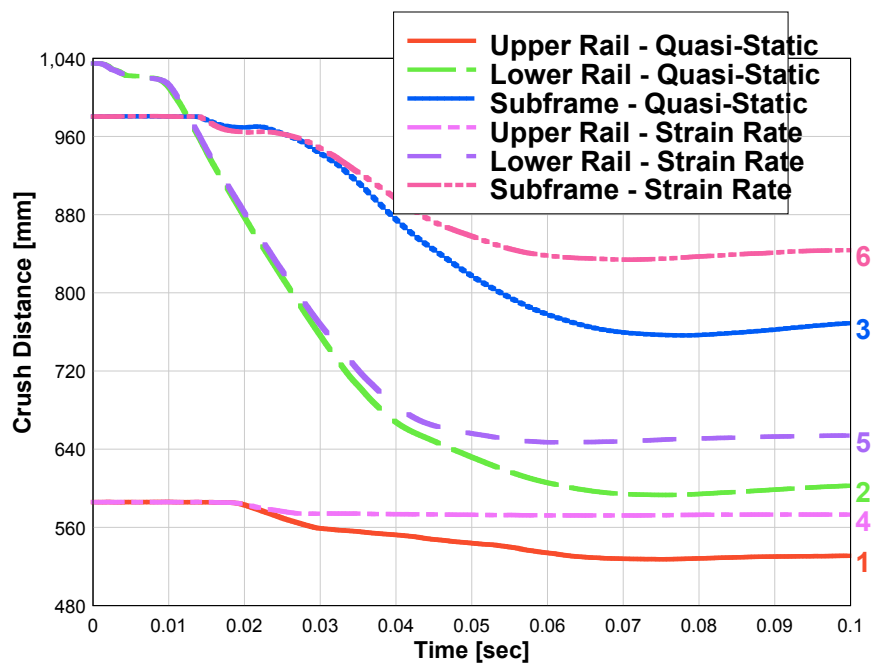

Figure 1.23. Collapse of Rails and Subframe. 
Overall, the crush of the entire rail system is shorter and the strain-rate effect is significant enough that it should be considered in the detailed vehicle impact analysis. (Note that the upper rail involves cross sections as shown in Figure 1.31, and does not include deformation in the front end.) The reader is reminded at this point that the previous conclusions are based mostly on computational simulations and have not been verified by the physical crash experiment. Nevertheless, the objective of the study remains valid. Simulation results clearly indicate that the strain-rate is an important factor that can have considerable effect on overall vehicle response and, thus, provides further rationale support for experimental and theoretical investigation of the subject.

\subsection{MATERIAL SUBSTITUTION ANALYSIS}

ULSAB material selection depended to a large extent on material yield characteristics, as it is customary in the current car design. Elasto-plastic response characteristics of conventional mild steel materials have been generally conformant to this assumption. To investigate the effect of material substitution of the HSS intensive design, using materials of similar yield but different strain-rate and hardening characteristic HSLA 340 of Figure 1.1 is substituted with DP 430. The strain-rate dependent material data for lower DP grades was not available so the closest material available was used [24]. In addition, the yield point for DP steels is not easily determined since it just presents a point on the very steep hardening curve. Material data for the two materials is shown in Figure 1.24.

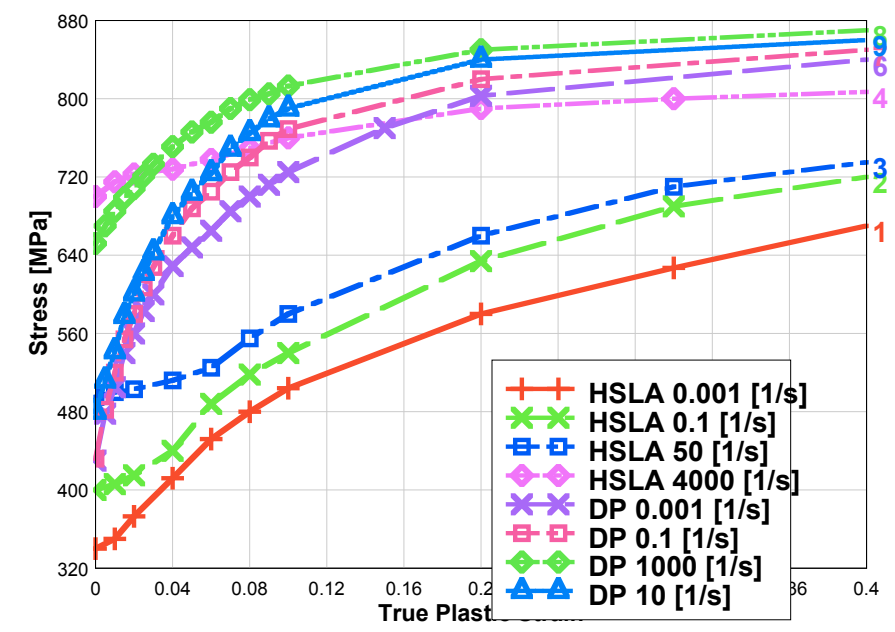

Figure 1.24. Comparison of Substituted Material Properties.

\subsection{CRASHWORTHINESS SIMULATIONS FOR MATERIAL SUBSTITUTION}

Displacement and accelerations in the car center, and rail collapse measures are shown in Figures 1.25 to 1.27 , respectively. 


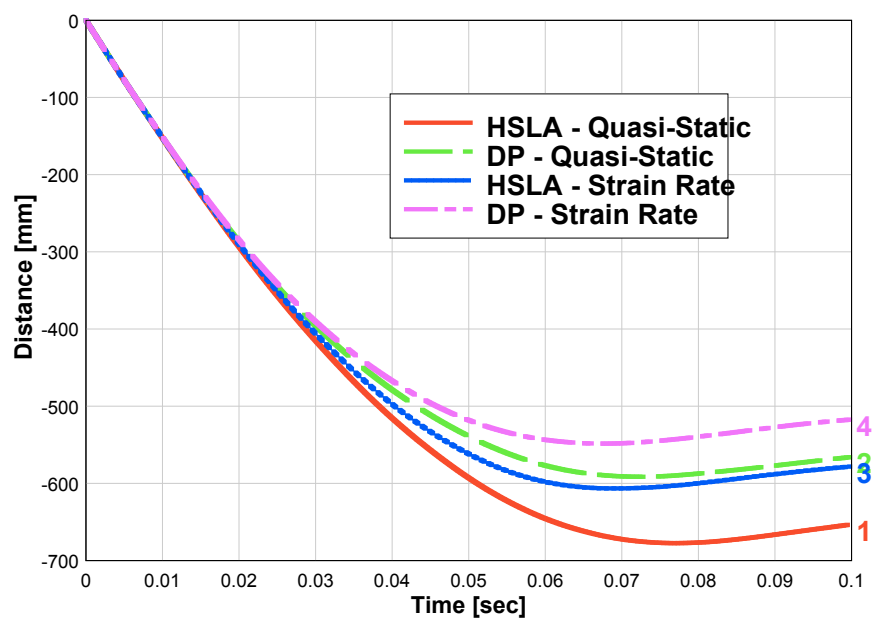

Figure 1.25. Displacements of Car Center.

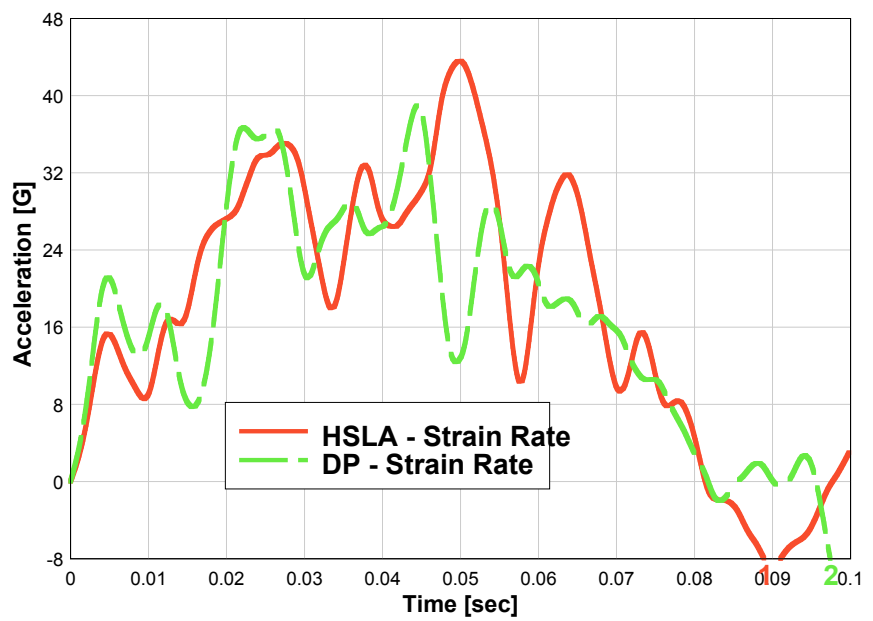

Figure 1.26. Accelerations of Car Center.

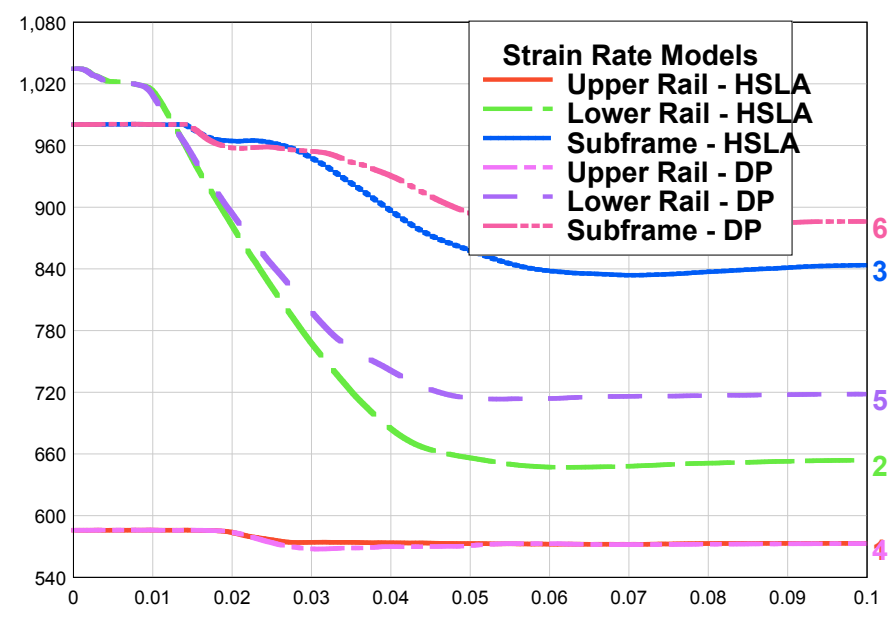

Figure 1.27. Rail Collapse. 
It is interesting to observe that even though the accelerations are very similar, the displacements and collapse measures are not. DP material is intrinsically less strain-rate sensitive when compared to HSLA and, therefore, differences between material models are less pronounced (see Figure 1.25). The load paths have been appreciably influenced in the lower rail and sub frame, while upper rail deformation is very similar to the original design.

\subsection{CONCLUSIONS}

Crash modeling simulations show a clear effect of strain-rate sensitivity on high strength steel (HSS) intensive vehicle. The influence of a strain-rate model can be an incremental sensitivity due to the increased flow stress when similar structure collapse modes are predicted. However, significant differences in crash energy management capacity can be predicted if the change in loading on members alters the predicted collapse mode of the structure. From the material substitution study it can be concluded that HSS material substitution cannot be performed on the basis of the material yield point only and that, especially for advanced HSS vehicle designs, the entire region of material plastic response has to be considered. However, the problem of modeling of the overall dynamic crush process still remains open and requires further experimental and theoretical investigation. 


\section{STEEL PROCESSING EFFECTS ON IMPACT DEFORMATION OF ULSAB}

\subsection{INTRODUCTION}

New HSS materials and processes are increasingly used in today's automobiles in order to reduce weight and improve performance. One challenge posed by these steels is that they deform differently from mild steels to which many component manufacturers are accustomed [25]. High strength steel stampings have greater springback and require different draw angles, and each different grade must often be treated by the design and manufacturing engineers as a unique material. Forming processes have to accommodate higher strength and thinner sections of HSS and result in same or better quality of the final part while reducing costs. Shapes are not becoming any simpler, either, fueled by the designs that are constantly challenging manufacturing feasibility. Computational modeling of stamping [26, 27] and crashworthiness [2] has been generally considered as two separate engineering disciplines. Stamping of automotive panels results in significant strain hardening and thinning in the formed parts. It is generally assumed that plastic hardening offsets the reduction in thickness and, consequently, that crash simulations can be carried out using properties of the virgin coil. Recent publications [29, 30] have shown that sheet metal forming has measurable effect on impact performance of automotive components. Forming integration into structural performance models has also been considered for other applications (see for example References 31, and 32). Even though the forming effects have been observed to have important effect on a component level, the effects on the entire vehicle have not been clearly demonstrated. The reasons for that are multifold. Current crash modeling technology employs numerous approximations, and the forming influence may be of a secondary nature in the crash models. The discrepancy in the level of detail between forming and full vehicle crash models can mask the effects that forming has on the vehicle response level. The stamping models can afford finer Finite Element Method (FEM) discretizations and when the forming results are averaged and mapped into coarser crash models, the local stamping variations can be lost. Forming effects will certainly be more apparent for lightweight structures that have been extensively stretched during forming and for materials with rapid strain hardening, such as Dual Phase and TRIP steels. Finally, the multitude of styles in modern vehicle designs and their crash absorbing structures makes developing definite quantifiers of forming influence on crashworthiness a futile task. However, trends can be examined and may lead to identification of needed improvements in modeling technology. Incorporation of stamping effects has to show clear effects on crash performance model responses in order to justify increased model complexity and effort.

The section outline is as follows: in the following subsection, ULSAB model and materials used in the original design are briefly described. Forming of crash relevant vehicle components is presented next. Then, crash simulation results for models with and without forming effects are analyzed using comparison of global vehicle response and individual structures. The conclusions of the research are stated in the final subsection.

\subsection{FORMING SIMULATIONS}

In order to investigate forming effects on crash performance, vehicle components that have the major influence on crash energy absorption have to be included in the forming analysis. Vehicle components that are designed to absorb crash energy during frontal crash are shown in Figure 2.1. The numbers in the figure denote vehicle part numbers as documented in the ULSAB report [1]. 


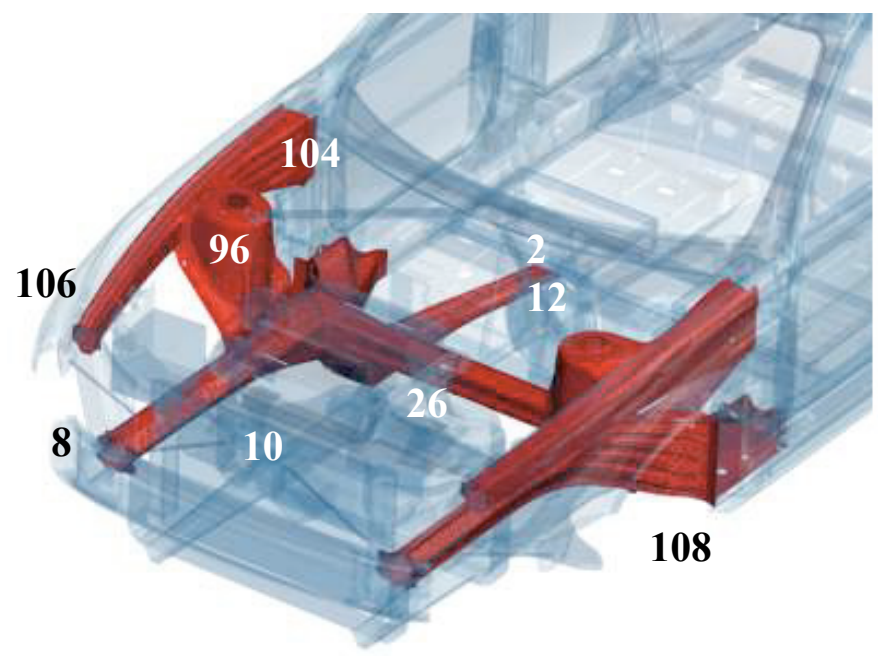

Figure 2.1. Main Frontal Crash Components.

The parts that were extracted from the crash model are shown in Figures 2.2-2.10.

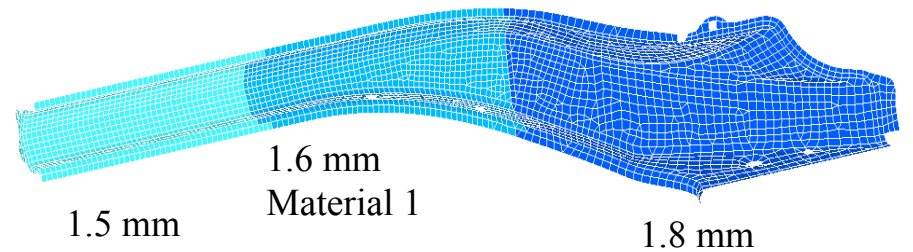

Figure 2.2. Part $10-$ Front Rail Inner TWB.

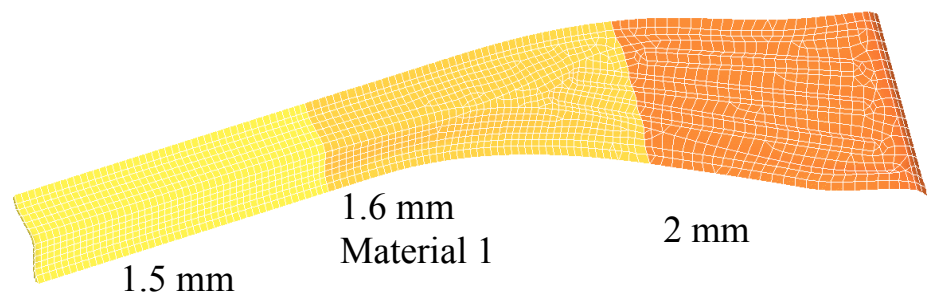

Figure 2.3. Part 8 - Front Rail Outer TWB.

$1.2 \mathrm{~mm}$ Material 5

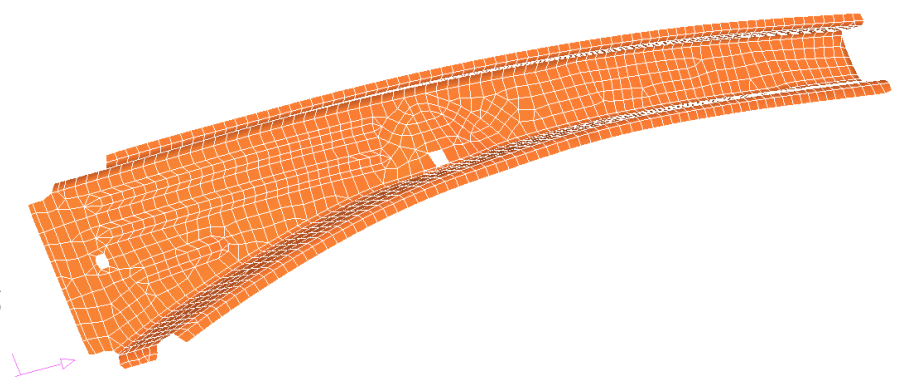

Figure 2.4. Part $104-$ Rail Fender Support Inner. 
$0.9 \mathrm{~mm}$

Material 1

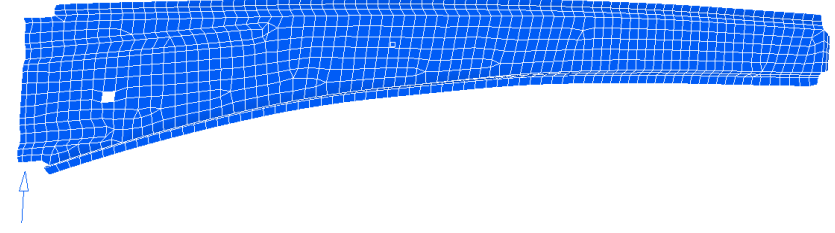

Figure 2.5. Part $104-$ Rail Fender Support Inner.

$1.4 \mathrm{~mm}$

Material 1

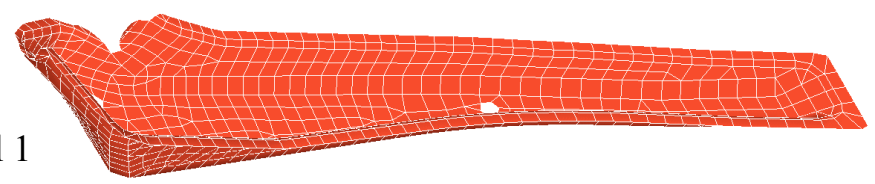

Figure 2.6. Part $12-$ Rail Front Extension.

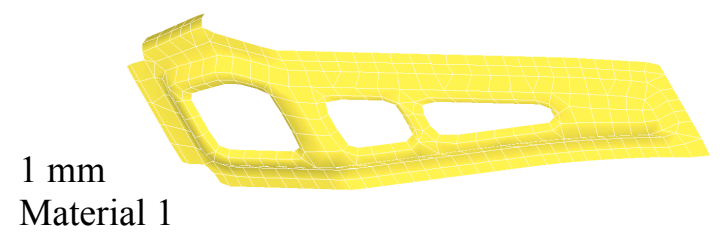

Figure 2.7. Part 2 Reinforcement Rail Front Extension.

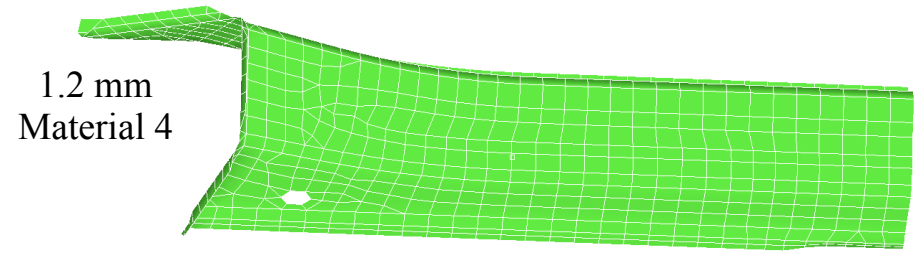

Figure 2.8. $\quad$ Part 26 - Member Dash Front (half).

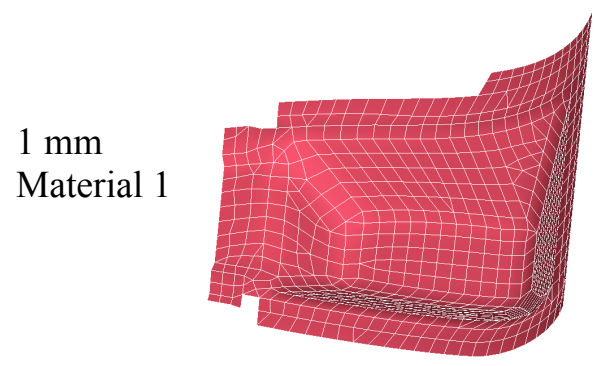

Figure 2.9. Part 108 - Reinforcement Front Rail. 
$2 \mathrm{~mm}$

Material 3

$1.6 \mathrm{~mm}$

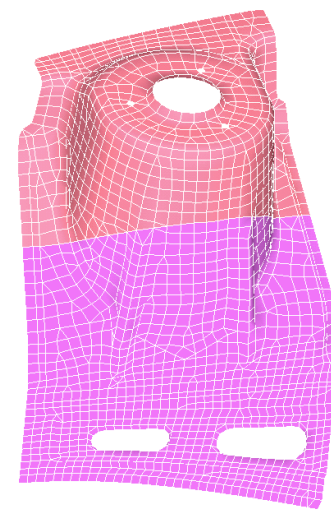

Figure 2.10.

Part 96 - Panel Skirt TWB.

Several parts are made out of tailor welded blanks. TWB joints were modeled only through the change of thickness that occur at the connection. The effects of the welding on material properties have not been included. The material properties for the selected parts are shown in Figure 2.11. The material data are based on quasi-static experiments and the corresponding true plastic strain-true plastic stress curves were used as parameters for the piece-wise-linear isotropic plasticity material model.

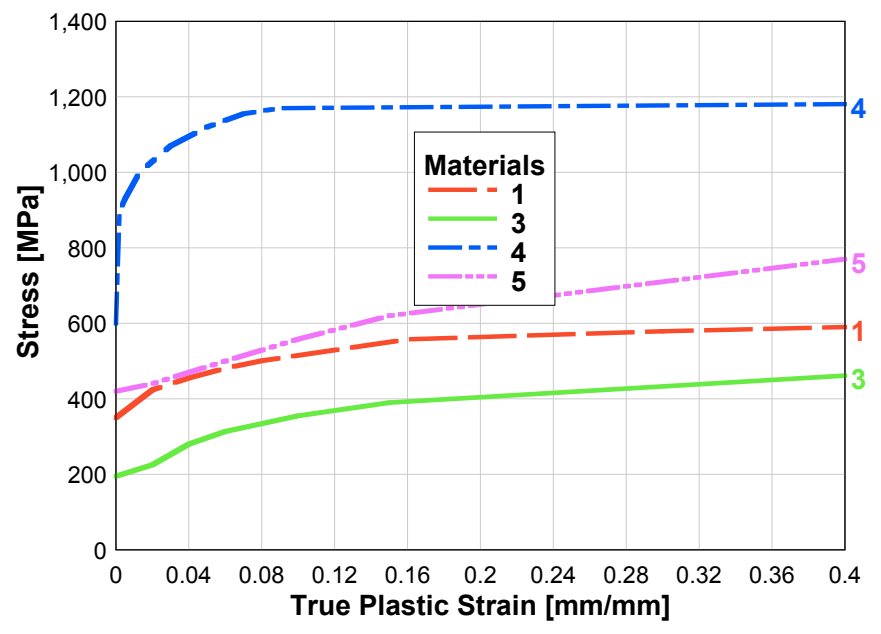

Figure 2.11. Material Properties.

Currently, there are several widely accepted FEM based formulations for modeling of sheet metal stamping [35,36]. Detailed forming simulations require combination of sophisticated software and hardware [37]. New methods have also been proposed and have demonstrated promising results [38], but have not yet been used on complex industrial problems. Selection of stamping model formulation depends primarily on the intended purpose of the model. We wanted to select a formulation that can give reasonably detailed estimates for the overall conditions in the formed part while not requiring large effort for modeling all the details of the forming process. The One-Step Forming Method [39, 40] fits this overall objective while providing reasonable accuracy [41]. One-Step Method is commonly used in steel industry at the product design stage for quick evaluation of manufacturing feasibility without considerable investing into die design. The starting point of this approach is the FEM model of the stamped part. The problem is formulated in terms of mapping the position of the final part configuration into the starting blank. Because of the assumed linear displacement path between the starting and the final configurations, 
as well as for other simplifications, the method is considered to be a complementary tool for more general incremental displacement approach.

The refinement of the crash model in the frontal crash absorbing components allowed for using the same FEM discretization in stamping simulations and the complex mapping schemes are therefore serendipitously avoided. The density of the FEM discretization in the selected parts is similar to the discretizations reported in the literature [26] and within the restrictions placed by the One-Step forming approach. The intention was to produce large, yet still reasonable stretch in the parts so that the forming effects would be more likely to influence the crash behavior.

The forming analysis of certain component parts of the ULSAB vehicle was performed using the PC based computer program FAST_FORM3D [42] developed by Forming Technologies Inc. The car components analyzed have been extracted directly from the finite element model of ULSAB, the files were then converted to a NASTRAN format and fed to the analysis program as a pre-processed file with attached finite element mesh. The forming analysis was performed on a 'repaired' mesh that had all the holes and irregularities removed from the original mesh. For some cases sections of the part were modified to remove regions that presented 'undercut' which correspond to the non-unique linear mapping of formed shape into the blank. Material properties and component specific data were obtained from the finite element model of ULSAB. Material stress-strain data (Figure 2.11) were input directly to the program. The analysis was performed without the use of 'curve binders', which may have resulted in higher strains and stresses at the bends near the boundaries of the parts. Three components are formed using TWB option with individual blank thickness data for each region but with a common material for the entire blank.

The analyzed parts are characterized by a channel type configuration with small flanges along the major axis; the parts have gentle curvature along an axis normal to the part long axis and some curvature in the web of the channel. The analysis was performed using a draw-bead blank holding feature with a magnitude of 'draw-bead-strength' that was adjusted so that tearing of the part was inhibited. Calculated thickness associated with the forming process resulted in some regions where there was a minor increase in thickness attributed to the flowing of the material near the flange bends. These regions were limited in relation to the size of the blank. The Table 2.1 shows the average plastic strain and thickness in the formed parts.

\begin{tabular}{|c|c|c|}
\hline $\begin{array}{c}\text { ULSAB } \\
\text { Part. ID }\end{array}$ & $\begin{array}{c}\text { Average } \\
\text { Strain [\%] }\end{array}$ & $\begin{array}{c}\text { Average Thickness } \\
\text { [mm] }\end{array}$ \\
\hline 8 & 4 & 1.8 \\
\hline 10 & 12 & 1.5 \\
\hline 26 & 3 & 1.18 \\
\hline 2 & 4 & 0.97 \\
\hline 12 & 22 & 1.19 \\
\hline 96 & 16 & 1.6 \\
\hline 108 & 13 & 0.93 \\
\hline 104 & 19 & 1.04 \\
\hline 106 & 4 & 0.87 \\
\hline
\end{tabular}

Table 2.1. Averages of Forming Effects on Selected Parts 


\subsection{CRASHWORTHINESS SIMULATIONS}

The forming strains and thickness variations for every finite element in the forming simulation were used for definition of part properties of the corresponding crash model parts. Certainly, there are other physical effects of forming process such as springback, residual stresses, damage, variations in Young's modulus, etc. In this study, they were considered to be secondary and were not included in the models. Crash scenario was frontal impact of ULSAB vehicle into flat rigid barrier with vehicle speed of $35 \mathrm{mph}$ as specified in the U.S. Department of Transportation, New Vehicle Assessment Program (NCAP) test.

NCAP crash simulations for vehicle models with and without forming effects were performed using the massively parallel version of LS-DYNA3D [14]. The simulations were run on ORNL 184-node IBM RS/6000 SP and 64-node Compaq AlphaServer SC computers. The details of computer performance for crash simulations can be found in Reference [43]. For example, crash simulations on IBM SP using 8node, 32 processor configurations required on average 8 hours of execution time. Addition of forming effects into crash model does not have effect on computational time since it involves only the initialization of the problem. The results show that the dynamic of the deformation between the two cases is quite similar and does not reveal significant differences in collapse models for the considered parts. The side view of the deformed rails at $80 \mathrm{~ms}$ into the crash is shown in Figures 2.1.12 and 2.13 for the two cases considered.

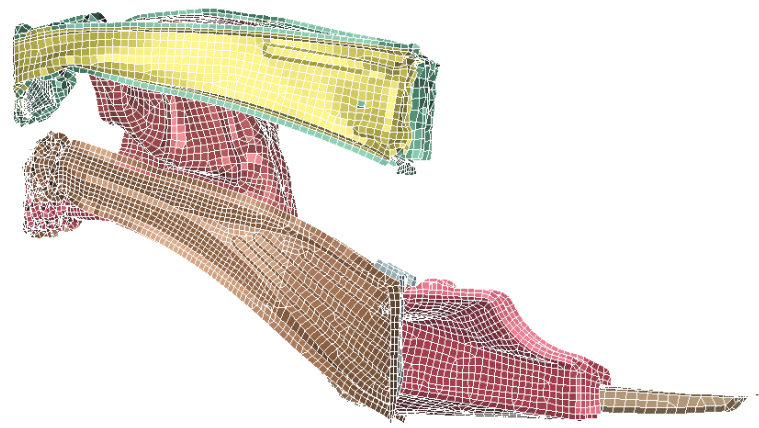

L.

Figure 2.12. $\quad$ Front Rails - Coil Properties.

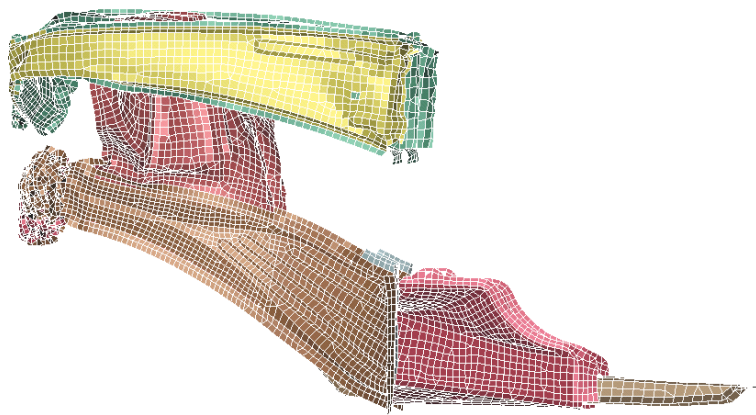

i.

Figure 2.13. Front Rails - As-Formed Properties. 
Lower rail is the main energy absorber in the frontal crash and its deformation for base and as-formed models are shown in Figures 2.14 and 2.15. As for the case of the entire rail system, the difference in the deformations is noticeable, however, not as important as for example for the case of strain rate dependent and strain rate independent material models [33].

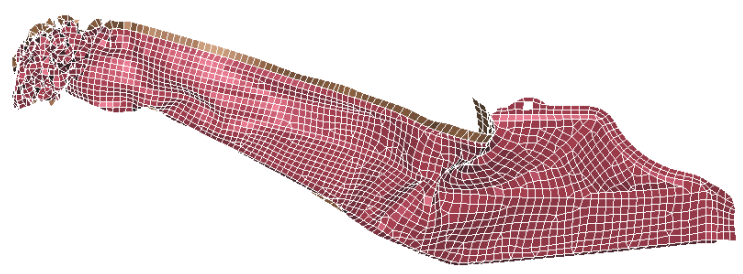

Figure 2.14. Lower Rails - Coil Properties.

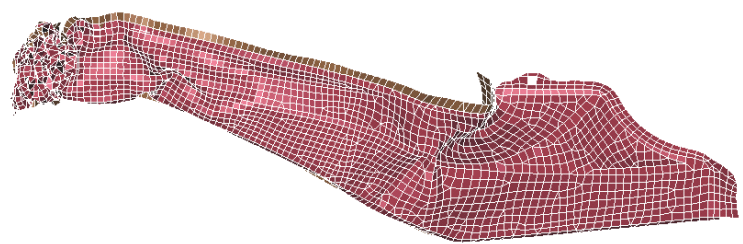

Figure 2.15. $\quad$ Lower Rails - As-Formed Properties.

Filtered (SAE J211) acceleration traces for the node at the rocker near the bottom of B-pillar are shown in Figure 2.16. This point on the vehicle is usually used as a link between occupant environment and the vehicle dynamics models.

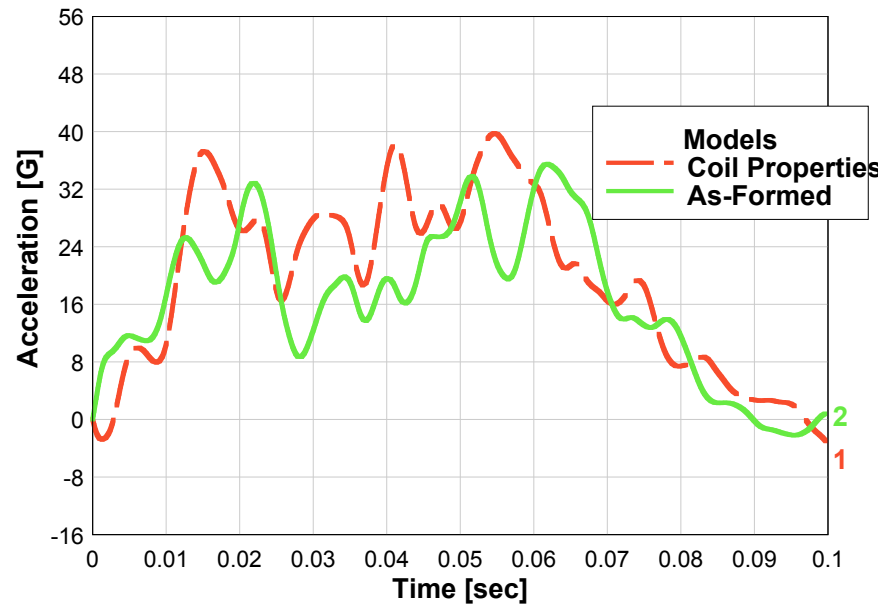

Figure 2.16. Acceleration at Rocker near B-pillar.

The average acceleration values are $19.4 \mathrm{G}$ and $16.5 \mathrm{G}$ for Coil and As-Formed cases, respectively. Average force in the lower rail is very similar for the two cases considered and even follows the same folding pattern as can be seen from oscillations in the force magnitude in Figure 2.17. 


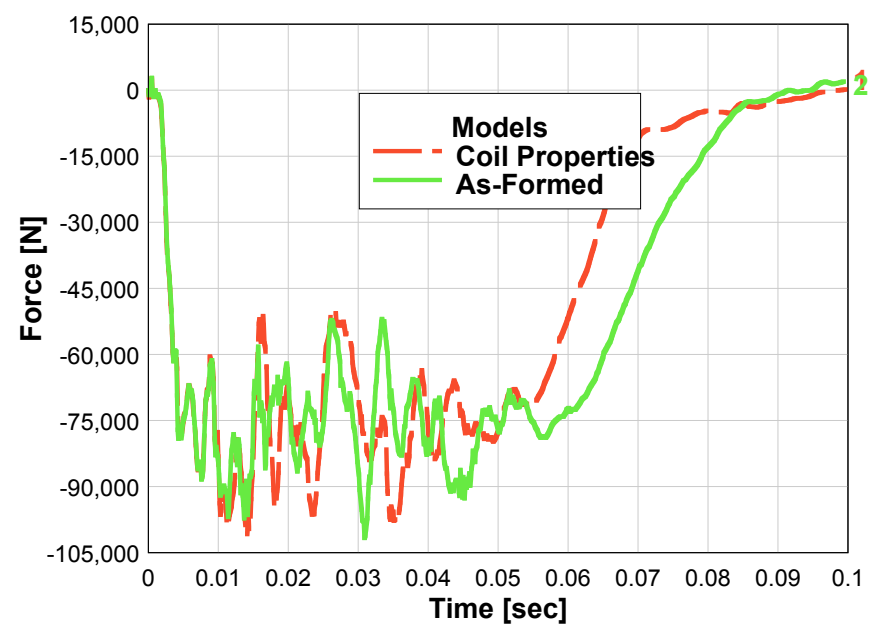

Figure 2.17. $\quad$ Force in Lower Rail.

The duration of the force is longer for the As-Formed case. The deformation of the rail is therefore $6 \%$ larger in the As-Formed case as can be seen in Figure 2.18. Curves in Figure 2.18 denote the distance between the centers of front and base cross sections of the rail.

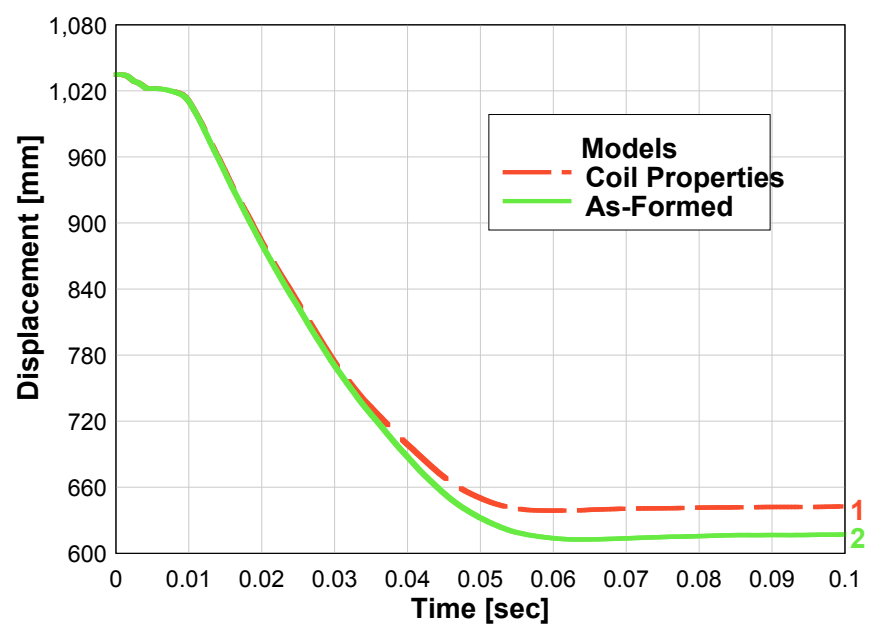

Figure 2.18. $\quad$ Lower Rail Length.

The fact that the forming results in larger deformation of the lower rail indicates that the forming thickness variations have larger effect than the plastic hardening. The stability of the sheet metal determines folding pattern and tendency to creation of localized hinges that dissipate crash energy. The last plastic hinge that is developing in the back of the crash zone in the rail is indeed more pronounced in Figure 2.15 than in Figure 2.14.

The effect of forming on crashworthiness was also investigated for ULSAB model in which HSLA350 steel has been replaced with DP430 steel. The simulations have shown a low effect of including the forming effects into crash model. 


\subsection{CONCLUSIONS}

Crash modeling simulations show a low to moderate effect of forming on overall crash performance. The design is the determining factor on the vehicle performance and, therefore, the results of this research cannot provide measures that can be used in a general case. However, it has been shown that for materials that have modest strain hardening, the forming effect is observable and that when more complex forming operations are used, especially in combination with rapid strain hardening materials, forming effects should be taken in the consideration in the computational crash models. 



\section{CRASH COMPATIBILITY OF THE ULSAB WITH CARS OF THE SAME SIZE}

\subsection{INTRODUCTION}

The real challenge of reducing vehicle weight is to meet and exceed safety standards without sacrificing affordability. ULSAB, shown in Figure 3.1, is steel-based autobody structure that weighed $203 \mathrm{~kg}$, exceeded all structural requirements, and offered a high degree of safety, while maintaining the affordability and 100 percent recyclability of steel. At $203 \mathrm{~kg}$, ULSAB has a body mass that is 25 percent less than average benchmark vehicles and up to 36 percent less than the average N-A mid-size body structure. ULSAB achieved its aggressive targets through the use of advanced technologies and materials combined with innovative design. The body structure comprised only 96 major parts and 158 total parts, compared with more than 200 parts for a typical auto body. High-strength (HS) and ultra-high-strength (UHS) steels account for more than 90 percent of the material. Half the mass comprised tailor-welded blanks (TWBs). Two other elements are the hydroformed side roof rail and the steel sandwich used for the spare tire tub and dash panel insert.

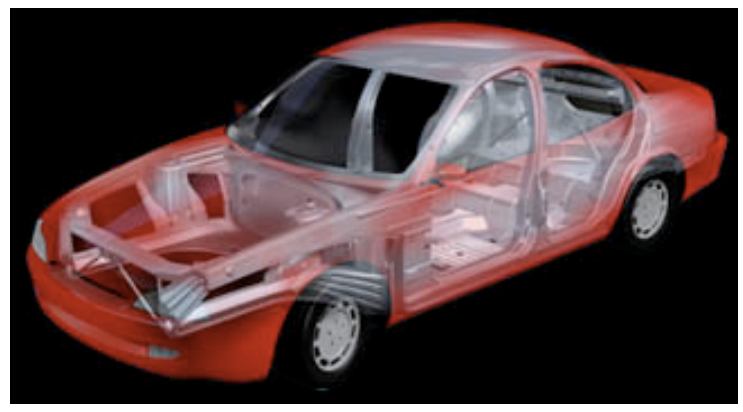

Figure 3.1. ULSAB Vehicle

With regards to crash events, the tests and current requirements in Table 3.1 were taken into consideration.

\begin{tabular}{|c|c|c|}
\hline Crash Event & ULSAB Program & NHTSA Requirements \\
\hline Frontal & $35 \mathrm{mph}$ & $30 \mathrm{mph}$ \\
\hline Frontal Offset & $34 \mathrm{mph} 50 \%$ Offset & No \\
\hline Side & $31 \mathrm{mph} 90$ degree & $33.5 \mathrm{mph} 63$ degree \\
\hline Rear & $35 \mathrm{mph}$ & $30 \mathrm{mph}$ \\
\hline Roll Over & $1.5 \times$ curb weight & $1.5 \times$ curb weight \\
\hline
\end{tabular}

Table 3.1. $\quad$ Crash Simulations Used in ULSAB Design

Crash performance was evaluated by using computer simulations; the simulations indicated that the vehicle would satisfy all the listed safety standards.

The recent initiatives by transportation safety agencies to consider different deformable and offset-barrier crash-test scenarios and technologies together with car-to-car impact evaluations indicate that the safety requirements will become broader and more stringent. Numerous publications, (see for example References 44-47, and references listed therein), have appeared on the subject of crash compatibility. These publications generallv address aspects of compatibilitv in the existing passenger fleet: and 
therefore, analyze standard design features. The three main factors influencing crash compatibility, namely curb mass, body stiffness and body geometry, are different for the ULSAB design relative to conventional car design. The need for car-to-car crash compatibility analysis is therefore justified and was the objective of the research presented in this report. This research takes advantage of ongoing automotive-related activities at the Oak Ridge National Laboratory (ORNL), the National Highway Traffic Safety Administration (NHTSA), and NHTSA contractors aimed at developing vehicle models that are representative of the vehicles in the U.S. car and truck fleet.

Characteristic crash-response parameters associated with crash-energy management in the frontal car-tocar impact simulations are discussed. The research work reported in the report was conducted in 1998.

\subsection{METHODOLOGY}

The crash compatibility of the ULSAB with cars of similar weight and geometric characteristics is assessed using the results of computer numerical simulation of the crash scenario that depicts the frontal collision with full engagement (no offset) of two cars, each with a forward velocity of $13.4 \mathrm{~m} / \mathrm{s}(35 \mathrm{mph})$. One of the cars is the ULSAB car. The other car is representative of an existing four-door passenger vehicle in the current U.S. fleet.

The uncoupled finite-element (FE) models of the vehicles representing the U.S. fleet have been developed for the NHTSA by different institutions. The vehicle models used in this study (Ford Taurus, Chevrolet Lumina, and the Dodge Intrepid) were developed by EASi Engineering, Inc. References 48 and 49 describe the model developments for the Ford Taurus; Reference 50 describes the development of the FE models for the Chevrolet Lumina and the Dodge Intrepid.

The results of the numerical analysis provide parameters that are used for comparison of the crash responses of the vehicles involved. Crash compatibility is evaluated using the deformation of the frontal area (crush-zone, CZ) of the cars and the integrity of the occupant compartment (OC). The deformation of $\mathrm{CZ}$ is quantified by the dimensional change measured in the longitudinal axis of the cars between a point on the bumper and a point on the firewall. The reduction in the distance between points at the base of the B-pillar of ULSAB relative to the same point on the other car reflects the severity of the frontal collision. Calculated acceleration traces and their average values can also be used as indicators of the severity of the collision. Finally, the forces in the ULSAB's frontal main load-carrying members in the car-to-car crashes are compared to the forces from the NHTSA New Car Assessment Program (NCAP) test that was one of the ULSAB design requirements (see Table 3.1).

The computer simulations of the car-to-car collisions were performed using the LS-DYNA computer program [14]. The assembly of the crash scenarios uncoupled car was done with program LS_INGRID. The numerical work was performed on a multiprocessor SGI-Origin 2000 and IBM RS6000 SP2 supercomputers.

\subsubsection{Finite Element Models}

Numerical analyses were performed for the crash scenarios that depicted the following frontal-collision events:

-ULSAB-1992 Ford Taurus

-ULSAB-1995 Chevrolet Lumina

-ULSAB-1994 Dodge Intrepid 
These vehicles are four-door, front-end-driven production models. All major structural components, including the body-in-white, are made of steel. Ford Taurus, Chevy Lumina, and Dodge Intrepid are classified as mid-size passenger cars, and are typical of the existent passenger cars in the U.S. fleet. The ULSAB car is a concept vehicle; this is a four-door, front-end driven, transverse-mountedengine/transmission vehicle with relatively low structural weight. Geometrically, both the concept and target vehicles are similar in bumper heights and general body dimensions.

An overview of the uncoupled vehicle FE models is shown in Table 3.2. The FE models of the target vehicles were obtained courtesy of NHTSA [51].

\begin{tabular}{lrrrr}
\hline Vehicle & \multicolumn{1}{c}{ Node } & Solid & Beam & \multicolumn{1}{c}{ Shell } \\
\hline ULSAB & 174294 & 0 & 934 & 177326 \\
Taurus & 26737 & 340 & 140 & 27873 \\
Lumina & 100769 & 3168 & 106 & 92960 \\
Intrepid & 90191 & 3732 & 118 & 82728 \\
\hline
\end{tabular}

Table 3.2.

FE Model Statistics of Vehicles used in Analysis

The level of complexity in the models has progressed in time as computational resources were made available and as refinements in analysis tools were implemented. The oldest model is the Ford Taurus, developed in 1993. The later models show significant increases in the number of elements as well as other refinements offered by the analysis software. Reference 52 can be consulted for in-depth background information on vehicle crashworthiness modeling and design.

The uncoupled models have been extensively verified and validated in several crash scenarios, one of which is the frontal collision with a flat rigid barrier (NCAP test). Validation and verification of each model were also conducted in house before the coupled model was generated. No changes have been made to the uncoupled models before the assembly of the full model used in the analysis. The total crash mass of the car models used in this project is given in Table 3.3.

\begin{tabular}{c|c}
\hline Vehicle & Total Crash Mass \\
\hline ULSAB & 1612 \\
Taurus & 1563 \\
Lumina & 1754 \\
Intrepid & 1682 \\
\hline Table 3.3. Calculated Vehicle Mass $(\mathrm{kg})$
\end{tabular}

The total crash mass of the vehicles also depends on the level of accessories, occupants, and luggage included. A detailed description of the additional weight for each of the vehicle was not available and may have caused the disparity between the real masses. However, the weights of the U.S. fleet vehicles were similar to the NCAP test weights reported in the NHTSA crash test database.

With regards to the detail of the FE models, some vehicle components were not included in the models. The ULSAB model did not include the engine lid, trunk lid, or glass panels in the front and rear doors; Chevy Lumina and Dodge Intrepid models did not have the rear and front doors. However, these components were included in the total crash mass of the vehicles. 


\subsubsection{Material Data}

The uncoupled FE models for all the vehicles in the study use material type 24 of the LS-DYNA repertoire; no strain rate dependency is used, and the stress-strain relationship is given in tabular form. Yield stresses and plots of stress-strain curves for these materials, for the structural components found in the frontal crush zone are given in the paragraphs that follow.

The ULSAB materials range in yield stress values from 140 to $800 \mathrm{MPa}$ (Figure 3.2).

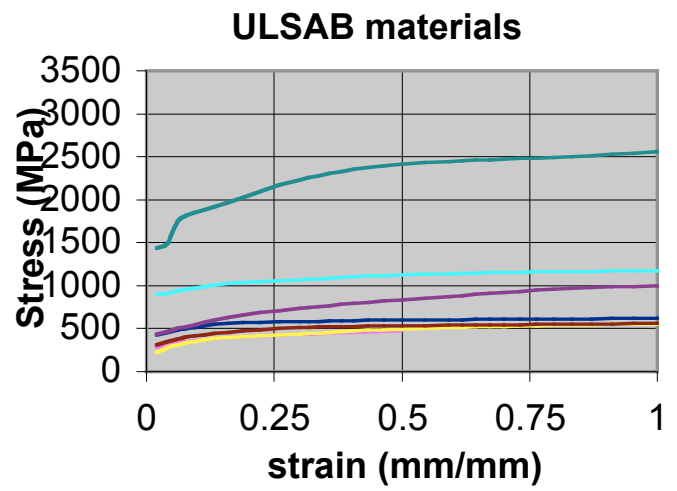

Figure 3.2. Material Data for ULSAB

The Taurus material yield stress is $215 \mathrm{MPa}$ (Figure 3.3).

Taurus materials

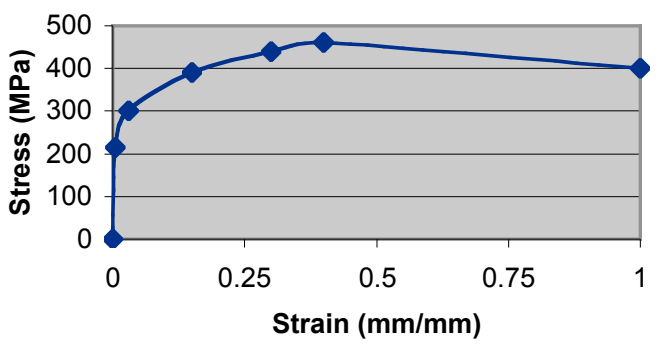

Figure 3.3. Materials for Ford Taurus

The Lumina material yield stress is $210 \mathrm{MPa}$ (Figure 3.4). 


\section{Lumina materials}

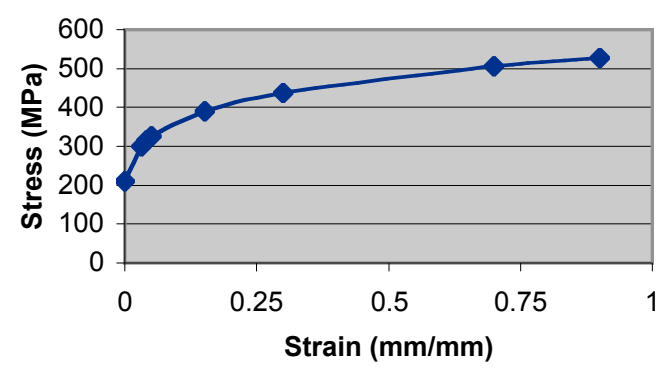

Figure 3.4. Materials for Chevrolet Lumina

The Intrepid materials range in yield stress values is from 210 to $273 \mathrm{MPa}$ (Figure 3.5).

Intrepid Materials

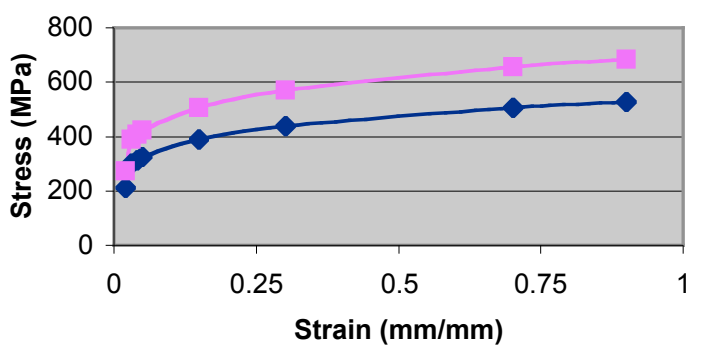

Figure 3.5. Materials for Dodge Intrepid

The data used in the above figures have been directly extracted from the uncoupled vehicle models.

\subsubsection{Finite-Element Formulations}

Shell elements in the FE models are based on the Belytschko-Tsay formulation. For consistency in the analysis, the most computationally conservative control parameters from the uncoupled models were used. Typical 10x10 mm aspect ratio is found in most of the shell elements. The Ford Taurus model has a larger shell aspect ratio simply because of the vintage of software and hardware available at the time the model was developed. Most of the beam elements used in the models are based on the Belytschko-Schwer formulation. The model of Chevy Lumina uses some Hughes-Liu beams.

In general, a unique contact formulation has been used (LS-DYNA3D type 13, defining a volume that includes the entire two cars). The coupled FE model also prescribes a rigid reference base defined using a "stonewall" that is not shown graphically.

\subsection{NUMERICAL SIMULATIONS}

Results of the numerical simulation of each of the three cases considered in the study are briefly discussed in the sections that follow. 


\subsubsection{ULSAB-Taurus Collision}

This section discusses the results of the simulation of the frontal collision of ULSAB and the 1992 Ford Taurus (Figure 3.6). The ULSAB model is slightly heavier than the Taurus model (1612 kg vs. $1563 \mathrm{~kg}$ ). The physical dimensions of both cars are comparable.

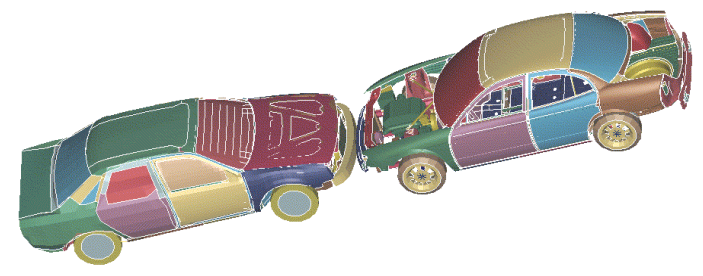

Figure 3.6. Taurus-ULSAB Collision Model

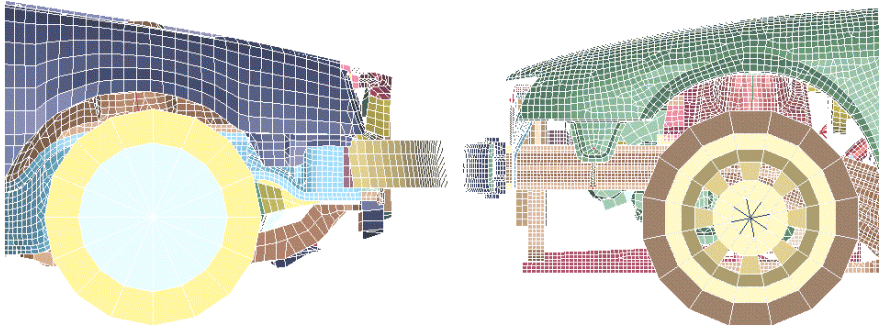

Figure 3.7. Initial Configuration- Taurus-ULSAB

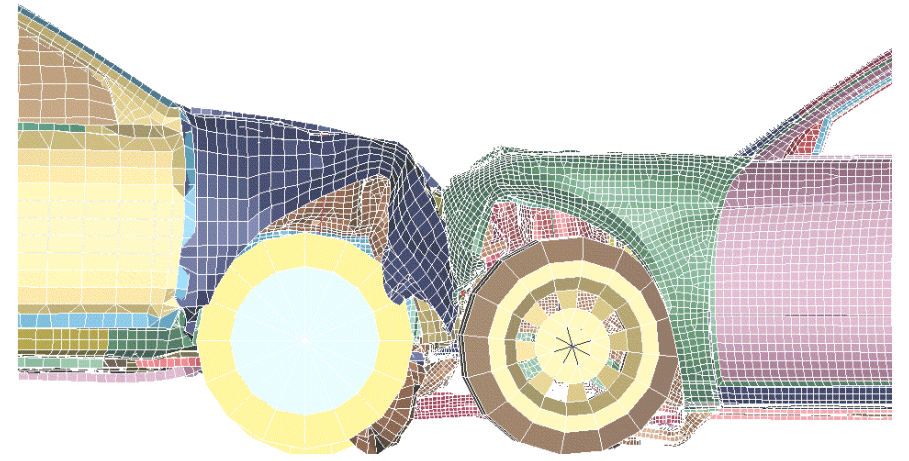

Figure 3.8. $\quad$ End of Simulation- Taurus-ULSAB

Figures 3.7 and 3.8 show the side view of the initial $\left(\mathrm{T}_{0}\right)$ and final simulation time $\left(\mathrm{T}_{\text {end }}\right)$ configurations of the frontal collision. Head-down view is shown in Figures 3.9 and 3.10. 

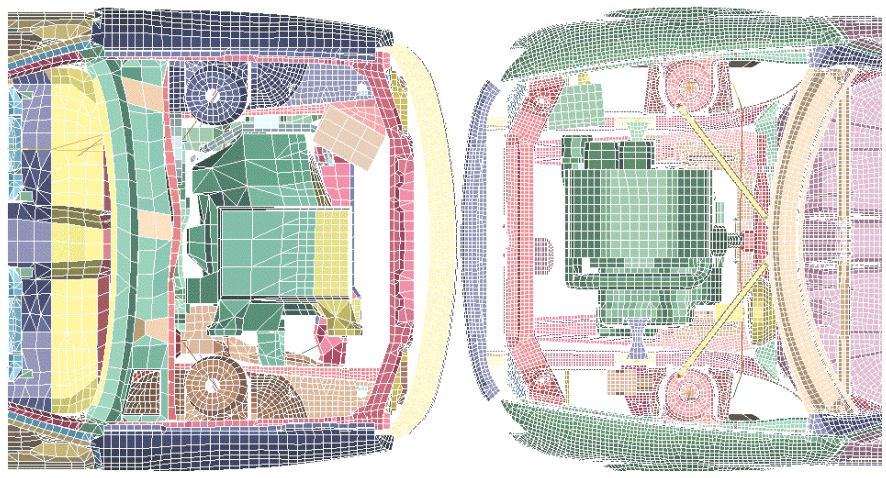

Figure 3.9. Overhead View, Initial Configuration

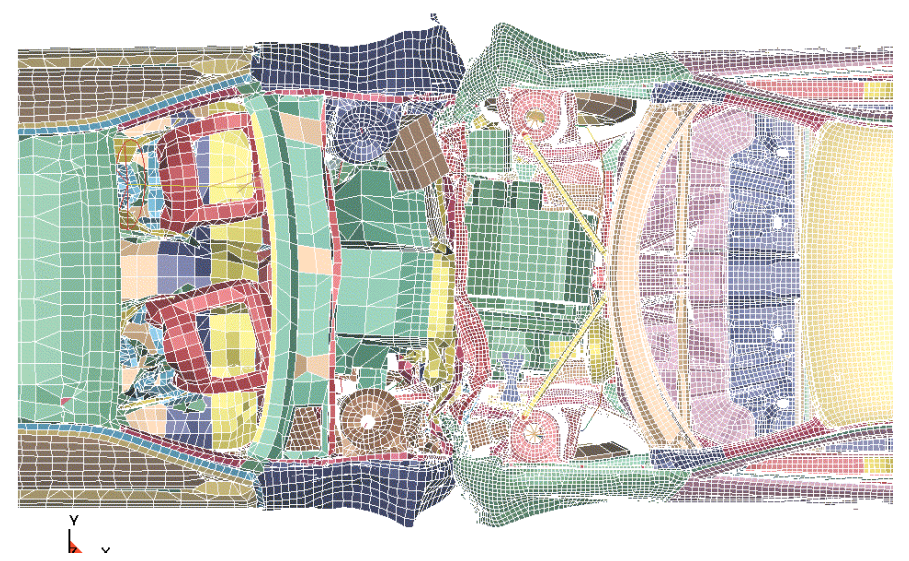

Figure 3.10. Overhead View, Final Configuration

The frontal region of Taurus progressively collapses during the first $20 \mathrm{~ms}$ from contact initiation. Subsequently, the engine cradle (sub-frame) of the Taurus undergoes large bending so that, after $35 \mathrm{~ms}$ from contact initiation, the engines of both cars make contact. Displacement of the engines is the driving mechanism that generates the deformation to the engine sub-frame. The engine remains attached to the sub-frame thorough the collision.

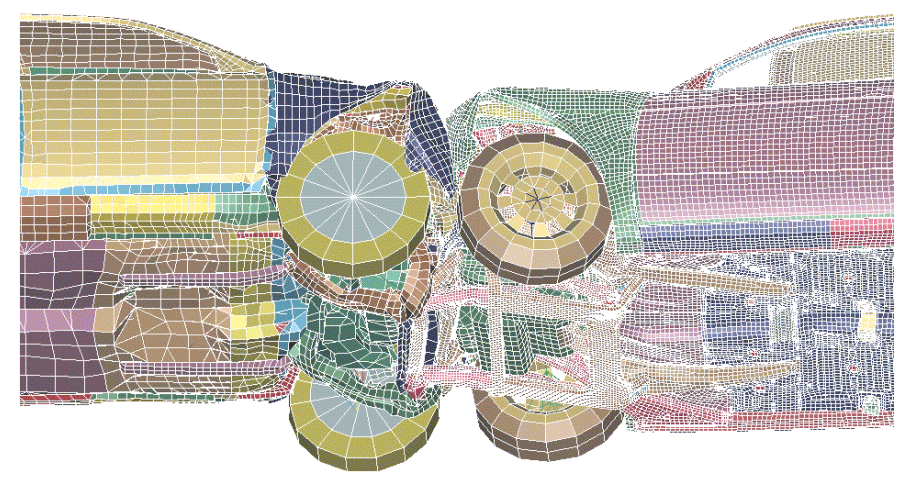

Figure 3.11. Deformed Configuration of Frame

The deformation in the undercarriage of the vehicles is shown in Figure 3.11 at a time when the kinetic energy is at a minimum $\left(\mathrm{T}_{\mathrm{v}=0}\right)$. A large deformation in the occupant compartment floor of the Taurus car 
that is associated with the loads imposed in this region by the engine cradle rear support point. Limited motion of the engine of ULSAB relative to its engine attachment points can be observed.

The reduction in lengths of the crush zones measured from the front of the bumper to a point in the firewall at time $\mathrm{T}_{\mathrm{v}=0}$ is shown in Table 3.4.

\begin{tabular}{l|cc}
\hline Vehicle & $\begin{array}{c}\text { Xreduction } \\
(\mathrm{mm})\end{array}$ & $\begin{array}{c}\text { Xreduction } \\
\text { (\% of initial) }\end{array}$ \\
\hline ULSAB & 566 & 48 \\
\hline Taurus & 634 & 58 \\
\hline
\end{tabular}

Table 3.4. Reduction of Length in Crush Zone

The longitudinal component of the change in length between points at the base of the B-pillar in the driver side of the ULSAB and the passenger side of the Taurus model, at time $T_{v=0}$ is $1257 \mathrm{~mm}$. The door frame of the Taurus undergoes deformation due to the bending of the upper rail of the doorframe. The reduction in length of the passenger floor measured from the firewall to the front of the driver seat is $10 \mathrm{~mm}$ and $166 \mathrm{~mm}$ for the ULSAB and Ford Taurus models, respectively.

The average acceleration values along the longitudinal car axes at two locations, the low B-pillar at the rocker panel elevation and in the occupant floor just below the driver seat, for each of the vehicles are given in Table 3.5. Average accelerations have been calculated in time interval between $T_{0}$ and $T_{v=0}$.

\begin{tabular}{|c|c|c|}
\hline Vehicle & $\begin{array}{l}\text { Base B- } \\
\text { pillar }\end{array}$ & $\begin{array}{l}\text { Floor below } \\
\text { driver seat }\end{array}$ \\
\hline ULSAB & 18 & 16 \\
\hline Taurus & 22 & 18 \\
\hline
\end{tabular}

Table 3.5.

Accelerations (G's) at Selected Locations

Figures 3.12 and 3.13 show the time history of accelerations at the selected locations.

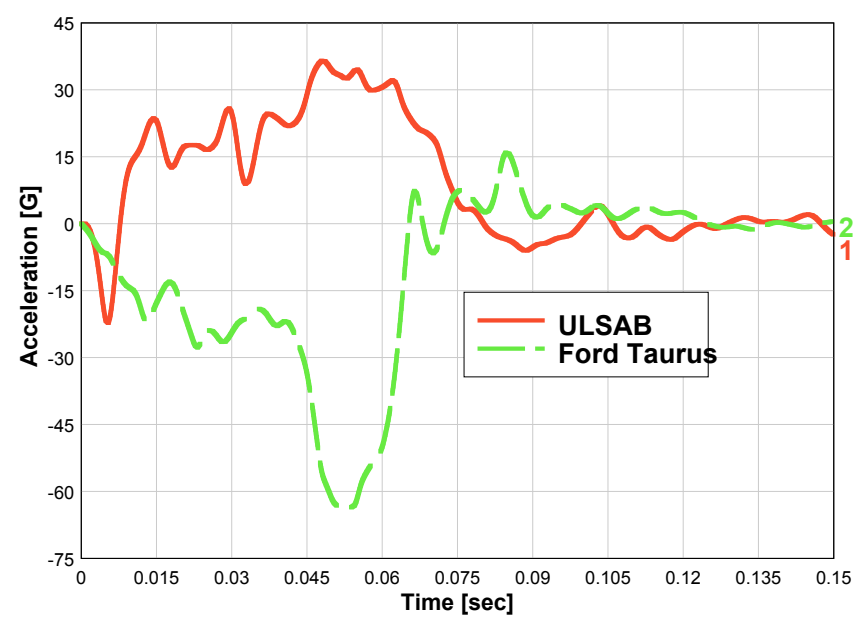

Figure 3.12. X-Acceleration at Base of B-Pillar 


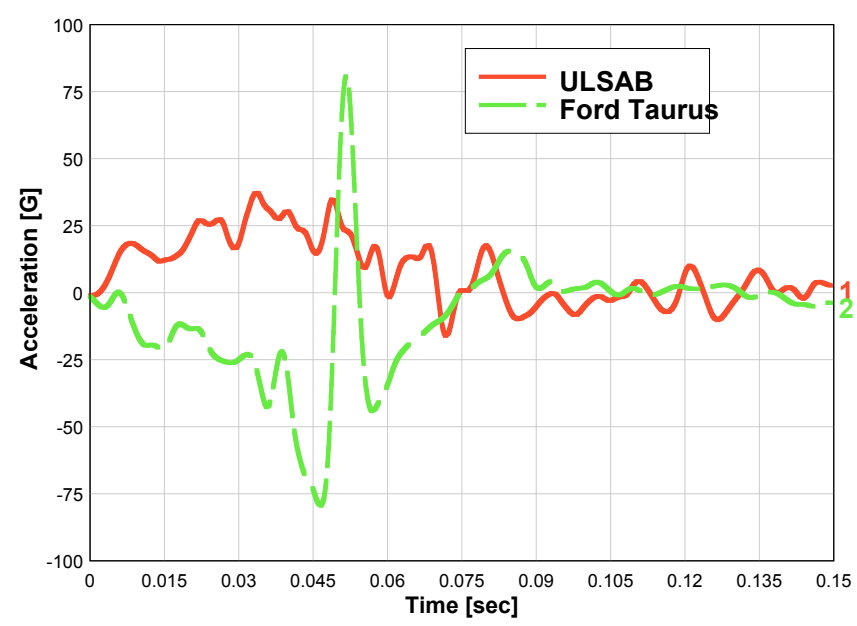

Figure 3.13. X-Acceleration at Driver's Side Floor

The forces carried out by the frontal structural crash zone components are displayed in Figure 3.14. The cross sections used for force calculations were placed in the rear base of the rails to estimate the forces transferred to the OC. Lower rail has sustained level of $70 \mathrm{kN}$ and peak force of $100 \mathrm{kN}$. The sub-frame has a higher peak than the upper rail.

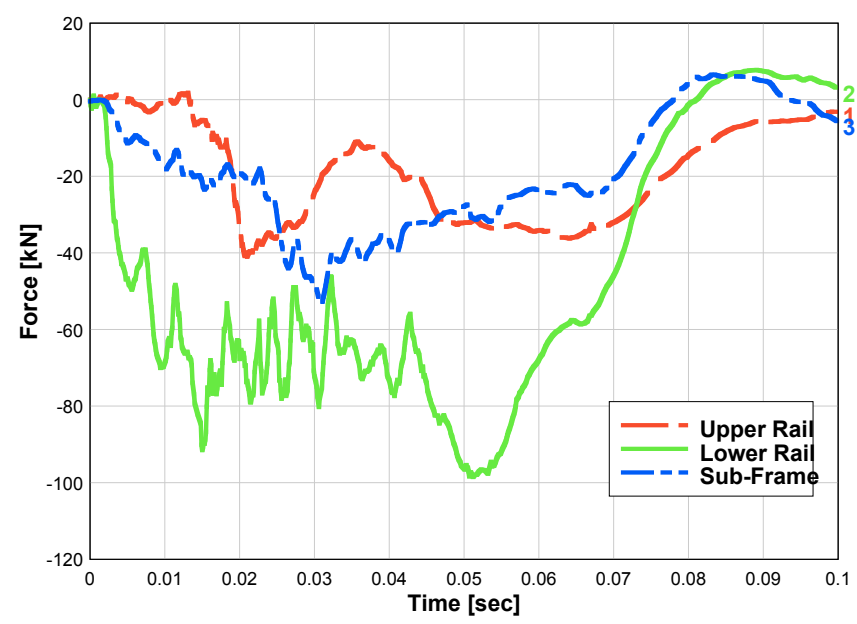

Figure 3.14. Front Rail Forces in ULSAB 


\subsubsection{ULSAB-Chevrolet Lumina Collision}

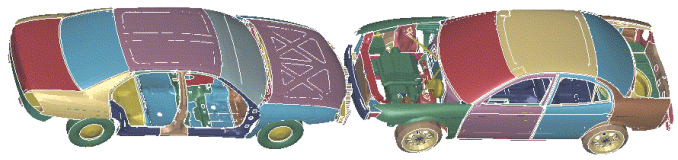

Figure 3.15. Lumina-ULSAB Collision Model

This section discusses the results of the simulation of the frontal collision of ULSAB and the 1995 Chevrolet Lumina models (Figure 3.15). The Lumina model is about 9\% heavier than the ULSAB (1754 $\mathrm{kg}$ vs. $1612 \mathrm{~kg}$ ). The physical dimensions of both cars are comparable.
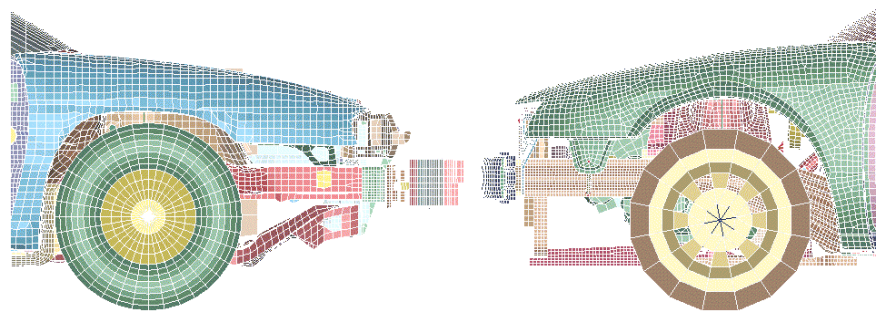

Figure 3.16. Initial Configuration, Lumina-ULSAB

The side view of the two vehicles at the beginning of the simulation given in Figure 3.16 shows good alignment of the centroidal axis of the rail sections near the bumper attachment points.

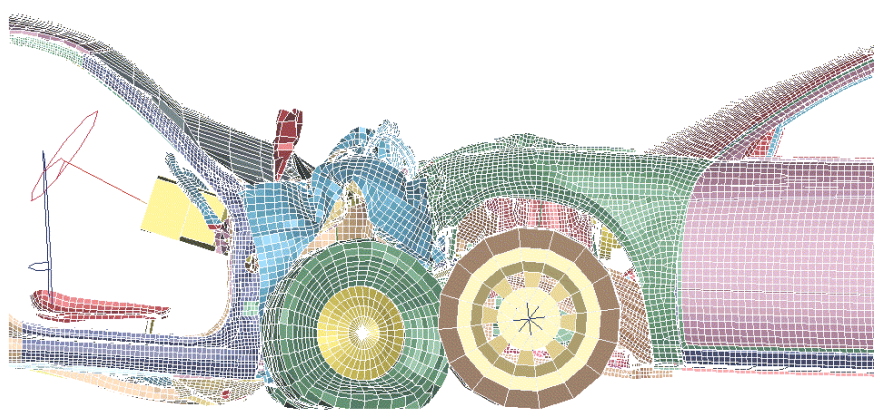

Figure 3.17. End of Simulation, Lumina-ULSAB

The configuration at the end of the simulation of the vehicles is shown in Figure 3.17, and Figures 3.18 and 3.19 show the heads-down view of the initial and final simulation configuration of this collision. 

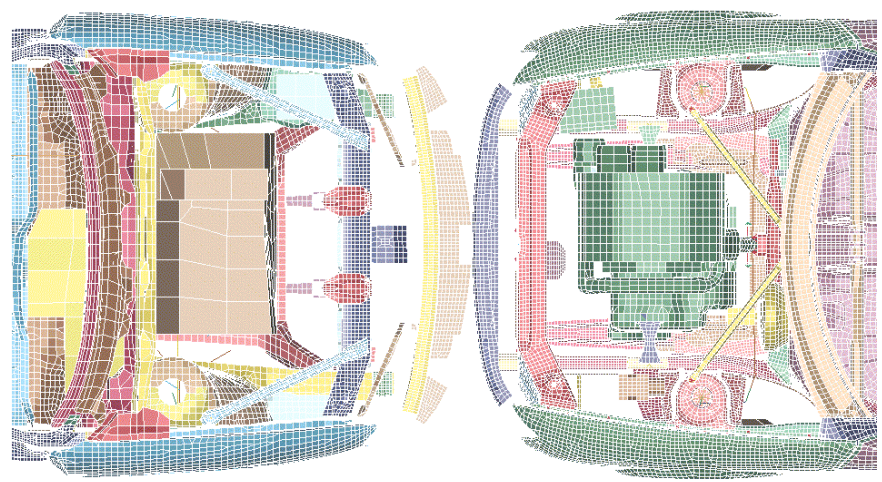

Figure 3.18. Overhead View, Initial Configuration

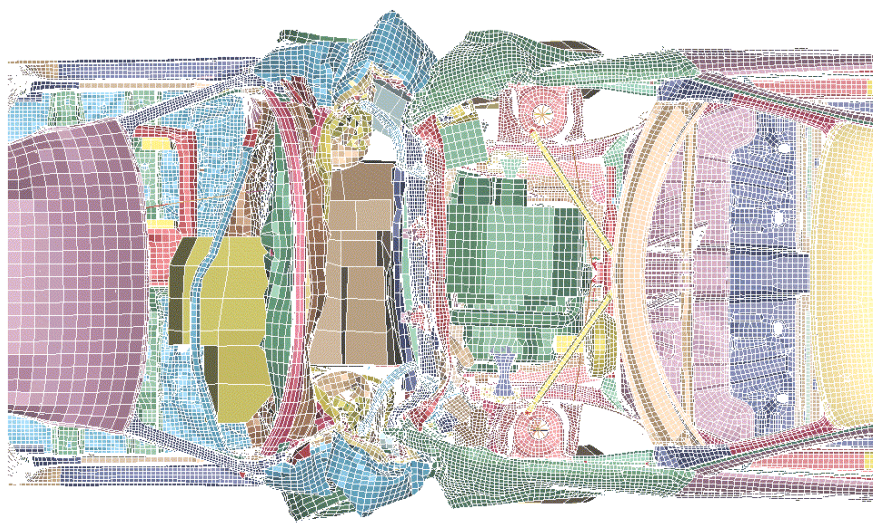

Figure 3.19. Overhead View, Final Configuration

Deformation of the Lumina's front structure is considerably larger than that of the ULSAB. It can be attributed to the collapse of the lower rail and the lower frame assembly (engine cradle) that supports the engine, drive train, and front suspension. During the frontal collision the sub-frame develops a plastic hinge near the engine support points. The engine remains attached to the engine cradle and causes the supports of the engine cradle that are attached to the floor to undergo large displacement. Large free space between the engine and radiator assembly in the Chevy Lumina model allows the ULSAB to translate into the Lumina's crush zone before significant loads in the forward assembly are developed. The engines of both cars make contact $37 \mathrm{~ms}$ from initiation of impact. The reduction in length of the section between the firewall and the front bumper along the center axis of the vehicles is given in Table 3.6.

\begin{tabular}{l|cc}
\hline Vehicle & $\begin{array}{r}\text { Xreduction } \\
(\mathrm{mm})\end{array}$ & $\begin{array}{c}\text { Xreduction } \\
\text { (\% of initial) }\end{array}$ \\
\hline ULSAB & 493 & 42 \\
\hline Lumina & 882 & 71 \\
\hline
\end{tabular}

Table 3.6. Reduction in Length in Crush Zone

The overall longitudinal component of the change in length between points at the base of the B-pillars in the driver side of the ULSAB and the passenger side of the Lumina model is $1622 \mathrm{~mm}$. The dimensional (reduction) change in the floor area just in front of the driver seat and behind the firewall for the ULSAB is $5 \mathrm{~mm}$. The corresponding change in dimension for the Lumina is $196 \mathrm{~mm}$. 
The filtered acceleration data is shown in Figures 3.20 and 3.21. The average values between $T_{0}$ and $T_{v=0}$ are reported in Table 3.7.

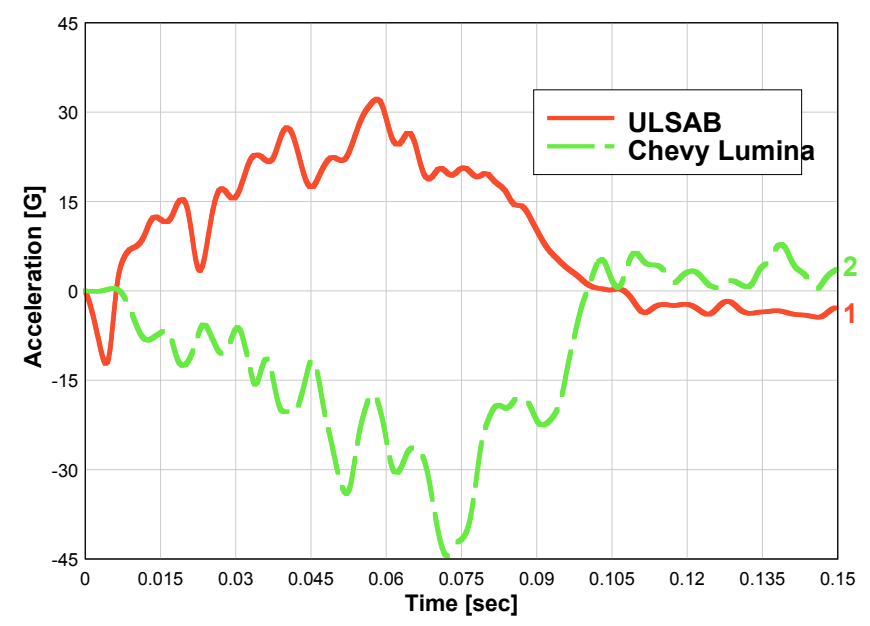

Figure 3.20. X-Acceleration, Base of B-Pillar

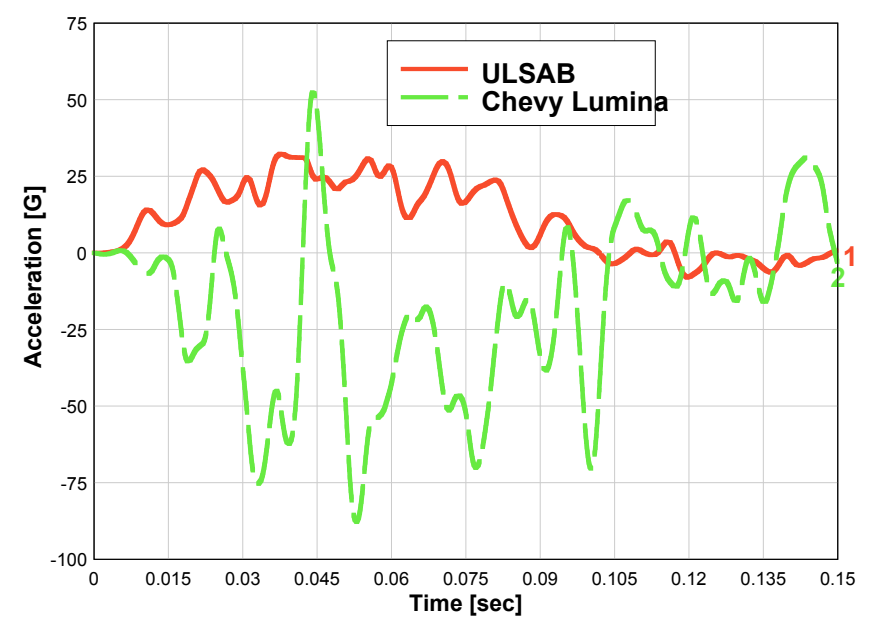

Figure 3.21. X-Acceleration, Driver's Side Floor

\begin{tabular}{l|cc}
\hline Vehicle & Base B-pillar & $\begin{array}{l}\text { Floor below } \\
\text { driver seat }\end{array}$ \\
\hline ULSAB & 17 & 19 \\
Lumina & 18 & $28^{*}$ \\
\hline
\end{tabular}

"High frequency component data, unreliable.

Table 3.7.

Average Accelerations (G's) at Selected Locations 
The traces of force in the forward assembly of the ULSAB vehicle are shown in Figure 3.22. The duration of the sustained force in the lower rail is $20 \mathrm{~ms}$ longer compared to the Taurus - ULSAB collision simulation.

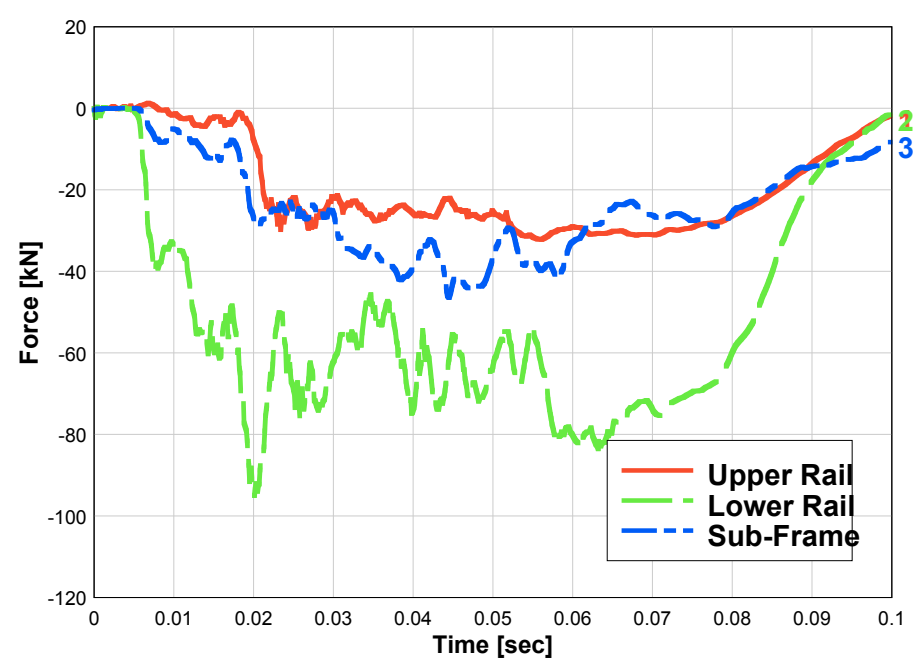

Figure 3.22. Front Rail Forces in ULSAB

\subsubsection{ULSAB-Dodge Intrepid Collision}

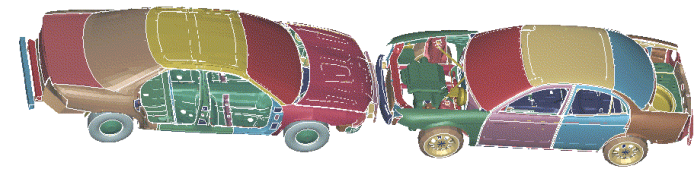

Figure 3.23. Dodge Intrepid-ULSAB Collision Model

The frontal collision of the ULSAB and the Dodge Intrepid is considered in this section (Figure 3.23). The Intrepid is $4 \%$ heavier than ULSAB $(1682 \mathrm{~kg}$ vs $1612 \mathrm{Kg})$. Figure 3.24 shows the bumpers mismatch $(40 \mathrm{~mm})$. The corresponding configuration at the end of the simulation is shown in Figure 3.25. 


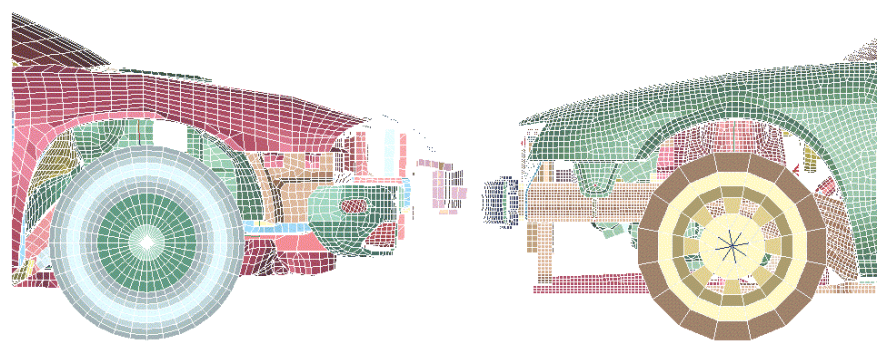

Figure 3.24. Initial Configuration, Dodge Intrepid-ULSAB

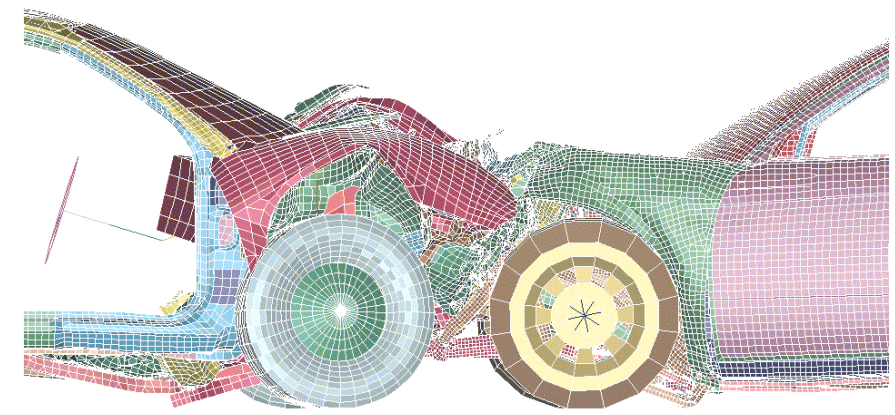

Figure 3.25. End of Simulation, Intrepid-ULSAB

Both vehicle models experience large deformation of the corresponding crush zones. In the ULSAB this deformation is due to the progressive collapse of the lower rail. A plastic hinge-like mechanism occurs at the engine mount location and rear attachments of the sub-frame. The deformation in the crush zone of the Intrepid is limited by the forward location of the engine. The engines make contact at $38 \mathrm{~ms}$ from initiation of impact.

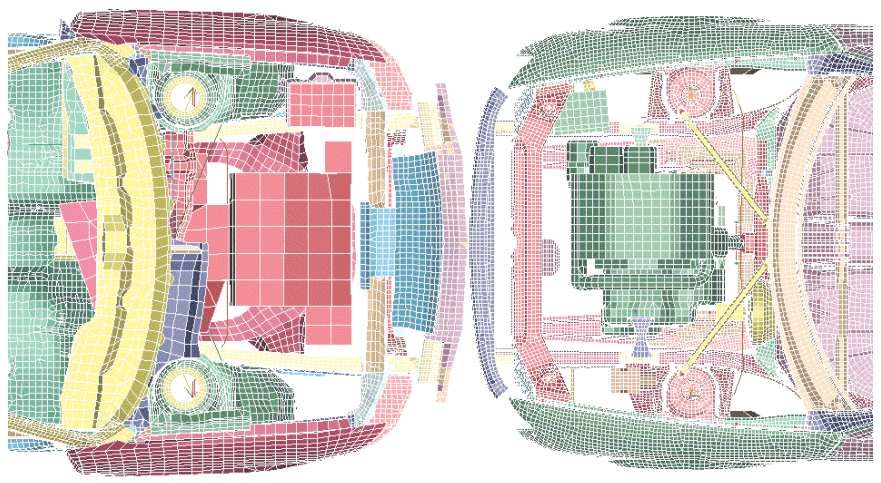

Figure 3.26. Overhead View, Initial Configuration 


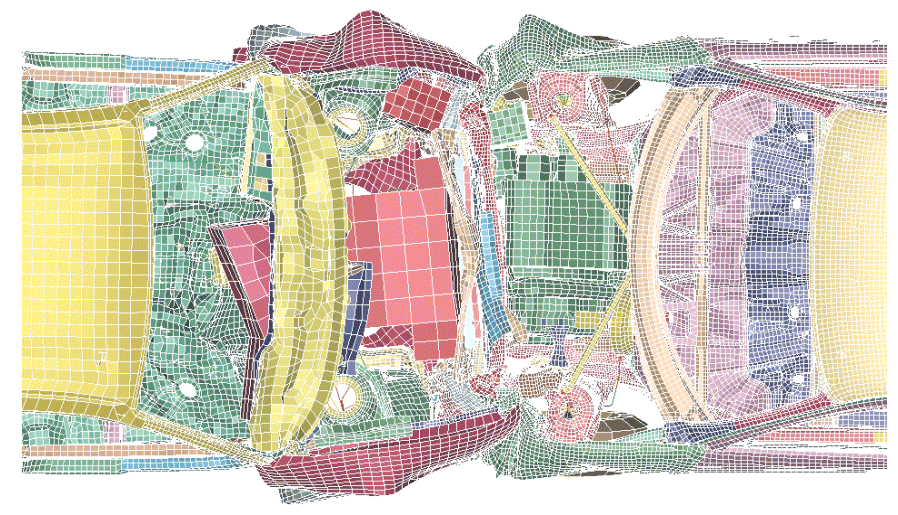

Figure 3.27. Overhead View, Final Configuration

Heads-down views at the beginning and end of the collision simulation are given in Figures 3.26 and 3.27. The motion of the engines can be assessed using the strut towers as reference points. In both cars this motion is attributed to the deformation of the sub-frames that support the engines. Engine supports are not allowed to break-off in the models. Consequently, the engines impart large deformations on the sub-frames and lower rails and control their collapse mechanisms. Figures 3.28 and 3.29 illustrate the extent of deformation in the sub-frames.

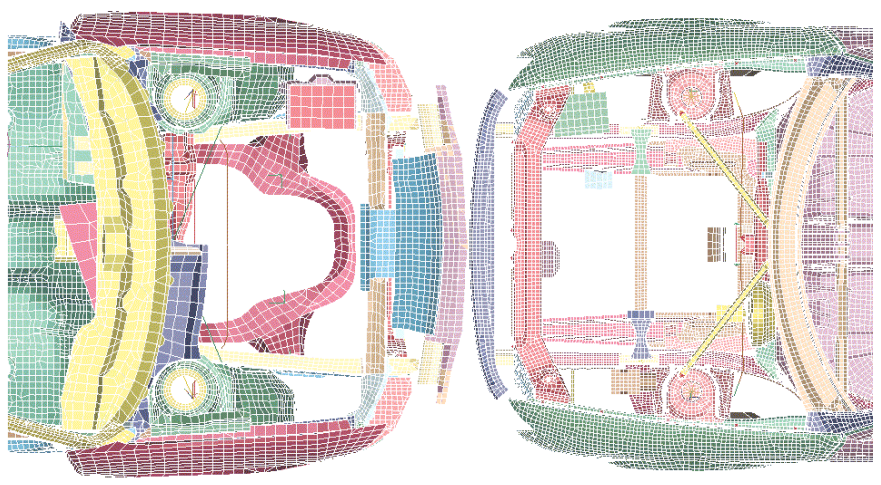

Figure 3.28. Sub-Frame Initial Configuration

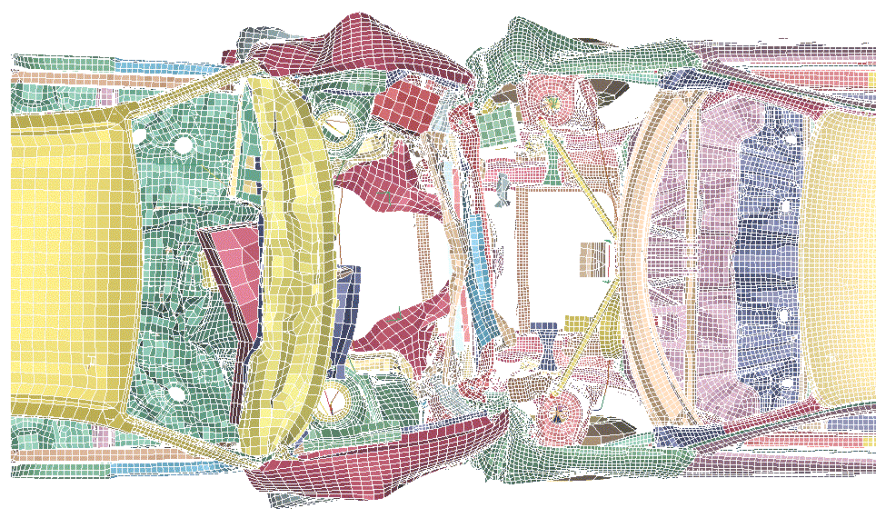

Figure 3.29. Sub-Frame Final Configuration 
The reduction in length of the crush zones is shown in Table 3.8. The change in length between the bases of the B-pillars in both cars is $1526 \mathrm{~mm}$.

\begin{tabular}{c|cc}
\hline Vehicle & $\begin{array}{r}\text { Xreduction } \\
(\mathrm{mm})\end{array}$ & $\begin{array}{c}\text { Xreduction } \\
\text { (\% of initial) }\end{array}$ \\
\hline ULSAB & 662 & 56 \\
\hline Intrepid & 721 & 58 \\
\hline Table 3.8. & \multicolumn{2}{|c}{ Reduction in Length in Crush Zone }
\end{tabular}

The floor intrusion in the driver-side floor is $10 \mathrm{~mm}$ for the ULSAB and $230 \mathrm{~mm}$ for the Dodge Intrepid model. Traces of nodal accelerations at the base of the B-pillar and at the floor below the driver seat are given in Figures 3.30 and 3.31. The average values are given in Table 3.9.

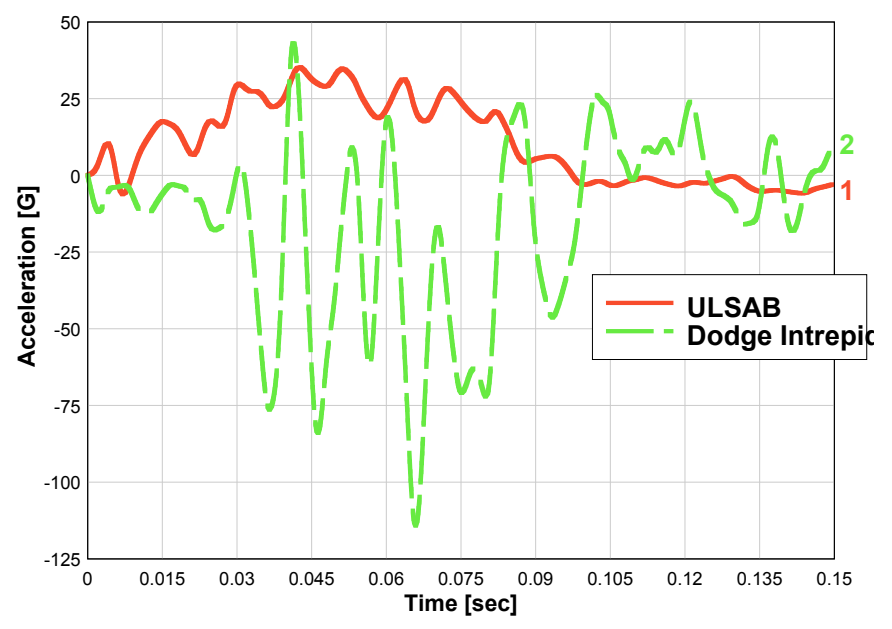

Figure 3.30. X-Acceleration, Base of B-Pillar

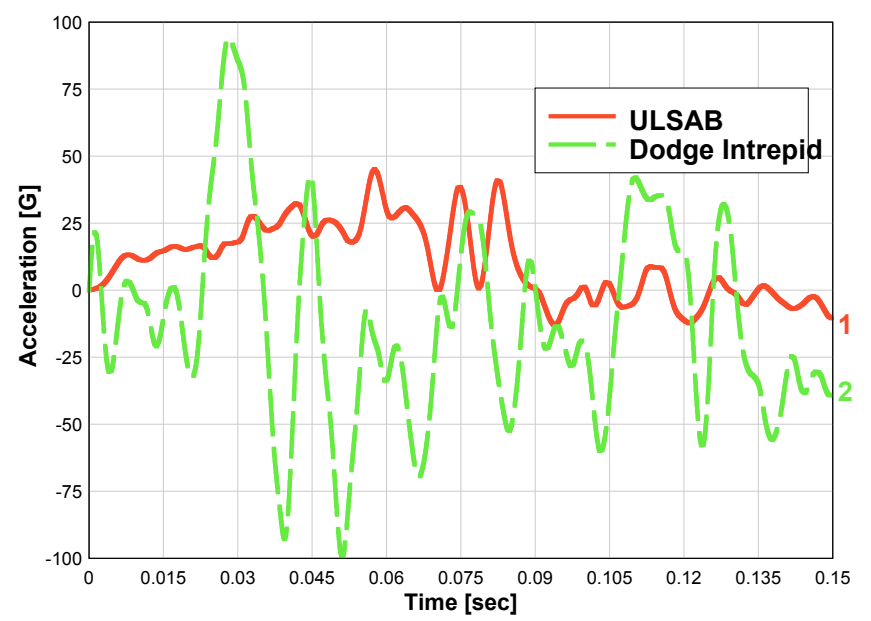

Figure 3.31. X-Acceleration, Driver's Side Floor 


\begin{tabular}{l|cc}
\hline Vehicle & Base B-pillar & $\begin{array}{c}\text { Floor below } \\
\text { driver seat }\end{array}$ \\
\hline ULSAB & 20 & 20 \\
Intrepid & 27 & $9^{*}$ \\
\hline \multicolumn{2}{|c}{ "High frequency component data, unreliable. }
\end{tabular}

Table 3.9.

Accelerations (G's) at Selected Locations

The forces in the longitudinal main load-carrying members in the ULSAB car are given in Figure 3.32. The bumpers mismatch does not seem to have a significant influence on the overall force levels in the ULSAB model.

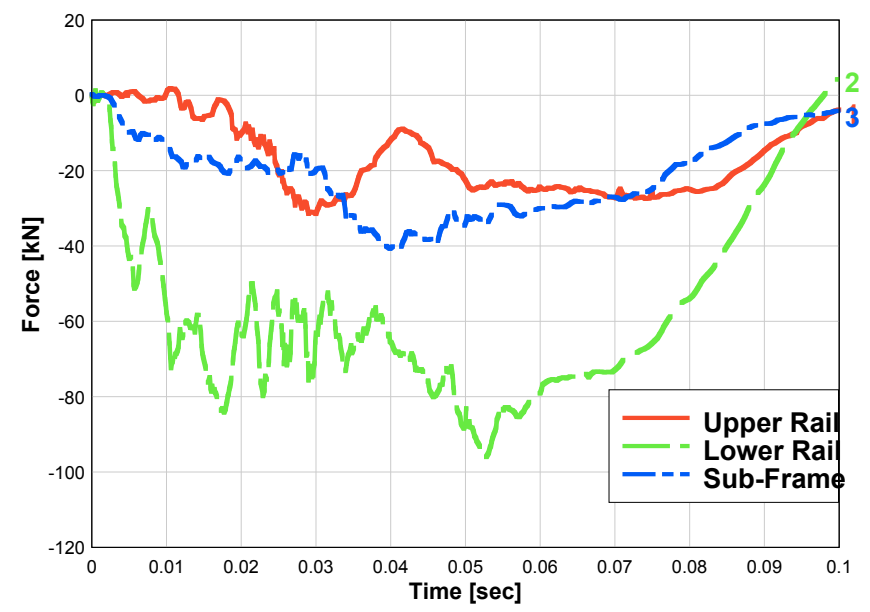

Figure 3.32. Front Rail Forces ULSAB

\subsection{DISCUSSION}

The results of numerical simulations of the front-end collision of the ULSAB concept car with models of passenger cars in the U.S. fleet have been presented in the previous sections. The study has been undertaken to assess the crash compatibility of the 'concept' car with cars with similar weight and geometric characteristics. A companion goal of the study was to investigate the feasibility of computational simulations for crash compatibility analysis using car models that employ different structural designs and modeling approaches.

Crash compatibility has been addressed from two points of view: a structural view in which the integrity of the ULSAB is compared with the integrity of the companion car, and a safety consideration that addresses the deceleration and integrity of the OC. The structural response of ULSAB in a frontal collision is assessed in terms of the reduction in the axial length of the crash-absorbing structure in front of the OC. Figure 3.33 shows the normalized reduction in length of the CZ for the ULSAB and the companion vehicle model for each of the "crash events" analyzed where the "event number" denotes ULSAB collision with the Ford Taurus, Chevy Lumina and Dodge Intrepid, respectively. 


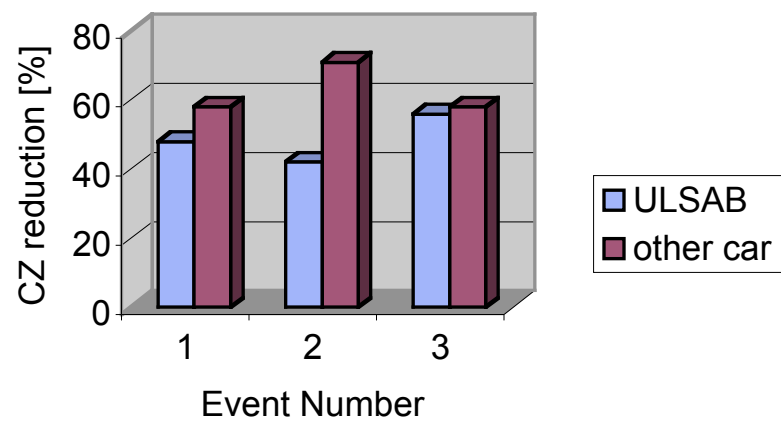

Figure 3.33. Comparison of Crush Zone Lengths

The label "other car" denotes the matching car model in the corresponding collision event (Ford Taurus, Chevy Lumina, and Dodge Intrepid). Comparisons of the average acceleration levels at two locations in ULSAB that are associated with the car-to-car collision are shown in Figures 3.34 and 3.35.

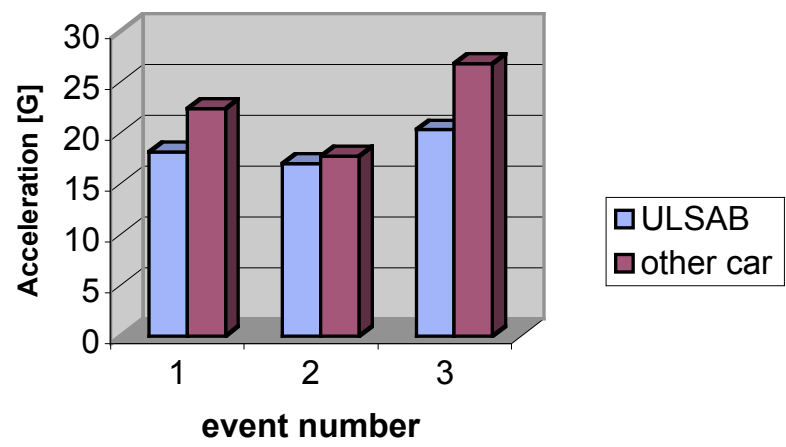

Figure 3.34. Average Acceleration at Base of B-Pillar

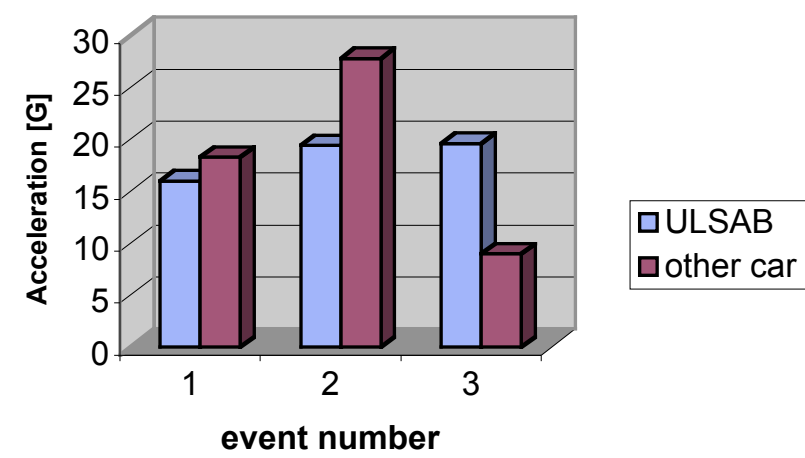

Figure 3.35. Average Acceleration in Occupant Floor

For the ULSAB model, the acceleration levels at the base of the B-pillar are proportional to the reduction in length of the $\mathrm{CZ}$. The accelerations in the floor area below the driver's seat exhibit markedly fewer oscillations in the ULSAB model than for the companion car model and, therefore, the two cannot be reliably compared. The floor accelerations in ULSAB depend largely on the deformation of the sub-frame and its attachment to the floor. Typical average acceleration values for vehicle-to-vehicle full frontal 
crash tests as reported in Reference 52 are between 8 and 20 G's. The calculated values in this analysis fall close to this range.

Table 3.10 shows the reductions in length (floor intrusion) in front of the driver's sides in each of the crash events. In general, the floor intrusion in the ULSAB is smaller than the intrusion on the companion car model. This is attributed to the larger stiffness of the CZ in the ULSAB relative to the companion car. The stiffness of the rail that supports the engine, the engine mount, and the attachment of the engine cradle to the floor contribute to the deformation of the occupant floor.

\begin{tabular}{c|cc}
\hline Crash Event. & ULSAB & Other Car \\
\hline ULSAB-Taurus & -10 & -166 \\
ULSAB-Lumina & -5 & -196 \\
ULSAB-Intrepid & -10 & -230 \\
\hline
\end{tabular}

Table 3.10. $\quad$ Floor Intrusion

Floor intrusion in the ULSAB model can be linked to the kinematics of the engine and to the relative stiffness of its supports. Table 3.11 shows the reduction in distance between the bases of the B-pillars of the two cars involved in the collision (driver side of ULSAB - passenger side of the companion car), and the sum of the reduction in $\mathrm{CZ}$ of both cars for each collision.

\begin{tabular}{c|cc}
\hline Crash Event & $\begin{array}{c}\text { B-Pillar to B- } \\
\text { Pillar }\end{array}$ & Sum of CZ \\
\hline ULSAB-Taurus & 1257 & 1200 \\
ULSAB-Lumina & 1622 & 1375 \\
ULSAB-Intrepid & 1526 & 1383 \\
\hline
\end{tabular}

Table 3.11. Crash Length and Summation of CZ

The difference in these two columns is due to the contribution of rigid body motions. The summation of reductions in CZ's seems to offer a better indication of crash performance because it does not include the rigid body movements. Time traces of forces for the bases of the upper rail, lower rail, and engine cradle of the ULSAB CZ have been shown in the Figures 3.14, 22 and 32. The peak load value for all the cases considered is $100 \mathrm{kN}$. From the crash-compatibility aspect, magnitude and character of forces in these structural members offer good measures for the ULSAB crash compatibility. Figure 3.36 presents the traces of load in the ULSAB main rails for the NHTSA NCAP test. The character and the magnitude of force-time curves are very similar to the rail forces associated with the simulated car-to-car collisions. The main differences are the crash duration, and the peaks in the upper rail and sub frame. For NCAP, the upper rail has pronounced high peak of $55 \mathrm{kN}$ compared to more gradual and sustained response for the car-to-car collisions where the maximum value is $40 \mathrm{kN}$. 


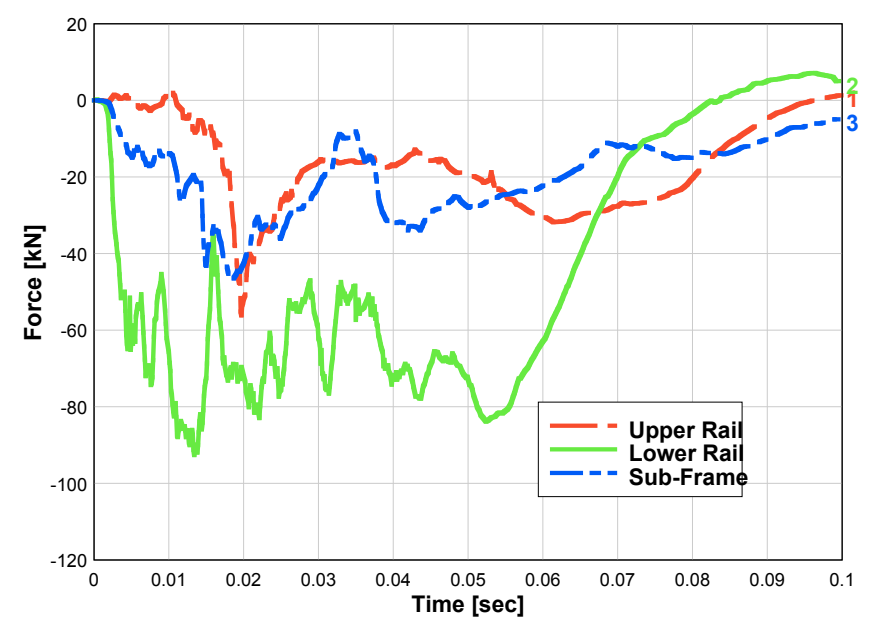

Figure 3.36. Rail Forces in ULSAB, NCAP test

\subsection{CONCLUSIONS}

Results of the project conducted to assess the crash compatibility of ULSAB with cars of similar geometric characteristics have been presented and discussed in this report. This is a computational study that had the objective of quantifying the crash compatibility of ULSAB relative to cars with similar geometric and inertia characteristics. Experimental verification has not been conducted and, as such, the study is confined to the realm of computational modeling.

The following conclusions can be drawn from the results of the study:

- In general, the design of ULSAB is compatible with the design of existing cars with similar inertia and geometric characteristics.

- The structural-performance characteristics of the vehicles involved in a car-to-car collision when one of the cars is the ULSAB are governed by the stiffness and geometry of the CZ in the vehicles.

- The effects of mass, being traditionally one of the most important parameters used to assess compatibility, could not be evaluated because of the similar mass of the vehicle models used in the analysis. Within the constraints of the current analysis it appears that, for the ULSAB, the effects of stiffness dominate the compatibility aspects for collisions with similar vehicles.

The study identified several areas that should be carefully considered to computationally simulate crashcompatibility:

- There is a need for establishment of general guidelines for model development if models from different sources are to be used in compatibility analysis. Models used in this study employed different approaches for materials modeling, element distribution, and connection between vehicle components.

- Modeling of the engine kinematics and attachments needs to be improved and verified experimentally. The current engine mount models seem to be too simplistic and confining, and it is felt that the modeled behavior in car-to-car collisions does not accurately represent the actual phenomena. 
- Numerical simulation of the collision between vehicles should be extended to include collision at several degrees of alignment and several levels of engagement. Performance measures should be established that could be used for quantification of crash response and for communicating information between the experimental, semi-empirical and detailed FEM crash-modeling methods. 



\section{REFERENCES}

1. Ultralight Steel Auto Body Final Report, Porsche Engineering Services, Inc. March, 1998.

2. Paluszny, A., State-of-the-art review of automobile structural crashworthiness, AISI publication AU2301 (1051), 1993.

3. Jones, N., Structural Impact, Cambridge University Press 1989.

4. Constitution and Properties of Steels, vol. ed. Pickering, F. B., Materials Science and Technology, vol. 7, VCH, New York, 1992.

5. Crisfield, M. A., Advanced Topics, Volume 2, Non-Linear Finite Element Analysis of Solids and Structures Non-Linear Finite Element Analysis of Solids and Structure, Wiley, 1997.

6. Belytschko, T., Liu, W. K., Moran, B., Nonlinear Finite Elements for Continua and Structures, Wiley, 2000.

7. Campbell, J. D., Dynamic Plasticity of Metals, Springer, New York 1972.

8. Davies, R. G. and Magee, C. L., The Effect of Strain-Rate Upon the Tensile Deformation of Materials, Journal of Engineering Materials and Technology, April 1975, pp. 151-155.

9. Davies, R. G. and Magee, C. L., The Effect of Strain-Rate Upon the Bending Behavior of Materials, Journal of Engineering Materials and Technology, January 1977, pp. 47-51.

10. Kassar, M.; and Yu, W.W., Effect of strain-rate on material properties of sheet steels, Journal of Structural Engineering v 118 n 11 Nov 1992 pp. 3136-3150.

11. Kassar, M.; Pan, C.L.; Yu, W.W., Effect of strain-rate on cold-formed steel stub columns, Journal of Structural Engineering Vol. 118 n 11 Nov 1992 pp. 3151-3168.

12. Thornton, P. H., Energy Absorption by Structural Collapse in Dual Phase Steel Tubes, Metallurgical Transactions A, Vol. 10A, 1979.

13. Mahadevan, K., Fekete, J. R., Schell B., McCoy, R., Faruque, O., Strain-Rate Characterization of Automotive Steel and the Effect of Strain-Rate in Component Crush Analysis, SAE paper 982392, 1998.

14. Hallquist, J. O., LS-DYNA3D, An explicit finite element nonlinear analysis code for structures in three dimensions, LSTC Manual, 1995.

15. Geoffroy, J.L.; Cambien, I.; Jouet, A., Contribution of high strength steels to the absorption of impact energy, Metallurgia Italiana v 85 n 6 Jun 1993 p 377-382.

16. Yoshitake, Sato, K., A. Hosoya, Y., A study on improving crashworthiness of automotive parts by using highstrength steel sheets, SAE paper 980382, 1998.

17. Sato, K., Yoshitake, A. Hosoya, Y., Mikami, H., FEM Simulation to Estimate Crashworthiness of Automotive Parts, SAE paper $982356,1998$.

18. Miura, K., Takagi, S., Hira, T., Furukimi, O. Tanimura, S., High strain-rate deformation of high-strength sheet steels for automotive parts, SAE paper 980952, 1998.

19. Hourman, T., Press forming of high strength steels and their use for safety parts, Revue de Metallurgie. Cahiers D'Informations Techniques v 96 n 1 1999. p 121-132 0035-1563

20. Johnson, G. R. and Cook, W. H., A Constitutive Model and Data for Metals Subjected to Large Strains, High Strain-rates and High Temperatures, Proceedings of the Seventh International Symposium on Ballistic, The Hague, The Netherlands, 1983, pp. 541-547.

21. Zerilli, F. J. and Armstrong, R. W., Dislocation-Mechanics-Based Constitutive Relations for Material Dynamics Calculations," Journal of Applied Physics V 61 (5), pp. 1816-1825, 1987.

22. Mahadevan, K., Fekete, J. R., Liang, P., Effect of Strain-rate in Full Vehicle Frontal Crash Analysis, SAE paper 2000-01-0625, 2000.

23. Bobrek, A., Simunovic, S., Aramayo, G., Collaborative Toolkit for Crashworthiness Research HICSS-34, Minitrack on Developing and Deploying Collaborative Problem Solving Environments 2001.

24. Yoshitake, A.; Sato, K.; Okita, T., Impact absorbed energy of hat square column in high strength steels, SAE International Congress \& Exposition Feb 26-29 1996 n1172 1996 Detroit, MI, USA, SAE Warrendale PA USA p 7 0099-5908 SAESA2.

25. Fekete, J., Overview of Sheet Metals for Stamping, SAE paper 970715, 1997.

26. Sheet Metal Stamping: Development Applications, Chen, K-K, Meuleman, D., Saran, M., Eds., SAE Publication SP-1221, 1997.

27. Sheet Metal Stamping, Menke, H., Saran, M., Eds., SAE Publication SP-1540, 2000.

28. Sheet Metal Forming, Friedman, P., Xia, C., Chu, C.-C., Pan, J., Eds., SAE Publication SP-1536, 2000.

29. Kaufman, M., Kundrick, K., Liu, S.-D., Integration of chassis frame forming analysis into performance models to more accurately evaluate crashworthiness, SAE Paper 980551, 1998.

30. Dutton, T., Iregbu, S., Sturt, R., Kellicut, A., Cowell, B., Kavikondala, K., The effect of forming on the crashworthiness of vehicles with hydroformed frame siderails, SAE Paper 1999-01-3208, 1999.

31. Marron, G., Patou, F., The effect of forming in the design of deep drawn structural parts, Modeling the Mechanical Response of Structural Materials, Taleff, E., Mahidhara, R., Eds., The Minerals, Metals \& Materials Society, pp. 25-36, 1997.

32. Teeparthi, S., Gandikota, V., Madhavan, V., Hooper, S., Bowden, M., Middleton, J., Multistage sheet metal forming with intermediate annealing: comparison of finite element simulations with experiments, SAE Paper 1999-01-1560, 1999. 
33. Simunovic, S., Shaw, J., Aramayo, G., Material modeling effects on impact deformation of ultralight steel auto body, SAE Paper 2000-01-2715, 2000.

34. Aramayo, G., Simunovic, S., van Schaik, M., Crash compatibility of the ultralight steel auto body (ULSAB) With cars of the same size, SAE Paper 2000-01-2711, 2000.

35. Wenner, W., State-of-the-art of mathematical modeling of sheet metal forming of automotive body panels, SAE Paper 970431, 1997.

36. Tang, S., Trends on simulation of sheet metal forming processes, SAE Paper 2001-01-1108, 2000.

37. Hallquist, J., Wainscott, B., Schweizerhof, K., Improved simulation of thin sheet metal forming using LSDYNA3D on parallel computers, J. of Mat. Proc Tech, vol. 50, pp. 144-157, 1995.

38. Liu, W. K., Qian, D., Li, S., Simulation of metal forming by a meshless contact algorithm, SAE Paper 2000-01$1110,2000$.

39. Guo, Y., Batoz, J., Detraux, J., Duroux, P., Finite element procedures for strain estimations of sheet metal forming parts, Int. J. Num. Methods Eng., vol. 30, pp. 1385-1401, 1990.

40. Chung, K., Richmond, O., Sheet forming process design based on ideal forming theory, NUMIFORM '92, pp. 455, 1992.

41. Saggese, L., Revellino, M., De Muro, T., Accuracy determination of sheet metal forming simulations using onestep code, SAE Paper 1999-01-3166, 1999.

42. FAST_FORM3D, User's Manual, Forming Technologies Inc., 2000.

43. Worley, P., Preliminary Results Using Car Crash Benchmarks, SuperComputing Conference 2000, http://www.csm.ornl.gov/ worley/evaluation/CRASH/index.html, 2000.

44. Jawad, S., Compatibility Analysis of Vehicle-to-Vehicle in Head-on Collision, AMD-Vol. 225/BED-Vol.38, Crashworthiness, Occupant Protection and Biomechanisms in Transportation Systems, ASME 1997.

45. Zobel, R., Accident Analysis and Measures to Establish Compatibility, paper 1999-01-0065, Vehicle Aggressivity and Compatibility in Automotive Crashes (SP-1442) SAE, March 1999.

46. Gabler, H., and Flides, B., Car Crash Compatibility: The Prospect for International Harmonization, paper 199901-006, Vehicle Aggressivity and Compatibility in Automotive Crashes (SP-1442) SAE, March 1999.

47. Crash Compatibility Status Report, Insurance Institute for Highway Safety, February 1998.

48. Simunovic, S., Aramayo. G., Zacharia, T., Toridis, Bandak, F. and Ragland, C., Advanced Computational Simulation for Design and Manufacturing of Lightweight Material Components for Automotive Applications, ORNL/TM-13407, Oak Ridge, TN, 1997.

49. Bedewi, N. E. and Kan, C. D. and Summers, S. Ragland, C., Evaluation of Car-to-Car Frontal Offset Impact Finite Element Models Using Full Scale Crash Data, SAE World Congress, 1995.

50. Gupta, V., Gunasekar, T. Rao, A., Kamarajan. J. and Summers, S., Reverse Engineering Method for Developing Passenger Vehicle Finite Element Models, SAE paper 1999-01-0083, International Congress and Exposition, Detroit, Mi., 1999.

51. Communication: Barsan-Anelli, A. (NHTSA) to Aramayo, G., Finite Elements Models of Passenger Cars, May 2000.

52. Agaram, V., Xu, L., Wu, J., Kostyniuk, G., Nusholtz, G., Comparison of Frontal Crash Test Pulses, Automotive Engineering International, July 2000. 
ORNL/TM-2002/148

\section{INTERNAL DISTRIBUTION}

1. Srdan Simunovic

2. Gustavo Aramayo

5. Thomas Zacharia

6. Peter Angelini

7. Philip Sklad
8. Richard Ziegler

9. Michael Karnitz

10. Central Research Library

12. ORNL Laboratory Records $\square$ RC

13. ORNL Laboratory Records $\square$ OSTI

\section{EXTERNAL DISTRIBUTION}

14. Marcel van Schaik, Manager, Advanced Materials Technology, American Iron and Steel Institute, 2000 Town Center, Suite 320, Southfield, MI 48075

15. Joseph Vehec, AISI Advanced Process Control Program, 247 Fort Pitt Boulevard, 2nd Floor, Pittsburgh, PA 15222

16. Jody Shaw, Automotive Center Manager, Automotive Product Technology, U.S. Steel Group, USX Corporation, 5850 New King Court, Troy, MI 48098-2692

17. Blake Zuidema, Manager, Advanced Engineering, National Steel Corp., Product Application Center, 12261 Market St., Livonia, MI 48150-1166

18. Stephen Denner, General Manager - Technology, National Steel Corporation, Technical Center, 1745 Fritz Dr., Trenton, MI 48183

19. Jonathan Harrington, American Iron and Steel Institute, 2000 Town Center, Suite 1900, Southfield, MI 48075

20. Lawrence Kavanagh, Vice President, Manufacturing and Technology, American Iron and Steel Institute, 1101 17th St., N.W., Washington, DC 20036-4700

21. William Obenchain, Director Manufacturing \& Technology, American Iron and Steel Institute, 1101 17th Street, N.W. Suite 1300, Washington, D.C. 20036-4700

22. Edward Opbroek, Program Director, ULSAB, 2000 Town Center, Suite 1900, Southfield, MI 48075-1138

23. Peter Salmon-Cox, DOE, Energy Efficiency and Renewable Energy, Office of Industrial Technologies, EE-20, 1000 Independence Ave. SW, Washington, DC 20585-0121 